DOCUMENTO DE TRABALHO N० $3 / 2003$

Evaluating Market Supervision

Through an Overview of Trading

Halts in the Portuguese Stock

Market

\begin{abstract}
JOÃo DUQUE
ANA RITA FAZENDA
\end{abstract}

ISSN $n^{\circ} 0874-8470$

DEPARTAMENTO DE GESTÃo

R. Miguel Lupi, 20 - 1249-078 Lisboa - Fax: 21.392.28.08 - Telf. 21.392.28.12/10

;91 


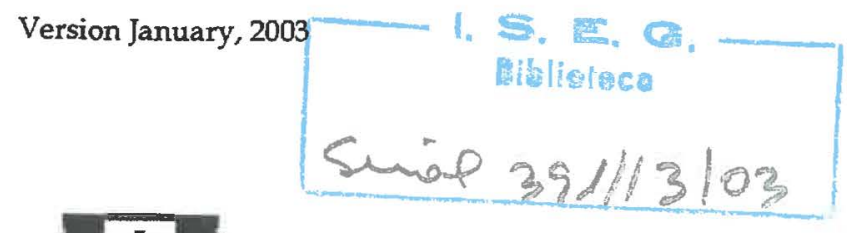

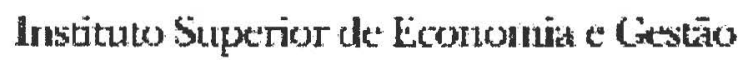

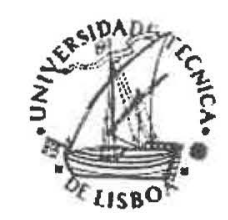

\title{
EVALUATING MARKET SUPERVISION THROUGH AN OVERVIEW OF TRADING HALTS IN THE PORTUGUESE STOCK MARKET
}

\author{
João Duque ${ }^{\dagger}$ \\ Universidade Técnica de Lisboa \\ Instituto Superior de Economia e Gestão \\ Rua Miguel Lupi, 20, 1249-078 LISBOA, PORTUGAL \\ Fax: 21. 39664 07/609867 - Telef. 21. 3925800 \\ Email: jduque@iseg.utl.pt
}

and

\begin{abstract}
Ana Rita Fazenda \#
CMVM - Comissão do Mercado de Valores Mobiliários Av. Fontes Pereira de Melo, 21, 1056-801 LISBOA, PORTUGAL

Telef. 21. 3177000

Email: anaritafazenda@cmvm.pt
\end{abstract}

\footnotetext{
† Financial support granted by the Fundação para a Ciência e a Tecnologia (FCT) and the Programa Praxis XXI is gratefully acknowledged.

It The opinions and conclusions do not express in any way the opinions of CMVM, and cannot be used in any circumstances in processes related to CMVM.
} 


\title{
EVALUATING MARKET SUPERVISION THROUGH AN OVERVIEW OF TRADING HALT IN THE PORTUGUESE STOCK MARKET
}

\author{
João Duque and Ana Rita Fazenda ${ }^{1}$
}

\begin{abstract}
In this study we analyse security-trading halts in the Portuguese capital market to measure the goodness of trading halts imposed by market authorities as well as its timing ability on both interrupting and restarting trading.
\end{abstract}

A sample of 54 equities whose trading has been halted from some hours to some days between 1992 and 1999 was collected. We used stock price returns, abnormal returns and volatility to compare and test the significance of differences for pre and post-halt periods. Firstly we consider the global sample to analyse stock abnormal returns and afterwards we split it into good and bad news halts. Concerning volatility, we applied t-test as a GARCH $(1,1)$ model to complete volatility analysis. The GARCH $(1,1)$ model has two additive dummy variables on the independent term of the mean and variance equations.

We found that justification for trading halts tend to increase as event window size increases, suggesting that supervisory authorities tend to spot better the dominant changes (mainly for the latest years considered in this research). In fact, when very short time sampling periods are used we found weaker justifications for stock halting. We also found a GARCH $(1,1)$ model useful and a more sensitive instrument on justifying trading halts.

The opportunity of market authorities to interrupt trading seems to be increasing, but in terms of timing, we found that they seem to be most of the times retarded when imposing trading halts or anticipated when authorizing restart trading. Nevertheless when considering "good" news, although the halt tends to be late, the restart seems to be on time.

Additionally we found that the methods under scope in this study are not redundant and should be jointly used by stock watch departments of supervision authorities for detecting trading under asymmetric information.

Keywords: Market supervision, capital markets, trading halts, stock price returns, volatility and GARCH models.

JEL classification: G14, G18, and G28.

\footnotetext{
1 The authors want to express a sincere acknowledgement to Mr. Helder Reis, Prof. João Nicolau and Prof. Paulo Basil de Brito (both from ISEG / Universidade Técnica de Lisboa), Prof. Ana Paula Serra (FEP/Universidade do Porto), Prof. Gordon Alexander (Department of Finance / University of Minnesota), discussant of this paper presented at the second Portuguese Finance Network Conference and to Prof. Dean Paxson (MBS / University of Manchester) for their very constructive comments in an earlier version of this paper.
} 


\section{INTRODUCTION}

Market efficiency is a vital topic in organised and well-established capital markets. This is the only way to keep investment flow and economic activity in open economies based on strong capital markets. In these markets information becomes the most important resource in the creation of expectations that lead to price formation. This turns the regulator's activity, particularly its supervision, into one of its most important activities. Regulators devote significant financial, human and technical resources to this supervisory activity. Investors and financial institutions through taxes, rates or financial contributions, according to the system that takes place in each jurisdiction, do the financing of this activity directly or indirectly. Financial literature has been quite interested in analysing and testing the market efficiency of investors and financial intermediaries, but this has scarcely been applied to regulators.

One of the major concerns of regulators is preventing crime related to market information. In this category of crime we may include lack of information, false, dubious, unclear, incomplete, confusing information and the transmission of information out of the appropriated context. All these factors may lead to information asymmetry. Market regulators also look for information exaggeration or with strong tendencies for fictitious trading that may lead to the formation of expectations on prices or volumes that are false. In preventing the spread of such symptoms that may lead to unfair trading, supervisory authorities tend to suspend trading in individual securities during a certain period of time, during which information has to be released in order to overcome the noticed bias (trading halts). With this mechanism, the main purpose of the authorities is to give investors a chance to react to new information and to help the formation of a consensus price. In what share trading in organised exchanges may concern, the power to impose trading halts is concentrated on financial regulators or exchanges or even split into both, according to each jurisdiction.

Besides trading halts, there are also circuit breakers'2, another market mechanism ordered by the authorities and studied in the literature to moderate excessive volatility and to allow for fair spread and absorption of information by all market participants. Nevertheless, in this paper we will only focus on trading halts imposed by surveillance bodies (regulators and exchanges) resulting from uncertain information surrounding trading?

\footnotetext{
2 These are market-wide approach to managing volatility by stopping trading in the entire market durirg normal business hours.

${ }^{3}$ While the arguments and evidence in this paper can likely be extended to the case of market-wide halts (or circuit breakers), our analysis will focus exclusively news related halts on individual securities.
} 


\subsection{REgULATORY AND INSTITUTIONAL DETAILS}

Until 1991 the financial supervision of the incipient Portuguese stock market was run by a governmental body working under the administration of the Portuguese Ministry of Finance. In 1991 a new Finance Act and a new and independent regulatory body was created (CMVM Comissão do Mercado de Valores Mobiliários). Ten years after, we feel that some attention should focus on how its activity has been developed. In order to do so, we thought that analysing trading halts could be just a start.

According to the law that regulates the Portuguese capital market since 1991, the regulator (CMVM) could impose trading halts on any security based on its initiative, by suggestion of the exchange, or even by proposal of the quoted company itselff. However, within the mechanism that was established in the Act, both the stock exchange and the regulator (CMVM) shared the power to suspend trading on stocks listed on the Market with Official Quotations (the blue chip stocks) ${ }^{5}$. For many years the information that was released concerning halts was unclear about its origin, i.e., who took the initiative that led to the decreed interruption on trading. Therefore, trading halt analysis could be significantly biased when used to infer about the regulator's efficiency in terms of its supervisory activity. Even though, the analysis of trading halts may be a good way to study the efficiency of the supervisory activity of the whole system where regulators and exchanges have the most significant role to play.

With the review of the Act and the implementation of the new Act issued in 2000 the power to impose trading halts is much more concentrated on the exchange. But as this research only collects and treats data before this new Act was approved and enforced, we will consider this analysis as a way of testing the efficiency of the supervisory system taken as a whole, in terms of timing (opportunity) and extension (durability) of trading halts'.

In order to do so, we explore stock price returns, abnormal returns and volatility using the event study methodology as in previous research papers but, differently, we use a GARCH model to explore in depth, volatility behaviour surrounding the events.

This paper is organised as follows. Section 2 reviews the literature on trading halts. Section 3 presents the theoretical model, section 4 the research design and section 5 the data collected. Section 6 explores some characteristics of trading halt activity in the Portuguese market and then we show the empirical results from the methodology used. Final comments are included in section 7 at the end of this document.

4 Articles $177^{\circ}$ and $448^{\circ}$ of the Decree of Law 142-A/91, published on April 10, 1991.

5 Although for the purpose of the law a distinction may be made, we will not distinguish between trading suspension and trading interruption.

${ }^{6}$ The supervisory system will be considered as the regulator and the exchange altogether. 


\section{LITERATURE REVIEW}

The basic literature starts with Roberts [1967], later reviewed by Fama [1970], when defining efficient capital markets in its semi-strong form. When new public and relevant information arrives, it should be spread around in order to be available to all investors and supposed to be incorporated in the new price formation process. There are two major ways to let market agents assimilate this information: i) by interpreting price behaviour as trades occur, or ii) by evaluating revealed information during forced trading halts'. The literature has presented a list of reasons for and against both procedures.

Several authors presented strong suspicions about the benefits of trading halts, suggesting that they may actually reduce the informative content of stock prices.

The model suggested by Glosten and Milgrom [1985] allows, by opposition to the Copeland and Galai [1983] model, a gradual information absorption process as a result of market activity. Therefore, trading prices would tend to reveal information and trading activity turned to be an efficient way to convert information into prices. According to Glosten and Milgrom [1985] when markets are opened, the expectations of informed and uninformed traders tend to converge as information is disseminated into the market prices. But when trading is halted, prices become unobservable and price sensitive information cannot be "released" by this mechanism. As reinforced by Grossman [1990] "... it merely prevents consenting adults from carrying out their desires on the floor of the stock exchange"! Other studies stand on the same line as Miller [1990], McMillan [1990], Grundy and McNichols [1989], Brown and Jennings [1989] or Dow and Gorton [1989]. These studies suggest that not only trading halts impose a liquidity cost on traders and a loss of opportunities, but also that information will not be readily revealed during a halt as through continuous trading. Furthermore, Ferguson [1988] argues that trading halts may cause market instability and an increasing cost for holding securities. If sellers perceive that a halt is to be imposed they will anticipate the move placing selling orders earlier, where before there was no reason for it, and bringing chaos to markets. Additionally, holding securities that are likely to be subject to trading halts will require an extra premium. This is the only way to compensate security holders for not selling, when thought appropriate. And, ceteris paribus, prices should decrease! The same reasons that tend to be applied when markets characteristics are moving down may be used for the reverse direction.

Hopewell and Schwartz [1978] studied daily abnormal returns around NYSE trading halts and also found large price changes over the day of the halt. This change increases with the halt time length.

\footnotetext{
7 We include in the first category the absence of trading due to very large bid-ask spreads quoted by specialists.
} 
During the pre halt period prices tend to anticipate the halt, particularly when good news are observed. Post halt returns tend to be negligent except on the very short-term period (day +1$)$.

Fabozzi and Ma [1988] showed that the first transaction price on the over-the-counter (OTC) market during the halt tends to be an unbiased estimate of the NYSE reopening price resulting in no apparent opportunities for arbitrage profits during NYSE halts. Schwartz [1982] and King et al. [1991] also supported this price learning process even when markets are closed. Therefore, if this is the case, why close the market if in the OTC market, on average, all participants tend to react adequately and fast to new and relevant information?

Other series of studies such as Grundy and McNichols [1989], Brown and Jennings [1989] or Dow and Gorton [1989] suggested models where trading is necessary in order to reveal and disseminate heterogeneous information. Amihud and Mendelson [1987] or Gerety and Mulherin [1992] supported the same idea showing that the reopening price is relatively noisy after regular breaks. The pressure to trade close to the market close or to the market opening is a way that investors use to avoid exposure to risk when markets are shut down. However, these studies used regular breaks based on exchange schedules, which is not the case under consideration. But if their conclusions were transposed to trading halts, its effects would tend to be negative. In the same line Lee et al. [1994] and Corwin and Lipson [2000] found, empirically, that trading halts do not reduce either trading or price volatility. On the contrary, in the post halt period volatility and trading volume tend to increase. This is presented as a result of the batch reopening mechanism employed by NYSE and therefore the paper tends to support the "learning through trading" class of models.

Kryzanowski and Nemiroff [1998] also presented empirical findings on which volatility and trading volume increase before and after trading halts, but return to the basic level after a while when information is completely incorporated into prices. These results support other findings such as Ferris, Kumar and Wolfe [1992]. Tanner and Pritchett [1992] also documented an increase in abnormal returns for stocks that experienced a delayed opening in NYSE, which seems to be inconsistent with the hypothesis that trading halts increase market efficiency.

However, using different approaches, several studies suggested models implying that non-trading periods can provide an opportunity for normal information transmission and, therefore, volatility and volume should decrease after trading halts. These are the cases of Stein [1987], Greenwald and Stein [1988], Kodres and O'Brien [1991], Goldman and Sosin [1979] or Greenwald and Stein [1991]. Engelen and Kabir [2001] studied abnormal returns surrounding Brussels Stock Exchange trading halts and found that there is no significant abnormal return pattern before or after the suspension. They concluded that there is a complete and instantaneous adjustment to the newly released information, which would mean a support in favour trading suspensions. More recently Christie, 
Corwin and Harris [2002] found empirical evidences that non-trading periods are a positive way for market agents absorb and digest information claiming for extended halts. And, of course, in favour of trading halts we find the major market regulators and exchange boards.

The great majority of the papers use traditional techniques to compare the behaviour of the variables under study which are among others price returns, trading volume, volatility, number of trades, quote depth, spreads, submissions and cancellations. Brailsford [1995] was one of the few authors that used a GARCH model to examine the relation between trading halts and volatility. Using Australian stock market data collected from 1974 to 1991, he studied the impact of trading halts on conditional volatility. When market closes or stops for any reason trading is interrupted but information flow does not cease. Using a GARCH-M model with a dummy variable on each day of the week, he found that Monday was the only day where the increase on volatility was significant after a trading break (the previous weekend). This seemed to confirm the hypothesis that information production during the close of the market has some impact on volatility that only has a visible consequence at the beginning of the week.

As a conclusion, we find two different positions when looking at security trading halts: i) from one side we have those that support the mechanism, considering that trading halts are beneficial. The underlying assumption is that traders are not able to obtain enough information about market conditions to encourage trading. ii) From the other side those that oppose suggesting models that support continuous trading. They implicitly assume that all market participants immediately observe market prices (which embody all market information in these models).

\section{THE THEORETICAL APPROACH}

The rational for market authorities to interrupt normal trading is the suspicion or the knowledge that information asymmetry exists, leading to irregular trading. Market authorities do not interrupt trading without a basis, and events, information or accusations from market participants are usually used as reasons. And when that happens we expect breaks on trading to go along with price behaviour changes. Otherwise unjustified trading halts promoted by market authorities may risk to be considered harmful, volatility prone and costly.

By increasing the subjective probability of halts, the security premium for holding stocks would increase and prices expected to be punished. Therefore, when supervisory authorities impose a break on market activity they must be convinced that the profit from breaking is higher than its

${ }^{8} \mathrm{All}$ their models argue that, on average, market quality is higher if "informative" halts are allowed. 
cost, which is the same as saying that, the cost of price discovery as a result of market activity is higher than its profit.

When trading is halted, price discovery through trading ceases. This will prevent informed traders from getting abnormal and illegal returns from others. But when this happens, several agents can be seriously penalised: for instance, people that strongly need to sell for liquidity or portfolio readjustment purposes in order to face compromises in other markets. If they are unable to sell the security in a market, some effect is expected on other markets9. This may seriously hit both players and other markets. The same happens with short sellers who may strongly need to close down their positions on the asset. Adding to that, when the market is closed, all the additional market agents find no way to learn from trading activity as documented in previous research.

We may argue that preventing trading will help sellers and buyers to get "fairer prices" than they would get if trading is continuous, although with a certain probability of not getting the relevant information. But this means delayed cash-in and the assumption that market prices may be "unfair", which is a reason difficult to sustain.

Therefore, whatever the decision to interrupt or to keep the market flow, we always find a significant number of market participants suffering some sort of potential damage and supervisory authorities must be absolutely convinced that social profits exceed the social costs.

But we may ask why to halt trading if all variables are unchanged when comparing pre to post halt periods. It may seem strange if there is no significant change in at least one of the market characteristics of the asset after the revelation of price sensitive information. This does not mean that all price characteristics should change when a halt is declared. But if they change after the release of new and significant information (or confirmation), this means that market authority had at least a reason to invoke the halt as an effective way to prevent unfair trading.

As a consequence, we start by making two basic assumptions: i) if no changes are noticed on market characteristics of the asset, we may infer that there was no reason for the trading halt and that market authorities may have reacted inopportunely; ii) if changes are noticed we may confirm the fears of market authorities and trading halts were justified.

Using a modified version of the visual approach suggested by Haugen [1997], we might say that in efficient markets, efficient reactions should follow new information arrival and a new state of stable conditions should be observed. We are not specifically talking about prices, but about any

${ }^{9}$ We may think on a market for a different asset such as the bond market, the real estate market or the market for another security where compromises have been assumed. 
abstract stock characteristic that we may define as variable $\Psi_{10}$. We will assume that variable $\Psi$ conditional under the information environment $\Omega$ is a martingale. When $\Omega$ changes (from $\Omega_{1}$ to $\Omega_{1^{+}}$) as a result of the arrival of the information piece $E$ at time $t_{1}$, this will imply a new level of $\Psi$ (passing from $\Psi_{1^{-}}=A$ to $\Psi_{1^{+}}=B$ in Figure 1). The new environmental information set will be:

$$
\Omega_{1^{+}}=\Omega_{1^{-}} \cup E
$$

The new level of variable of $\Psi$ will be:

$$
\Psi_{1^{+}}\left|\Omega_{1^{+}} \neq \Psi_{1^{-}}\right| \Omega_{1^{-}}
$$

And its expected value will differ:

$$
E\left[\Psi_{1^{+}} \mid \Omega_{1^{+}}\right] \neq E\left[\Psi_{1^{-}} \mid \Omega_{1^{-}}\right]
$$

Figure 1 shows the efficient market reaction on variable $\Psi$ to the arrival of new information conducting to a jump from level A to level B. If variable $\Psi$ reacts differently we may suspect of some form of inefficiency, possibly caused by inefficient spread or absorption of the new bit of information $E$.

\section{PLEASE INSERT FIGURE 1 HERE}

Let us assume that variable $\Psi$ reacts according to the inefficient path (b) of Figure 1 that resembles a delayed reaction. If that was the case as earlier market authorities react, interrupting trading, the better. This would correspond to a trading halt starting at time $t_{1}$. But stock watch departments of exchanges and regulators, the typical departments that induce trading halts, base their interventions, much of the time, on historical price behaviour observations. Therefore, only when time passes they are able to spot a significant change, reacting accordingly. This corresponds to interrupt trading at time $t_{2}$. At time $t_{2}$ market supervisors may observe, and confirm, that variable

10 Stock price returns, volatility, duration, delta, skewness of price returns, etc.. For instance, Glosten and Milgrom [1985] suggest trading volume as a variable with potential for insider activity signalling. Lee et al. [1994] use trading volume and volatility; Kryzanowski and Nemiroff [1998] study volatility and the number of trades; Kryzanowski and Nemiroff [2001] study quote depth, spreads and spread component costs; Corwin and Lipson [2000] use depth, number of orders sent and cancelled and spreads; and Christie, Corwin and Harris [2002] use spreads, abnormal returns, number of quote revisions, share volume, number of trades and average trade size. 
$\Psi$ has changed, basing their observation on the comparison of the information set $\varphi_{2}$ against the information set $\varphi_{3}$. Information sets $\varphi_{\mathrm{i}}$ are composed by a collection of observations of variable $\Psi$.

After the halt has started a new decision has to be made: when should trading be restarted? If market authority suspicions were proved to be groundless, the earlier trading restarts the better. But if they were correct, the timing for the restart of the trading becomes a new problem. The rational for trading halts is to avoid trading based on asymmetric information. And the big issue becomes when has the market already absorbed the new set of information. Returning to Figure 1 if trading restarted at time $t_{3}$ it is clear that the start would be too early. But this is only confirmed after comparing the sets $\varphi_{4}$ with $\varphi_{5}$. Clearly, the optimal time decision would be to restart trading at time $t_{4}$ when variable $\varphi$ shows signs of stability, confirmed by the comparison of information sets $\varphi_{5}$ with $\varphi_{6}$.

Therefore opportunity may be measured by comparing levels of $\Psi$ (particularly $\Psi\left(t<t_{1}\right)$ compared with $\left.\Psi\left(t>t_{4}\right)\right)$ and timing by comparing information sets $\varphi_{i}$ with $\varphi_{i+1}$ either before the halt either after the halt ${ }^{11}$.

Hence, the theoretical model is based on the path of some variable(s) that may be a significant indicator(s) of stock price characteristics and that may lead to express some statement on how information has been absorbed by market participants when trade occurs.

\section{RESEARCH DESIGN}

In order to test whether trading halts ordered by market authorities were somehow related to a significant change on market price behaviour, we observed prices around the dates of the events. Two main methodologies were used: firstly we used average stock price returns and secondly volatility. For both variables we started by comparing the periods before with after the event date. In relation to volatility, we also tried to fit a $\operatorname{GARCH}(1,1)$ model into the stock price returns around the dates of the event. These two variables (stock price returns and volatility) were commonly used in similar studies such as Lee et al. [1994], Kryzanowski and Nemiroff [1998].

We started by defining a time window of 40 days before the first day of the trading halt (event) and 40 days after the last day of that same event. In some cases we observed that the same company

11 This approach has two drawbacks in the absence of an over-the-counter market: i) it is impossible to disguise too early halts from interruptions on time or too late restarts from restarts on time; ii) if halts are due to false rumours even halts and restarts are on time they are not spot as if they were justified. 
had two consecutive breaks on its share trading. Whenever these consecutive breaks occurred within a 6 days period we assumed they were still related with the first halt. Therefore, in these cases, we assumed that trading has been suspended from the start of the first break until the end of the second. This would mean that we treated it as a single event.

We defined "Test 1" as the statistical test that compares the 5 daily observations previous to the event with the 5 daily observations after the event (observe Figure 2), testing the opportunity of trading halts imposed by market supervisory authorities, as explained before. In order to check whether possible changes in price behaviour could already be reflected on prices previously to the trading halt, we defined "Test 2 " that compares two consecutive time periods of 5 days before the date of the event. Accordingly, in order to check whether the trading halt had a sufficient time extension, we defined "Test 3 " that compares two consecutive time periods of 5 days each, both after the date of the event. Therefore, "Test 2" and "Test 3" became our method of testing timing ability of market supervisory authorities, because they reflect how the moment chosen to impose trading halts and to restart trading suites changes on price characteristics.

\section{PLEASE INSERT FIGURE 2 HERE}

We chose 5 days-time periods because we thought this would be a reasonable balance between the minimum data required to get significant results when testing, and the short-term impact that we want to analyse. Furthermore, other studies where information absorption is studied, similar time windows are used. This is the case of Antoniou, Galariotis and Spyrou [2001] that used one week of data. When a longer time window is used we increase the likelihood of including other undesirable effects that could contaminate the sample, but results may be interesting to compile.

In fact we have also repeated the three tests using the same approach with a 10 and 20 days time windows. We selected these time periods also based on previous research about testing events or market reaction to news absorption. Kryzanowski and Nemiroff [2001] studied the effect around trading halts using a 10 days maximum window and Cox and Peterson [1994] or Ratner and Leal [1998] suggested time periods from one week to 20 days maximum. Although these are overreaction tests, they are also concerned with processes governing information absorption in trading prices. 


\subsection{STOCK PRICE RetURNS ANALYSIS}

\subsubsection{Individual Analysis of Stock Price Returns}

We started by choosing stock price returns as one of the variables that could characterise assets and therefore that could show some evidence of the information arrival. This would result in an expected significant impact of trading halts on stock price returns.

Afterwards we collected 80 prices around the date of the event and managed to compute 39 instantaneous daily rates of return before and 39 instantaneous daily rates of return after each event:

$$
R_{i, t}=\ln \left(\frac{P_{i, t}}{P_{i, t-1}}\right)
$$

where $R_{i, t}$ stands for the daily instantaneous rate of return of asset $i$ on day $t$ and $P_{i, t}$ represents the closing price of asset $i$ on day $t$. We assumed random variables, independent, identically distributed following a normal distribution in order to use a t-test12 for comparing average rates of return before and after the event ("Test 1").

$$
H_{0}: \bar{R}_{B, i}=\bar{R}_{A, i} \quad \text { vs } \quad H_{0}: \bar{R}_{B, i} \neq \bar{R}_{A, i}
$$

Where, for testing purpose, $\bar{R}_{B, i}$ represents the average instantaneous rate of return of stock $\mathrm{i}$ for the time period of 5 days before the event and $\bar{R}_{A, i}$ represents the mean instantaneous rate of return of stock $i$ for the time period of 5 days after the event:

$$
\bar{R}_{B, i}=\sum_{t=-5}^{-1} \frac{R_{i, t}}{5} \quad \text { and } \quad \bar{R}_{A, i}=\sum_{t=+1}^{+5} \frac{R_{i, t}}{5}
$$

As explained earlier, we also compared two consecutive periods both before the event ("Test 2 "). This would give us a way of measuring the timing ability of market supervision authorities when interrupting trading.

$$
H_{0}: \bar{R}_{B B, i}=\bar{R}_{B, i} \quad \text { vs } \quad H_{0}: \bar{R}_{B B, i} \neq \bar{R}_{B, i}
$$


where, for testing purpose, $\bar{R}_{B B, i}$ represents the average instantaneous rate of return of stock i from day $[-10]$ to day $[-6]$ (before the event):

$$
\bar{R}_{B B, i}=\sum_{t=-10}^{-6} \frac{R_{i, t}}{5}
$$

If the average return were significantly different for the two previous periods, we may ask why not interrupt trading before the moment when actually happened? Would this mean a delayed reaction from supervisory authorities or simply a result of the supervision mechanism that is based on stock market observations?

As a way of testing the time extension of the trading halt we compared two consecutive 5-days windows after the event ("Test 3"):

$$
H_{0}: \bar{R}_{A, i}=\bar{R}_{A A, i} \quad \text { vs } \quad H_{0}: \bar{R}_{A, i} \neq \bar{R}_{A A, i}
$$

where, for testing purpose, $\bar{R}_{A A, i}$ represents the average instantaneous rate of return of stock $i$ from day $[+6]$ to day $[+10]$ after the event:

$$
\bar{R}_{A A, i}=\sum_{t=+6}^{+10} \frac{R_{i, t}}{5}
$$

The rational for this test relies on the assumption that if significant differences are still observed on the two consecutive time periods after the event, the restart of trading may be too soon. Therefore, this test also reflects the timing ability of market supervision authorities.

Later we repeated the tests using a 10 and a 20-days time window.

\subsubsection{Individual Analysis of Abnormal Returns}

In order to analyse stock price return behaviour surrounding trading suspensions, we also analysed abnormal stock price returns.

12 We used, $t=\frac{\left(\bar{R}_{A, i}-\bar{R}_{B, i}\right)}{\sqrt{\frac{\sigma_{A, i}^{2}}{n_{A}}+\frac{\sigma_{B, i}^{2}}{n_{B}}}}$ where $\sigma_{A, i}^{2}$ and $\sigma_{B, i}^{2}$ are the corresponding variances and $n_{A}$ and $n_{A}$ represent the number of observations. 
Individual abnormal stock price returns are measured as the difference between the daily return on stock $\mathrm{i}$ at day $\mathrm{t}\left(R_{i, t}\right)$, and its expected return $\left(E\left[R_{i, t}\right]\right)$ :

$$
A R_{i, t}=R_{i, t}-E\left[R_{i, t}\right]
$$

We used the market-adjusted return model to estimate the expected stock price return as in Engelen and Kabir [2001] ${ }^{13}$ :

$$
E\left[R_{i, t}\right]=R_{m, t}
$$

where $R_{m, t}$ stands for the daily market instantaneous rate of return on day $t{ }^{14}$.

We used the same methodology as in the stock price returns analysis, that is, we compared average abnormal returns before and after the suspension, assuming again independent normally distributed random variables in order to use a t-test.

$$
H_{0}: \overline{A R}_{B, i}=\overline{A R}_{A, i} \text { vs } H_{1}: \overline{A R}_{B, i} \neq \overline{A R}_{A, i}
$$

For example, the 5-days average abnormal return of stock $i$ after the event is calculated by the statistic:

$$
\overline{A R}_{A, i}=\frac{1}{5} \sum_{t=+1}^{+5} A R_{i, t}
$$

Then, we compared average abnormal returns in two consecutive periods before and after the suspension using:

$$
H_{0}: \overline{A R}_{B B, i}=\overline{A R}_{B, i} \text { vs } H_{1}: \overline{A R}_{B B, i} \neq \overline{A R}_{B, i}
$$

and

$$
H_{0}: \overline{A R}_{A, i}=\overline{A R}_{A A, i} \text { vs } H_{1}: \overline{A R}_{A, i} \neq \overline{A R}_{A A, i} \quad \text { respectively. }
$$

As we used a 41-days window event, we only made these tests for 5 and 10-days time windows.

\footnotetext{
${ }^{13}$ Engelen and Kabir [2001] also used this model to measure expected stock returns in order to analyse stock returns behaviour around trading suspensions.
} 


\subsubsection{Aggregated Abnormal Returns Analysis}

In order to draw overall inferences we aggregated the abnormal return observations, testing whether the average abnormal return of the sample for each day $\left(\overline{A R}_{t}\right)$ of the event window equals zero. The hypothesis tested is expressed as follows:

$$
H_{0}: \overline{A R}_{t}=0 \text { vs } H_{1}: \overline{A R}_{t} \neq 0
$$

The average abnormal return on each day (from $t=-20$ to $t=+20$ ) was calculated by aggregating individual stock abnormal returns lined up on the same day:

$$
\overline{A R}_{\iota}=\frac{1}{n} \sum_{i=1}^{n} A R_{i, t}
$$

where $n$ is the number of stocks in the sample.

We analysed a 41-days event window that includes the event day and twenty trading days before and after suspension. We defined the event day (day [0]) as the day on which trading suspension occurs, day [-1] as the day immediately before the day of the suspension, and day [+1] as the day immediately after the end of the suspension. The return of day [0] is calculated using the last closing price before suspension and the first closing price after suspension. Similarly, the return of day [+1] is calculated as the return from the first closing price of the stock after the trading suspension to the next closing price. Many trading halts are single day suspensions but some are multiple day suspensions. So, in order to obtain a comparable daily return on the event day, the multiple day retum over the suspension period is scaled down by the number of suspension days. And whenever there were two consecutive suspensions we calculated the average of daily returns within that event period.

Then we calculated the cumulative abnormal return $C A R_{i}\left(t_{1}, t_{2}\right)$ for stock $i$ from time $t_{1}$ to $t_{2}$, and the cumulative average abnormal return $\overline{C A R_{i}}\left(t_{1}, t_{2}\right)$ as follows:

$$
C A R_{i}\left(t_{1}, t_{2}\right)=\sum_{t=t 1}^{t 2} A R_{i, t} \quad \overline{C A R_{i}}\left(t_{1}, t_{2}\right)=\frac{1}{n} \sum_{t=t 1}^{t 2} A R_{i, t}
$$

Some halts are due to impending "good" news and some are due to impending "bad" news. As mentioned before, these two cases should be separated, otherwise we may get biased conclusions. Considering that $50 \%$ of the sample was good news and the other half was bad news, we would

14 We used the PSI Geral index produced by Euronext Lisbon in order to compute the market instantaneous rate of return. 
risk getting on average, no significant changes. So, conclusions obtained by the previous methodology may be biased and therefore in the next section (4.1.4) we will analyse good and bad news separately.

\subsubsection{Aggregated Abnormal Returns Analysis- "good" news vs "bad" news}

As previously referred, we weren't able to collect information about the reasons for all the trading halts included in sample. To overcome this gap we used the following methodology to qualify them according to the price change signal as in Christie, Corwin and Harris [2002]:

i) When the instantaneous rate of return of stock $i$ on day [0] was positive we classified it as "good" news;

ii) When the instantaneous rate of return of stock $i$ on day [0] was negative we classified it as "bad" news.

Afterwards the tests and the methodology explained in 4.1 .3 were repeated.

\subsection{VOLATILITY ANALYSIS}

\subsubsection{Volatility}

As a second variable we selected volatility measured by the classic estimator:

$$
\sigma_{B, i}=\left[\sum_{t=-5}^{-1} \frac{\left(R_{i, t}-\bar{R}_{i}\right)^{2}}{4}\right]^{1 / 2} \text { and } \sigma_{A, i}=\left[\sum_{t=1}^{+5} \frac{\left(R_{i, t}-\bar{R}_{i}\right)^{2}}{4}\right]^{1 / 2}
$$

where $\sigma_{B, i}$ represents the historical volatility of the 5 days previous to the event and $\sigma_{A, i}$ represents the forward volatility of the 5 days period after the event.

As we assumed daily instantaneous rates of return following independent normal distributions, we used F-tests to compare the significance of volatility change around the date of the event:

$$
H_{0}: \sigma_{B, i}^{2}=\sigma_{A, i}^{2} \text { vs } H_{1}: \sigma_{B, i}^{2} \neq \sigma_{A, i}^{2}
$$

We followed a similar procedure with volatility as with the instantaneous rate of return. Applying "Test 2 " we compared two consecutive periods, both before the event: 


$$
H_{0}: \sigma_{B B, i}^{2}=\sigma_{B, i}^{2} \text { vs } H_{1}: \sigma_{B B, i}^{2} \neq \sigma_{B, i}^{2}
$$

where $\sigma_{B B, i}$ represents the volatility of stock i from day $[-10]$ to $[-6]$ (before the event):

$$
\sigma_{B B, i}=\left[\sum_{t=-10}^{-6} \frac{\left(R_{i, t}-\bar{R}_{i}\right)^{2}}{4}\right]^{1 / 2}
$$

And similarly to what was tested for stock price returns we tested two 5-days time periods volatility, consecutive to the event:

$$
H_{0}: \sigma_{A, i}^{2}=\sigma_{A A, i}^{2} \text { vs } H_{1}: \sigma_{A, i}^{2} \neq \sigma_{A A, i}^{2}
$$

where $\sigma_{A A, i}$ represents the volatility of stock i from day [+6] to day [+10] (after the event):

$$
\sigma_{A A, i}=\left[\sum_{t=+6}^{+10} \frac{\left(R_{i, t}-\bar{R}_{i}\right)^{2}}{4}\right]^{1 / 2}
$$

And once again we repeated the tests for a 10 and a 20 days time window.

The volatility in the charts (Appendix 2) is the standard deviation of a 20-days period. For example, the volatility on day [-2] was computed as follows:

$$
\sigma_{-2, i}=\left[\sqrt{\sum_{t=-21}^{-2} \frac{\left(R_{i, t}-\overline{R_{i}}\right)^{2}}{20}}\right]^{1 / 2},
$$

and on the day [+3]:

$$
\sigma_{+3, i}=\left[\sqrt{\sum_{t=+3}^{+22} \frac{\left(R_{i, t}-\overline{R_{i}}\right)^{2}}{20}}\right]^{1 / 2} .
$$

\subsubsection{GARCH $(1,1)$ Model}

Lastly, as in Brailsford [1995] we tested whether volatility had changed its path after the halt. As suggested in previous literature, stock price volatility tends to show signs of cluster behaviour: 
high volatilities tend to follow high volatilities and low volatility periods tend to follow low volatilities. This means that conditional volatility may be a good way to model market behaviour for volatility and GARCH $(1,1)$ models seem to fit well (Bollerslev [1986]). The GARCH model has some advantages in relation to the previous volatility analysis (F-tests). For instance: i) it assumes a time varying volatility; ii) there are no assumptions on the independence and normality of stock returns.

Therefore, we hypothesise that a GARCH $(1,1)$ model fits and that it may possibly "match" the behaviour of trading halts volatility.

Starting with a simple GARCH $(1,1)$ model as:

$$
\left\{\begin{array}{l}
R_{t}=\mu+u_{t}, \quad u_{t} \mid \Omega \sim N\left(0, \sigma_{t}^{2}\right) \\
\sigma_{t}^{2}=\alpha_{0}+\alpha_{1} u_{t-1}^{2}+\beta_{1} \sigma_{t-1}^{2}, \quad \alpha_{0}>0, \alpha_{1}, \beta_{1} \geq 0
\end{array}\right.
$$

the $\operatorname{GARCH}(1,1)$ process is wide-sense stationary with $E\left(u_{t}\right)=0, \operatorname{Var}\left(u_{t}\right)=\alpha_{0}\left(1-\alpha_{1}-\beta_{1}\right)^{-1}$ and $\operatorname{Cov}\left(u_{t}, u_{s}\right)=0$ for $t \neq s$ if and only if $\alpha_{1}+\beta_{1}<1$ (see Theorem 1 in Bollerslev [1986]).

We then added two dummy variables to the independent term of the mean equation ( $\phi_{B}$ and $\left.\phi_{A}\right)$ and to the variance equation $\left(\phi_{1}\right.$ and $\left.\phi_{2}\right) . \phi_{B}$ e $\phi_{1}$ represent the time period before the event in each equation and $\phi_{A}$ and $\phi_{2}$ the period after the event (using 80 observations ${ }^{15}$ ). The equations of the mean and the variance were then converted into:

$$
\left\{\begin{array}{l}
R_{t}=\mu+\phi_{B} d_{1 t}+\phi_{A} d_{2 t}+u_{t} \\
\sigma_{t}^{2}=\alpha_{0}+\alpha_{1} u_{t-1}^{2}+\beta_{1} \sigma_{t-1}^{2}+\phi_{1} d_{1 t}+\phi_{2} d_{2 t}
\end{array}\right.
$$

where $\quad d_{1 t}=\left\{\begin{array}{ll}1, & -5 \leq \mathrm{t} \leq-1 \\ 0, & \mathrm{t}<-5 \vee \mathrm{t}>+1\end{array} \quad\right.$ and $\quad d_{2 t}= \begin{cases}1, & +1 \leq \mathrm{t} \leq+5 \\ 0, & \mathrm{t}<-1 \vee \mathrm{t}>+5\end{cases}$

In order to find the parameters of the GARCH model we used the following maximum likelihood logarithm:

$$
l(\theta)=-\frac{1}{2} \ln (2 \pi)-\frac{1}{2} \ln \left(\sigma_{t}^{2}\right)-\frac{u_{t}^{2}}{2 \sigma_{t}^{2}}
$$

\footnotetext{
15 As larger the sample size (n) the lower is the volatility associated with $\phi_{1}$ and $\phi_{2}$ estimates (although from a certain dimension the gain is almost null). So, if $\mathrm{n}$ is relatively high it is possible to gain some efficiency on estimating $\phi_{1}$ and $\phi_{2}$ even with a small window (5 observations before and 5 after the event).
} 
Brailsford [1995] suggested a similar approach when testing the weekend effect as an information absorption process.

Then we tested if the parameters of each dummy variable in the mean and variance equations differ:

$$
\begin{aligned}
& H_{0}: \phi_{B}=\phi_{A} \text { vs } H_{1}: \phi_{B} \neq \phi_{A} \\
& H_{0}: \phi_{1}=\phi_{2} \text { vs } H_{1}: \phi_{1} \neq \phi_{2}
\end{aligned}
$$

The parameters affecting the dummy variables (in the mean and variance equation) measure how sensitive is the model on the approach of the trading halt (dummies B and 1) and how sensitive is the model on fading the effect of the trading halt (dummies A and 2). This methodology is supposed to conclude on a more sensitive basis around the event because we use a larger time window with 80 price observations for each stock. We may argue that a 5 days time window for each dummy variable could be insufficient to spot significant differences, but we wanted to compare this methodology with the previous one. It could be used a larger time window for the dummy variables (10 or 20 days) but the proportional increase in the total sampling period would have a very strong impact on the significance of the conclusions since we increase the probability of including other relevant effects on results.

\section{DAta}

We started by observing all interruptions of companies listed in the Euronext Lisbon ${ }^{16}$ between January 1991 and December 1999. We gathered information on the start and the end of the suspension period. Stock prices were collected immediately before and after trading suspension, but the reasons for suspension weren't available for all stocks. The information about these events was collected using different sources, namely monthly reports of the Lisbon Stock Exchange, the Department of Markets Surveillance of CMVM and the database Dathis ${ }^{17}$.

As observed in Table 1 there were 331 news related suspensions during the period January 1991 and December 1999. Among these there are single and intra-day suspensions but also multiple day suspensions.

\footnotetext{
16 By the time the data was collected the stock exchange was called BVLP - Lisbon and Oporto Stock Exchange.

17 Prices were collected from this database and consist of closing prices adjusted for dividends, stock splits and other similar price sensitive events.
} 


\section{PLEASE INSERT TABLE 1 HERE}

After a significant increase either in terms of number of breaks or in terms of days consumed in halts, the tendency has been a decrease for both variables until 1999. In 1999 we observed another increase that is still to be confirmed if it stands as a new trend or if it is just an outlier. The same conclusion is extended to the average time of the halt, which dropped significantly since the analysis started. Compared with the average of 5.2 days, recent data shows that the average halt only lasts a bit above 1.5 days. The reasons for this decrease may be related to the speed of the processes based on the triviality of the act, the increased quality of communications between the regulator, the exchange and the issuing firms and the speed of response that is taken by these firms when questioned by the supervising authorities. Nevertheless, this is still a huge time period once Christie, Corwin and Harris [2002] report an average trading halt in Nasdaq of about 54 minutes for the late nineties.

Although we could determine with precision all the events under scope, we selected a smaller sample to carry this research. The reason to do so relates to the methodology in use. In order to apply the methodologies presented earlier, we needed to collect prices for a limited number of days to insure that only one event could be the main cause of a change in the price behaviour. Hence, the time window selected to collect prices should be sufficiently small in order to guarantee the single effect assumption, but sufficiently large in order to grasp a significantly large number of prices that would turn significant any statistical test. We chose an 80 days time window centred on the event.

If the trading halt took only one or part of a day, we collected the previous 40 closing prices of the event, as well as the following 40 closing prices after the same event. Whenever the trading halt took more than one day the procedure was similar with the necessary adjustment as if the event was compressed into a single moment in time.

As a consequence we only selected to the sample all the halt (events) that passed, simultaneously, the two following criteria:

i. The stock should price at least 76 days within the time window of 80 days;

ii. There was no other trading halt observed on that specific stock within the time window. Exceptions: we considered cases that observed another trading halt within a 6 days time. In these cases we assumed that the halt was still related with the first trading halt and the whole period from the first to the second trading halt was considered as a 
single event ${ }^{18}$. Prices were then collected for the 40 days previous to the start of the first trading halt and for the 40 days subsequent to the end of the second trading halt.

After applying these criteria a sample of 54 events was selected. Appendix 1 lists the sample used in this study. For the earlier cases in the sample we could not recover the specific moment within the day when share trading was interrupted (at least for some of them).

Table 2 summarises the sample size per year and compares it with the universe.

\section{PLEASE INSERT TABLE 2 HERE}

In general terms we would say that the sample goes along with the universe either in terms of number of events or in terms of time extension per trading halt. We also underline that the sample tends to be more representative of the universe as we approach the most recent years.

\section{EMPIRICAL RESUlts}

We started by observing the charts of daily prices, stock returns and volatilities computed as described in the methodology, for each of the 54 trading halts included in the sample and presented in Appendix 2. For a reasonable number of cases we visually observe a quite remarkable difference on market price behaviour when comparing before with the corresponding time period after the event.

\subsection{Comparing Stock Price Returns}

\subsubsection{Comparing Individual Rates of Return}

We started by comparing the sample stock price returns around trading halts and found that, on average, they were statistically significant with an average of $3.64 \%$ and a standard deviation of $7.77 \%$.

Then we compared individual average stock price returns using "Test 1", as explained before. We observed that only in a very small number of cases average stock price returns were significantly

${ }^{18}$ Four events in this situation were included in the sample (see Appendix 1). 
different when comparing before with after trading halts. From a total sample of 54 cases we only found 4, 6 and 4 cases with statistically different average returns when using-respectively 5, 10 and 20 days of observations ${ }^{19}$. The overall average increase on the rate of return was only $0.10 \%$ when comparing 5 days around the halt, $0.33 \%$ for the 10 -days and $0.06 \%$ for the 20 -days period. We also computed the absolute value of the average stock price returns (see Appendix 3 ).

We may conclude that instantaneous stock price returns seem insensitive to trading halts. The same conclusions were found when applying "Test 2" and "Test 3 ". Therefore and like many other authors, like Hopewell and Schwartz [1978], Tanner and Pritchett [1992], Engelen and Kabir [2001], we will try, instead, abnormal returns.

\subsubsection{Comparing Individual Abnormal Returns}

Then we compared individual average abnormal stock price returns using the same methodology as for stock price returns. The number of cases for which the average abnormal stock price returns were significantly different when comparing before with after trading halts was even smaller than the results found for stock price return analysis. From a sample of 54 stocks we found respectively 2, 5 and 5 cases with statistically significant different average returns when using 5, 10 and 20 days of observations. But the overall average increase on the abnormal returns was much higher: $0.79 \%$ when comparing 5 days around the halt; $0.56 \%$ for the 10 -days; and $0.53 \%$ for the 20 -days period. We also computed the absolute value of the average abnormal returns (see Appendix 4). In addition the same conclusions were found when applying "Test 2 " and "Test 3 ".

When we analyse stock price returns and average abnormal returns they seem insensitive to trading halts ${ }^{20}$. Based exclusively on these variables we could argue that either market authorities tend to interrupt trading on an unfounded basis, or those variables are not appropriate for the purpose. Nevertheless, we obtained better results when aggregating abnormal returns of all stocks (see 6.1.3.).

\footnotetext{
19 Please refer to Appendix 3 that shows the tests of the differences on average returns and their absolute values.

20 Although the overall average abnormal return increase around the halts ("Test 1 ") is higher than the similar increase in the overall average stock price return for all the windows considered $(5,10$ and 20 -days), the number of individual abnormal returns with statistically significant differences is lesser than the similar number found when studying stock price returns (equivalent conclusion was found when applying "Test 2" and "Test 3 ").
} 


\title{
6.1.3. Comparing Aggregated Abnormal Returns - Global Sample
}

After comparing abnormal price returns around trading halts we found that on average they were not statistically significantly with an average of $1.36 \%$ and a standard deviation of $7.93 \% 21$ - see Figure 3 and Table 3. Therefore we could not confirm the findings of Hopewell and Schwartz [1978] nor Engelen and Kabir [2001] when studying daily abnormal returns around trading halts.

\section{PLEASE INSERT TABLE 3 HERE}

\section{PLEASE INSERT FIGURE 3 HERE}

\begin{abstract}
Abnormal stock returns seem to increase during the days preceding trading halts, but they are relatively small in magnitude and also statistically insignificant. Therefore, there seems to be no signs of information leakage during the pre halt period.
\end{abstract}

The adjustment of prices to the newly released information only happens on the day after the event (day [+1]), where average abnormal return $(\overline{A R})$ is the highest $(1.61 \%)$ and also statistically significant. After the restart of trading we observe small and insignificant abnormal returns. Therefore, as in Hopewell and Schwartz [1978], we also observed statistically significant average abnormal returns on the very short period (day +1 ) which may result from the fact that for some sample observations, the release of new information was only publicised at the end of a session, or after the market close. If that was the case information could only be incorporated in stock prices on day [+1].

When analysing average cumulative abnormal returns $(\overline{C A R})$ we found that it increases as the day of the event approaches - see Table 3 and Figure 4. However, we reject the hypotheses of these values being statistically significant in the pre halt period and even on day [0]. It seems that no information leakage was released on that period. But as we pass the event day cumulative abnormal returns become statistically significant, although not permanently. These findings are consistent with Engelen and Kabir [2001] but contradictory to those presented by Hopewell and Schwartz [1978].

${ }^{21}$ See Table 3 - Annex. 


\section{PLEASE INSERT FIGURE 4 HERE}

Figure 4 shows an increase in $\overline{C A R}$ after the restart of trading that extends up to day [+4], followed by an unstable behaviour till the end of the period. Assuming that there was no additional release of relevant information, this may suggest two different conclusions: i) the Portuguese stock market is not efficient in a semi-strong informational form, because the relevant information wasn't fully incorporated in the day it was publicly revealed22; ii) market regulators authorised the restart of trading too early.

These weak and unclear results until now are also a possible consequence of having mixing up until now, in the same sample, good with bad news. In the next section we explore the possibility and present the results after having split up the sample into good and bad news (section 4.1.4.).

\subsubsection{Comparing Aggregated Abnormal Returns - "good" news vs "bad" news}

From a global sample of 54 halts, we were able to select 39 good news and 15 bad news ${ }^{23}$. And as we can see from the following figures, in both cases there is a complete and instantaneous adjustment of prices to the newly released information on the day of the halt (day [0]).

\section{PLEASE INSERT FIGURE 5 HERE}

Apart day zero [0], we observed, for both sub-samples, a relatively stable and statistically insignificant average abnormal return'24, either on pre halt period or post halt period. T-tests are significantly different from zero on day [0], presenting the highest value of the sample $(+3.83 \%)$ on the "good" news day and the lowest $(-5.05 \%)$ on the "bad" news day (please refer to Table 4 ). Having split the sample into good and bad news we manage to found consistent results with those presented by Hopewell and Schwartz [1978] and Engelen and Kabir [2001].

\footnotetext{
22 Stocks observe some price volatility in the post halt period.

${ }^{23}$ Although "good" and "bad" news were defined by stock price returns the results did not differ if instead abnormal returns were used.

${ }^{24}$ Excluding day [0], in "good" news halts only days [-7] and [-3] are statistically significant and in "bad" news only days [-18], [-11], [6], [13] e [18].
} 
Nevertheless, when analysing $\overline{C A R}$ we concluded differently. As presented in Table 5, only "good" news reveals an average cumulative abnormal return statistically significant on day [0] $(+6.88 \%)$. For the "bad" news, only day $[-18]$ shows an average cumulative abnormal return significantly different from zero (see Figure 6) 25 . Therefore we could not confirm the findings of Hopewell and Schwartz [1978] who suggested that in the pre halt periods prices tend to anticipate the halt, particularly when "good" news were observed

\section{PLEASE INSERT FIGURE 6 HERE}

Therefore, according to the theoretical model, we may conclude that both "good" news and "bad" news show significant changes around trading halts. When a "good new" is to be released, we found that $\overline{C A R}$ starts to increase on day $[-5]$, only stabilizing on the day following the event. From day [+1] till the next 19 days there was a small decrease in cumulative abnormal return behaviour and then some stability. This empirical finding is in general consistent with market efficiency hypothesis, considering that profits obtained on day [0] do not seem to persist for long and the regulator's activity seems fully justified. When observing "bad" news $\overline{C A R}$ reveals not even a single statistically significant figure (not even on the event day) and then we could raise doubts on the goodness of the regulator's intervention.

\subsection{COMPARING VOLATILITY}

\subsubsection{Volatility}

As with the analysis of stock price returns, we started by comparing volatility applying "Test 1 " to compare two consecutive 5-days periods. As a first look to Appendix 5 shows a significant increase in the number of cases where volatility significantly changes after the event $(10,18$ and 27 for the 5,10 and 20 days of observations). This means that although, on average, changes are not severe, volatility seems to change with statistical significance after the halts. Most of the differences are observed in the most recent years under analysis and, interestingly, as we increase the time period for analysis, the number of significant differences increases. This means that: i) volatility seems to be a more efficient variable to detect why regulators tend to halt trading; and ii) regulators seem to spot more accurately structural changes on volatility than short-term changes.

25 Therefore we could not confirm Hopewell and Schwartz [1978] findings when suggesting that pre halt 
Although halts seem to be justified by volatility analysis, we still have market supervisors' timing ability to test. In order to test the timing ability, we started by selecting exclusively those observations where we observed a difference on volatility when comparing stock price returns before and after the halt. If either before or after the two consecutive periods presented similar levels of volatility than, the timing for interrupting and suspending was perfect. Otherwise we may ask about the timing suitability.

We started with the "Test 1 " applied to the 5-days window. We found 10 observations where volatility observed a significant change comparing before the halt and after the halt. Then we applied "Test 2" and "Test 3" to these 10 observations. Table 6A summarises the results whose data comes from Appendix 5. Table 6A reflects those 10 observations where we found significant differences on volatility when comparing the volatility of 5 days before with 5 days after the trading halt. As observed, only for 2 out of 10 observations we found having an appropriate timing ability either for trading suspensions, either for trading restarts. For the remaining 8 observations market supervision fails to be on timing.

For the remaining 44 observations we failed to reject different levels of volatility when comparing pre with post halt windows ("Test 1"). In such a situation we may wonder why interrupt trading if no significant differences were found? In addition the question seems to have even a more difficult answer when checking the timing of these occurrences. And in fact, for 26 observations there were no differences on volatility for any of the three tests we developed and for 18 observations we found the halt to show signs of timing unsuitability (see Table 6B).

When repeating the analysis for 10 and 20 days of observations the conclusions reverse! The number of observations that show a justification for interruption increases when we use higher time windows, reaching $50 \%$ (27 out of 54 when using the 20 days time period - Table 6E). And within those 27 , we found 8 cases $(29.6 \%$ ) where the timing for interruption seemed to be suited either in terms of stop trading or in terms of restart trading. This means a significant increase in percentage terms.

Trading halts can be lately imposed as a result of two major reasons. Firstly because market supervision authorities observe historical prices as a supervisory instrument, reacting frequently as a result of some unusual price movement. If this is the case we may observe a delayed stop on trading, particularly when we use small time periods for testing. But when longer time periods for testing are used this excuse should not be applied because market authorities have a quite long time for considering intervention. Secondly we may hypothesise that market authorities are inefficient when interrupting trading.

period prices tend to antecipate the halt, particularly when "good" news are observed. 
Therefore, if we neglect the analysis on the starting of trading halts, considering only the post halt period, the conclusions did not change much: most of the times market authorities seem out of timing when restart trading, suspending the halt apparently too early (around $60 \%$ of the times for 5,10 and 20 days of sampling). If this is the case we may well argue why to interfere on the market?

\section{PLEASE INSERT TABLE 6 HERE}

\subsubsection{Using a GARCH Model}

GARCH $(1,1)$ models were found a useful and appropriate tool by a vast number of researchers when studying stock price volatility. This good modelling performance applies either to stock price returns forecasting or to stock price volatility behaviour.

We are particularly interested on studying both the stock returns and stock volatility. When we tested the GARCH $(1,1)$ model as described earlier we found an increase on the number of situations where market authorities seemed to have a clear reason for interruption. Instead of 10 cases we found 20 cases where we could reject the hypothesis that both dummies of the variance equation were equal. This means that for 20 observations the sensitivity of volatility when trading halts approach differs from similar sensitivity when trading restarts.

\section{PLEASE INSERT TABLE 7 HERE}

But most interestingly from those 20 cases, 6 were observed in 1998 and 7 were observed in 1999, representing almost $50 \%$ of the cases of those years. In addition to the fact that the average time length of the halts has been reduced since 1992, this means that GARCH $(1,1)$ model seems more appropriate to study the information absorption processes under scope. Additionally we may infer that the accuracy of market authorities has increased on the opportunity for interrupting trading.

As the meaning of this research method is different from the previous method used when comparing volatilities it is not inconsistent if cases do not match on the same conclusion. Instead of competing, we think that both methods should complement each other. Nevertheless we found 9 cases in common by both methods (GARCH $(1,1)$ model and volatility comparisons) - 1 in 1997, 4 
in 1998 and 4 in 1999. Therefore, GARCH $(1,1)$ methodology may represent an instrument with increased power to detect and justify trading halts imposed by market authorities. And it seems to be more helpful as halts become shorter.

\subsection{Using All the METHods}

When we use all the methods to study the opportunity for halting trade we found that larger time windows reveal more clearly reasons to suspend trading. As Table 8 shows, when using a 5-days window even working with three different methods the opportunity for trading halt is only spot in $24 \%$ of the cases. However, when increasing the window size for 10 and 20 days we observe a significant increase in the percentage of cases where interruption seems plausible ( $44 \%$ and $56 \%$ correspondingly). When on top of that we use all the methods, including the GARCH $(1,1)$ methodology, with all the time windows available we increased to $70 \%$ the percentage of cases where trading halts seem justified. Therefore, based on our empirical evidence, we would advise stock watch departments of market authorities to use combined methods, namely those used in this study, in search for signs on trading under information asymmetry.

\section{PLEASE INSERT TABLE 7 HERE}

\section{CONCLUSION}

Trading halts are frequently imposed on listed companies by supervisory authorities. These are usually justified on a basis of presumed asymmetric information among market players. In the literature we find two very opposite positions when looking at security trading halts: those that support the mechanism and those that oppose. Both sides base their perspectives on economic reasons, theoretical models and empirical findings.

We used the Portuguese market to observe and test how prices behave around trading halts looking for signs of timely and appropriate intervention of market supervising authorities. A sample of 54 observations was compiled covering the period between 1992 and 1999, a homogeneous period in regulatory terms. During this period, both, the stock exchange and the regulator had the power to suggest and/or impose the trading breaks that are under scope.

We used two variables to study these effects (stock price returns and volatility). When analysing each trading halt we soon found that only volatility could bring some insight to the research. 
Therefore we observed that trading halts are much more related with "dominant" changes in volatility than with very short-term changes. This may lead one to conclude that market authorities tend to disguise better volatility changes as the time window increases, denoting some incapacity to detect changes ex-ante. We may consider this a result of methods employed for market supervision but also as a consequence of some delayed reaction (this timing incapacity was also confirmed when observing the end of the trading halts).

We then used a $\operatorname{GARCH}(1,1)$ model with two added dummy variables (in the mean and variance equations) in order to study very short-term volatility changes in more detail. We concluded a superior ability of the $\operatorname{GARCH}(1,1)$ model to associate trading halts to volatility changes. This superior ability was dominant in most of the recent years of the sample. In 1999 the GARCH model confirmed almost $50 \%$ (7 out of 15) of the cases where volatility changed from pre to post halt periods. We found this methodology a very useful complement of previous methodology for comparing impacts on volatility.

From the aggregated abnormal returns analysis of the global sample we didn't find any significant changes around the day of the event and we also concluded that market regulators timing on restarting trading was not appropriate. By splitting the sample, we found significant changes over the day of the halt on "good" news, although the moment chosen to halt the trading seems behind time. Nevertheless the restart seemed to be appropriated and on time. Concerning "bad" news we also observed abnormal losses around the halt, though it is not possible to draw reasonable conclusions about the timing of market authorities.

In conclusion, from all the methodologies used, we couldn't find consistent signs of an increase in volatility after halts occurred, but we found consistent changes in volatility. We conclude for an increased ability of Portuguese market supervising authorities, for the opportunity of halts, but consistently out of timing as Christie, Corwin and Harris [2002] also found. Nevertheless, we found in "good" news that although the halt tends to be late, the restart seems to be on time. Additionally we found that the methods under scope in this study are not redundant and should be jointly used by stock watch departments of supervision authorities for detecting trading under asymmetric information.

\section{REFERENCES}

Amihud, Yakov and Mendelson Haim (1987) "Trading mechanisms and stock returns: an empirical investigation", Journal of Finance, 42, pp. 533-553. 
Antoniou, A., E. Galariotis and S. Spyrou (2001) "Contrarian profits and the overreaction hypothesis: the case of the Athens Stock Exchange", Center for Empirical Research in Finance.

Bollerslev, Tim (1986) "Generalized autoregressive conditional heteroskedasticity", Journal of Econometrics, 31, pp. 307-327.

Brailsford, Timothy J. (1995) "Market Closures and time-varying volatility in the Australian equity market", Journal of Empirical Finance, 2, pp. 165-172.

Brown, David P. and Robert H. Jennings (1989) "On technical analysis", Review of Financial Studies, 2, pp. 527-552.

Christie, William G., Shane A. Corwin and Jeffrey H. Harris (2002) "Nasdaq trading halting: the impact of market mechanisms on prices, trading activity and executions costs", The Journal of Finance, 57, 3, pp. 1443-1478.

Copeland, Thomas and Dan Galai (1983) "Information effects on the bid ask spread", The Journal of Finance, 38, pp. 1457-1469.

Corwin, Shane A. and Marc L. Lipson (2000) "Order flow and liquidity around NYSE trading halts," The Journal of Finance, 55, 4, pp. 1771-1801.

Cox, D. and D. R. Peterson (1994) "Stock returns following Large One-Day Declines: Evidence on Short-Term Reversals and Longer-Term Performance", The Journal of Finance, 39, 1, pp. 255-267.

Dow, James and Gary Gorton (1989) "Self-generating trade and rational fads: The response of price to new information", Unpublished manuscript, London Business School.

Engelen, Peter-Jan and Rezaul Kabir (2001) "Empirical Evidence on the Role of Trading Suspensions in Disseminating New Information to the Capital Market", Discussion Paper, Center, Tilburg University, the Netherlands.

Fabozzi, Frank J. and Christopher K. Ma (1988) "The over-the-counter market and New York Stock Exchange trading halts", Financial Review, 23, pp. 427-437.

Fama, Eugene (1970), "Efficient Capital Markets II", Journal of Finance, 26, 5, pp. 1575-1617.

Ferguson, Robert (1988) "What to do, or not to do, about the markets", Journal of Portfolio Management, pp. 14-19.

Ferris, S. P., R. Kumar and G. A. Wolfe (1992) "The effect of SEC-ordered suspensions on returns, volatility, and trading volume", Financial Review, 27, pp. 1-34. 
Gerety, Mason S. and Harold J. Mulherin (December 1992) "Trading halts and Market activity: An Analysis of Volume at the Open and the Close", The Journal of Finance, 47, 5, pp. 1765-1784.

Glosten, Lawrence R. and Paul R. Milgrom (1985) “Bid, Ask and Transaction Prices in a Specialist Market with Heterogeneously Informed Traders", Joumal of Financial Economics, 14, pp. 71-100.

Goldman, M. Barry and Howard B. Sosin (1979) "Information dissemination, market efficiency and the frequency of transactions", Journal of Financial Economics, 7, pp. 29-61.

Greenwald, Bruce and Jeremy Stein (1988) "The task force report: The reasoning behind the recommendations", Journal of Economic Perspectives, 2, pp 3-23.

Greenwald, Bruce and Jeremy Stein (1991) "Transactional risk, market crashes, and the role of circuit breakers", Journal of Business, 64, pp. 443-462.

Grossman, Sanford J. (1990) "Introduction to NBER symposium on the October 1987 crash", Review of Financial Studies, 3, pp. 1-3.

Grundy, Bruce D. and Maureen McNichols (1989) "Trade and revelation of information through prices and direct disclosure", Review of Financial Studies, 2, pp. 485-526.

Haugen, Robert A. (1997) Modern Investment Theory $4^{\text {th }}$ Edition, Prentice-Hall International Editions, London, UK.

Hopewell, Michael and Arthur L. Schwartz (1978) "Temporary trading suspensions in individual NYSE securities", Journal of Finance, 33, pp. 1355-1373.

King, Ronald, Grace Pownall and Gregory Waymire (1991) "Corporate disclosure and price discovery associated with NYSE temporary trading halts", Contemporary Accounting Research, 8, pp. 509-531.

Kodres, Laura E. and Daniel P. O'Brien (1991) "The existence of Pareto superior price limits and trading halts", Mitsui Life Financial Research Center, Working Paper 91-20, University of Michigan.

Kryzanowski, Lawrence and Howard Nemiroff (1998) "Price discovery around trading halts on the Montreal Exchange using trade-by-trade data", The Financial Review, 33, pp. 195-212.

Kryzanowski, Lawrence and Howard Nemiroff (2001) "Market quote and spread component cost behavior around trading halts for stocks interlisted on the Montreal and Toronto stock exchanges", The Financial Review, 37, pp. 115-138. 
Lee, Charles M. C., Mark J. Ready and Paul J. Seguin (1994) "Volume, volatility, and New York Stock Exchange trading halts", Journal of Finance, 49, pp. 183-214.

McMillan, Henry (1990) "Circuit breakers in the S\&P500 futures market: Their effect on volatility and price discovery in October 1989", Unpublished manuscript, Securities and Exchange Commission.

Miller, Merton H. (1990) "Volatility, episodic volatility and coordinated circuit-breakers", Unpublished manuscript, University of Chicago.

Ratner, M. and R. Leal (Fevereiro 1998) "Evidence of Short-Term Price Reversals Following Large One Day Movements in the Emerging Markets of Latin America and Asia", Rider University.

Roberts, H. (1967) "Statistical versus Clinical Prediction of the Stock Market", unpublished manuscript, Center for Research in Security Prices, University of Chicago, May.

Schwartz, Arthur L. (1982) "The adjustment of individual stock prices during periods of unusual disequilibria", Financial Review, 17, pp. 228-239.

Stein, Jeremy (1987) "Informational externalities and welfare-reducing speculation", Journal of Political Economy, 95, pp. 1123-1145.

Tanner and Pritchett (1992) "The effects of trading halts on excess returns during periods of system overload", Review of Financial Economics, 1, 2, pp. 1-16. 


\section{TABLES AND FigURES}

Figure 1 - Different market reactions to the arrival of new information

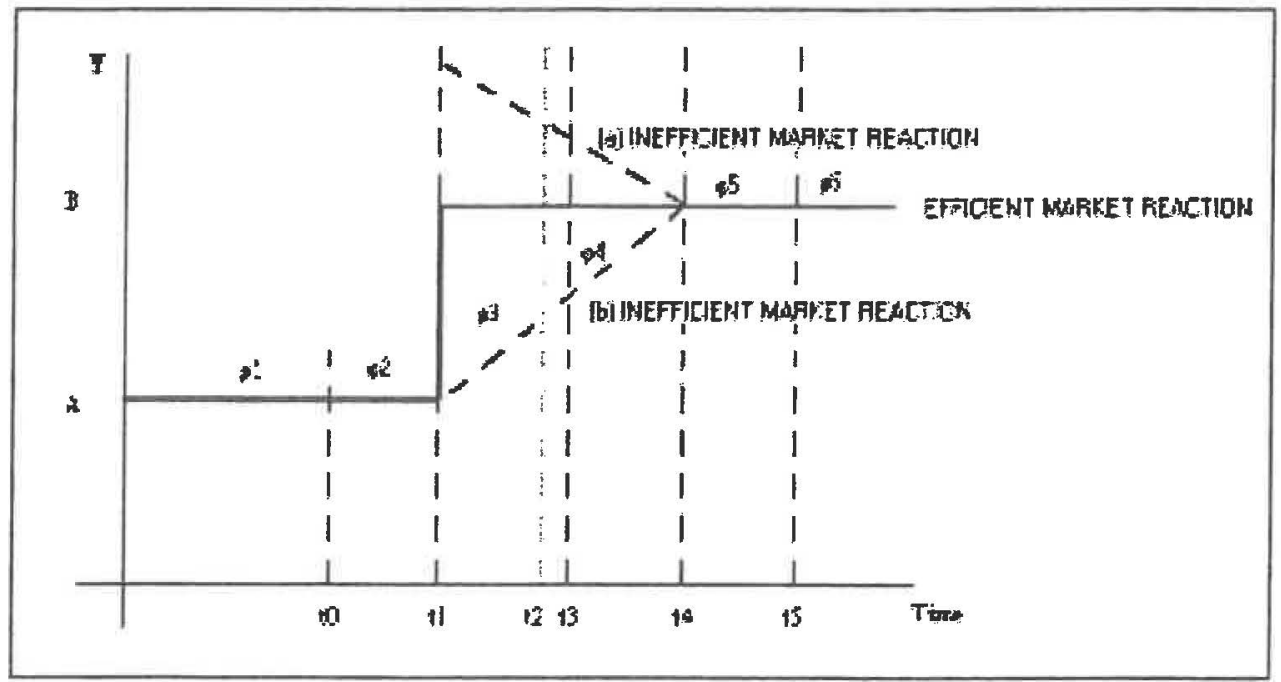

Figure 2 - Description of "Test 1", "Test 2" and "Test 3 "

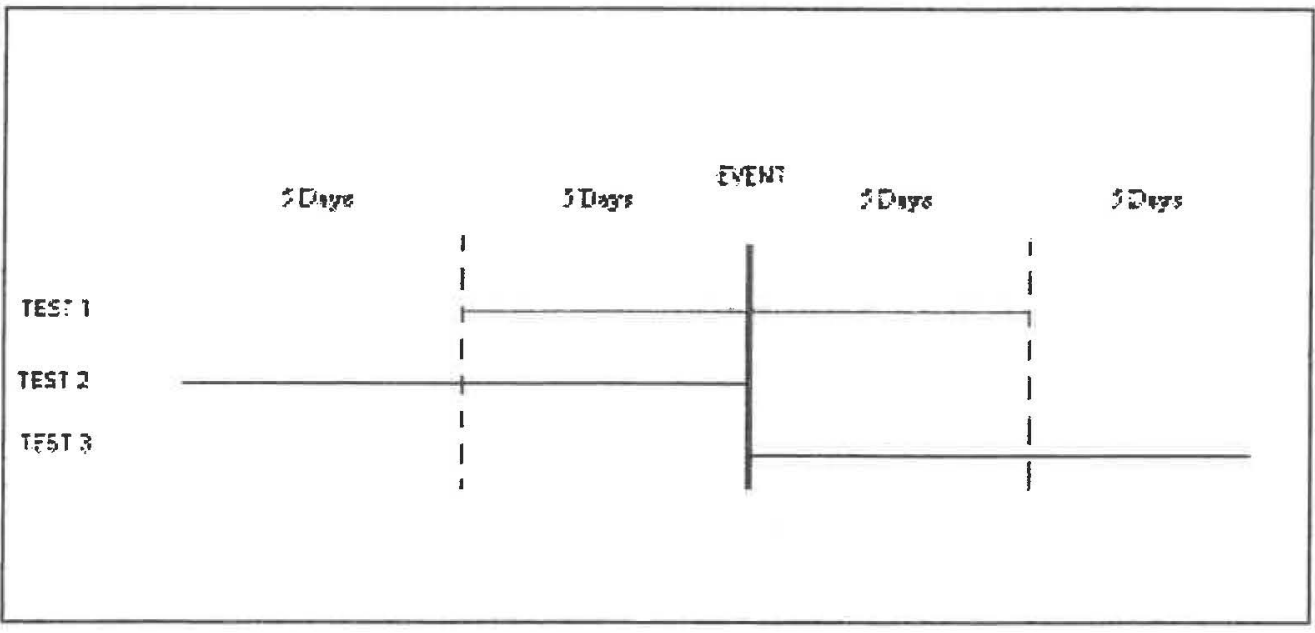

Table 1 - Annual Number and Extension of Trading halts

\begin{tabular}{cccc}
\hline & Number of Trading halts & Number of Days & $\begin{array}{c}\text { Average Number of Days per } \\
\text { Trading halt }\end{array}$ \\
\hline 1992 & 30 & 155 & 5.2 \\
1993 & 70 & 414 & 5.9 \\
1994 & 42 & 170 & 4.0 \\
1995 & 50 & 164 & 3.3 \\
1996 & 27 & 55 & 2.0 \\
1997 & 27 & 47 & 1.7 \\
1998 & 26 & 39 & 1.5 \\
1999 & 59 & 101 & 1.7 \\
\hline Total & 331 & $\mathbf{1 1 4 5}$ & $\mathbf{3 . 5}$ \\
\hline Mear & $\mathbf{4 1}$ & $\mathbf{1 4 3}$ & \\
\hline
\end{tabular}

Source: CMVM, Euronext Lisboa. 
Table 2 - Sample Size and Characteristics

\begin{tabular}{cccc}
\hline & Number of Trading halts & Number of Days & $\begin{array}{c}\text { Average Number of Days per } \\
\text { Trading halt }\end{array}$ \\
\hline 1992 & 2 & 11 & 5.5 \\
1993 & 5 & 24 & 4.0 \\
1994 & 8 & 26 & 3.3 \\
1995 & 1 & 1 & 1.0 \\
1996 & 4 & 8 & 2.0 \\
1997 & 5 & 10 & 2.0 \\
1998 & 14 & 17 & 1.2 \\
1999 & 15 & 27 & 1.5 \\
\hline Total & 54 & 124 & 2.3 \\
\hline Mean & 6.75 & 15.5 & \\
\hline
\end{tabular}

Source: CMVM, Euronext Lisboa.

Table 3 - Average AR and CAR, AR and CAR Standard Deviations

\begin{tabular}{|c|c|c|c|c|c|c|}
\hline Day & Average AR (\%) & $\begin{array}{c}\text { AR Standard } \\
\text { Deviation }(\%)\end{array}$ & $\mathbf{t}$-test & Average CAR (\%) & $\begin{array}{l}\text { CAR Standard } \\
\text { Deviation }(\%)\end{array}$ & t- test \\
\hline-20 & $0.36 \%$ & $1.75 \%$ & 1.529 & $0.36 \%$ & $1.75 \%$ & 1.529 \\
\hline-19 & $0.09 \%$ & $1.71 \%$ & 0.366 & $0.45 \%$ & $2.32 \%$ & 1.424 \\
\hline-18 & $0.30 \%$ & $1.75 \%$ & 1.247 & $0.75 \%$ & $2.69 \%$ & $2.042 *$ \\
\hline .17 & $0.39 \%$ & $1.49 \%$ & 1.909 & $1.13 \%$ & $3.30 \%$ & $2.527^{\star}$ \\
\hline-16 & $0.04 \%$ & $1.69 \%$ & 0.188 & $1.18 \%$ & $4.15 \%$ & $2.088^{\star}$ \\
\hline-15 & $-0.14 \%$ & $1.44 \%$ & -0.712 & $1.04 \%$ & $3.82 \%$ & 1.996 \\
\hline-14 & $-0.33 \%$ & $1.46 \%$ & -1.640 & $0.71 \%$ & $4.24 \%$ & 1.232 \\
\hline-13 & $0.03 \%$ & $1.83 \%$ & 0.107 & $0.74 \%$ & $4.71 \%$ & 1.152 \\
\hline-12 & $0.08 \%$ & $2.55 \%$ & 0.238 & $0.82 \%$ & $5.66 \%$ & 1.066 \\
\hline-11 & $-0.14 \%$ & $2.24 \%$ & -0.465 & $0.68 \%$ & $5.96 \%$ & 0.837 \\
\hline-10 & $0.40 \%$ & $228 \%$ & 1.297 & $1.08 \%$ & $6.08 \%$ & 1.307 \\
\hline-9 & $-0.02 \%$ & $1.46 \%$ & -0.124 & $1.06 \%$ & $6.36 \%$ & 1.221 \\
\hline-8 & $0.08 \%$ & $1.47 \%$ & 0.409 & $1.14 \%$ & $6.60 \%$ & 1.267 \\
\hline-7 & $-0.22 \%$ & $1.63 \%$ & -0.977 & $0.92 \%$ & $6.51 \%$ & 1.040 \\
\hline-6 & $-0.01 \%$ & $1.79 \%$ & -0.056 & $0.91 \%$ & $6.98 \%$ & 0.955 \\
\hline-5 & $-0.39 \%$ & $3.20 \%$ & -0.885 & $0.52 \%$ & $9.29 \%$ & 0.413 \\
\hline-4 & $0.22 \%$ & $2.03 \%$ & 0.809 & $0.75 \%$ & $9.69 \%$ & 0.565 \\
\hline-3 & $0.31 \%$ & $1.91 \%$ & 1.172 & $1.05 \%$ & $10.06 \%$ & 0.767 \\
\hline-2 & $0.23 \%$ & $1.72 \%$ & 0.972 & $1.28 \%$ & $10.60 \%$ & 0.886 \\
\hline-1 & $0.59 \%$ & $2.41 \%$ & 1.795 & $1.87 \%$ & $11.80 \%$ & 1.163 \\
\hline 0 & $1.36 \%$ & $7.93 \%$ & 1.261 & $3.23 \%$ & $16.61 \%$ & 1.429 \\
\hline 1 & $1.61 \%$ & $5.54 \%$ & $2.129^{*}$ & $4.83 \%$ & $16.61 \%$ & $2.139^{*}$ \\
\hline 2 & $0.32 \%$ & $3.62 \%$ & 0.657 & $5.16 \%$ & $16.06 \%$ & $2.360^{\star}$ \\
\hline 3 & $-0.07 \%$ & $2.84 \%$ & -0.185 & $5.09 \%$ & $14.78 \%$ & $2.529^{\star}$ \\
\hline 4 & $-0.28 \%$ & $2.31 \%$ & -0.906 & $4.80 \%$ & $15.94 \%$ & $2.213^{*}$ \\
\hline 5 & $-0.26 \%$ & $3.60 \%$ & -0.523 & $4.54 \%$ & $18.24 \%$ & 1.831 \\
\hline 6 & $-0.45 \%$ & $1.35 \%$ & $-2.483^{*}$ & $4.09 \%$ & $18.70 \%$ & 1.607 \\
\hline 7 & $-0.58 \%$ & $2.71 \%$ & -1.566 & $3.51 \%$ & $19.82 \%$ & 1.302 \\
\hline 8 & $0.23 \%$ & $2.21 \%$ & 0.766 & $3.74 \%$ & $20.78 \%$ & 1.323 \\
\hline 9 & $0.41 \%$ & $2.93 \%$ & 1.019 & $4.15 \%$ & $19.75 \%$ & 1.543 \\
\hline 10 & $0.25 \%$ & $2.71 \%$ & 0.665 & $4.39 \%$ & $20.09 \%$ & 1.607 \\
\hline 11 & $-0.02 \%$ & $2.31 \%$ & -0.076 & $4.37 \%$ & $19.68 \%$ & 1.631 \\
\hline 12 & $0.35 \%$ & $1.93 \%$ & 1.331 & $4.72 \%$ & $19.62 \%$ & 1.767 \\
\hline 13 & $-0.63 \%$ & $1.88 \%$ & $-2.451^{*}$ & $4.09 \%$ & $20.34 \%$ & 1.479 \\
\hline 14 & $-0.15 \%$ & $2.30 \%$ & -0.496 & $3.94 \%$ & $20.47 \%$ & 1.414 \\
\hline 15 & $-0.06 \%$ & $2.14 \%$ & -0.215 & $3.88 \%$ & $20.59 \%$ & 1.383 \\
\hline 16 & $0.07 \%$ & $2.27 \%$ & 0.212 & $3.94 \%$ & $20.21 \%$ & 1.433 \\
\hline 17 & $-0.40 \%$ & $2.06 \%$ & -1.428 & $3.54 \%$ & $20.18 \%$ & 1.290 \\
\hline 18 & $-0.45 \%$ & $1.57 \%$ & $-2.093^{*}$ & $3.09 \%$ & $20.28 \%$ & 1.120 \\
\hline 19 & $0.09 \%$ & $1.67 \%$ & 0.377 & $3.18 \%$ & $20.65 \%$ & 1.131 \\
\hline 20 & $0.03 \%$ & $2.84 \%$ & 0.087 & $3.21 \%$ & $21.02 \%$ & 1.123 \\
\hline
\end{tabular}

Note: * represent parameters that are statistically significant at a 5\% confidence level. 
Figure 3 - Daily Average Abnormal Returns and t-tests

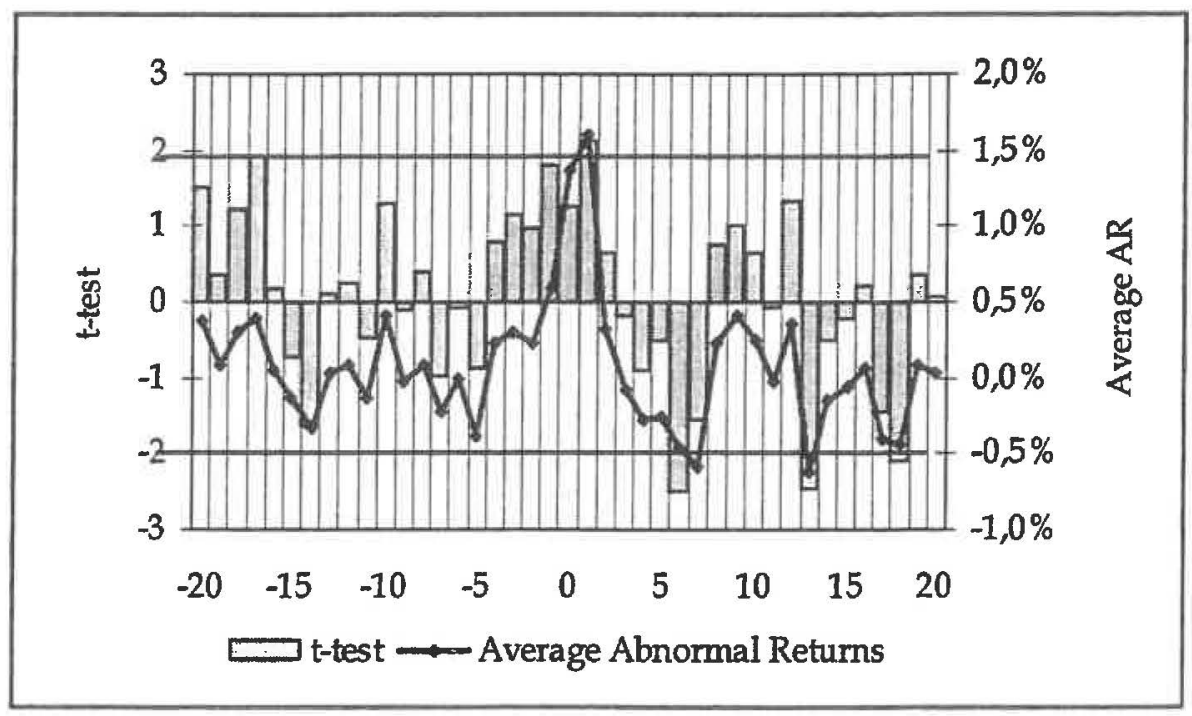

Figure 4 - Average Cumulative Abnormal Returns and t-tests

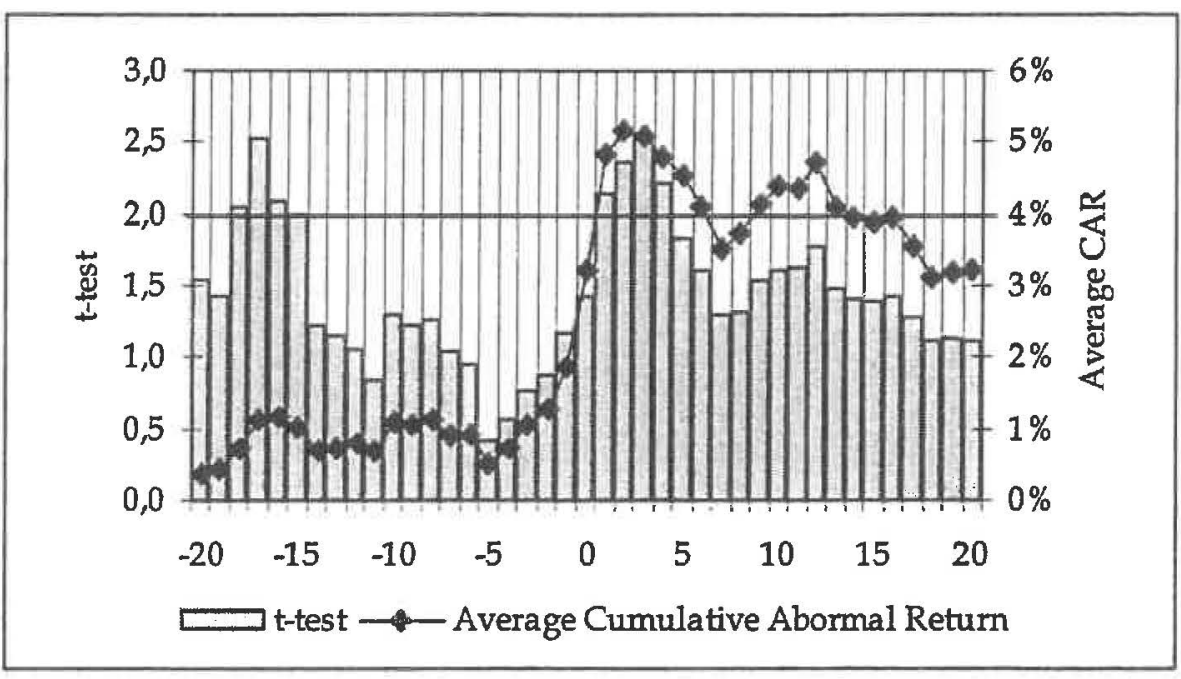


Figure 5 - Average Abnormal Returns

("good" news vs "bad" news)
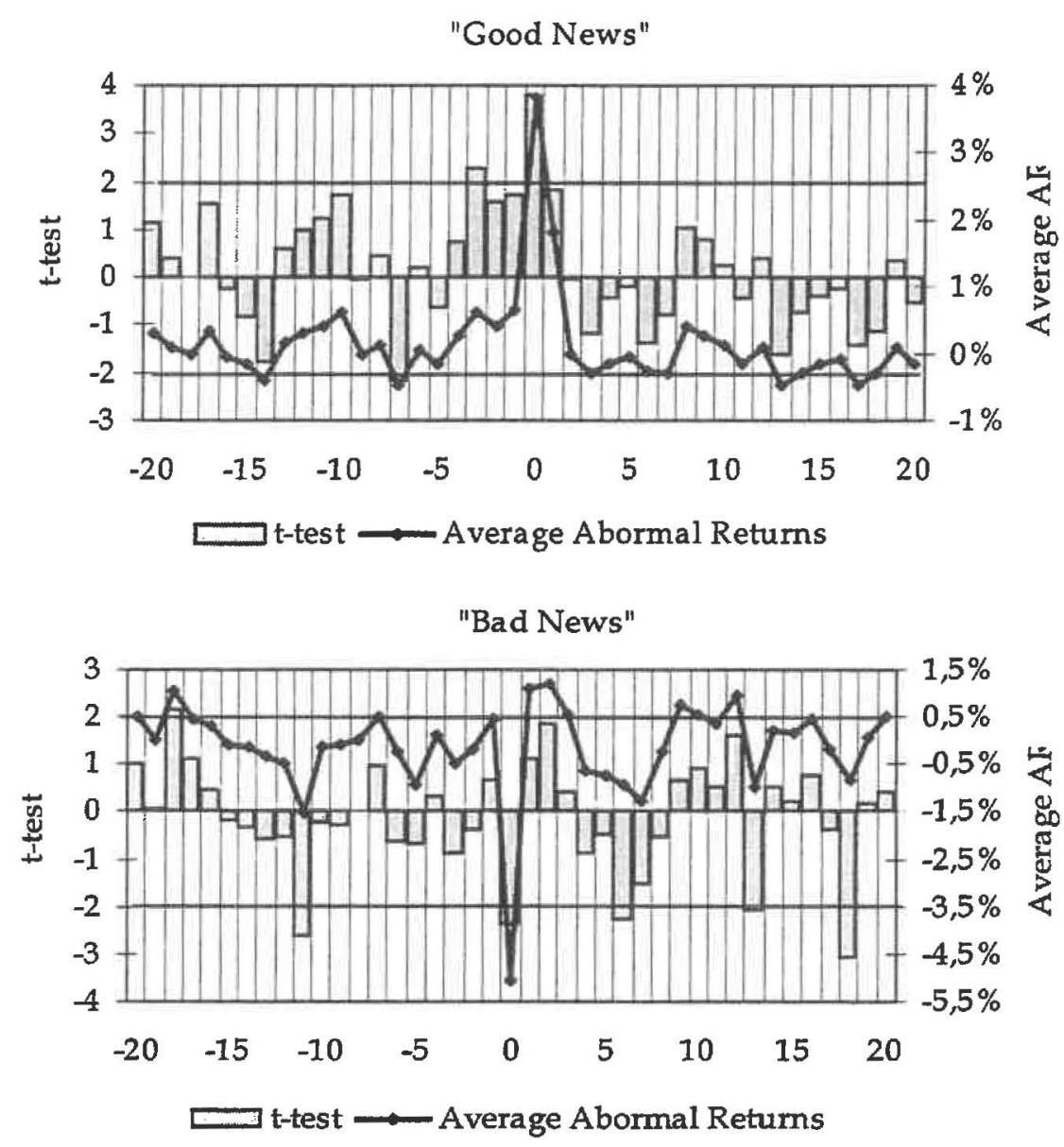
Table 4 - Average AR and t ratios ("good" news vs "bad" news)

\begin{tabular}{|c|c|c|c|c|c|c|}
\hline \multirow[b]{2}{*}{ Day } & \multicolumn{3}{|c|}{ "good" news } & \multicolumn{3}{|c|}{ "bad", news } \\
\hline & Average AR $(\%)$ & $\begin{array}{l}\text { AR Standard } \\
\text { Deviation (\%) }\end{array}$ & $t$-test & Average AR (\%) & $\begin{array}{l}\text { AR Standard } \\
\text { Deviation (\%) }\end{array}$ & t -test \\
\hline-20 & $0.31 \%$ & $1.69 \%$ & 1.147 & $0.51 \%$ & $1.97 \%$ & 0.998 \\
\hline-19 & $0.11 \%$ & $1.73 \%$ & 0.387 & $0.03 \%$ & $1.72 \%$ & 0.065 \\
\hline-18 & $0.00 \%$ & $1.60 \%$ & -0.006 & $1.08 \%$ & $1.94 \%$ & $2.147^{\star}$ \\
\hline-17 & $0.36 \%$ & $1.46 \%$ & 1.522 & $0.47 \%$ & $1.62 \%$ & 1.123 \\
\hline-16 & $-0.05 \%$ & $1.37 \%$ & -0.240 & $0.29 \%$ & $2.38 \%$ & 0.477 \\
\hline-15 & $-0.16 \%$ & $1.21 \%$ & -0.825 & $-0.09 \%$ & $1.97 \%$ & -0.171 \\
\hline-14 & $-0.40 \%$ & $1.40 \%$ & -1.784 & $-0.14 \%$ & $1.65 \%$ & -0.318 \\
\hline-13 & $0.16 \%$ & $1.68 \%$ & 0.593 & $-0.32 \%$ & $2.18 \%$ & -0.568 \\
\hline-12 & $0.31 \%$ & $1.90 \%$ & 1.017 & $-0.51 \%$ & $3.79 \%$ & -0.521 \\
\hline-11 & $0.39 \%$ & $2.00 \%$ & 1.232 & $-1.53 \%$ & $2.29 \%$ & $-2.589^{*}$ \\
\hline-10 & $0.61 \%$ & $2.19 \%$ & 1.727 & $-0.13 \%$ & $2.48 \%$ & -0.203 \\
\hline-9 & $-0.01 \%$ & $1.60 \%$ & -0.028 & $-0.07 \%$ & $1.04 \%$ & -0.261 \\
\hline-8 & $0.11 \%$ & $1.52 \%$ & 0.458 & $0.00 \%$ & $1.37 \%$ & 0.013 \\
\hline-7 & $-0.49 \%$ & $1.43 \%$ & $-2.138^{*}$ & $0.49 \%$ & $1.95 \%$ & 0.973 \\
\hline-6 & $0.07 \%$ & $1.94 \%$ & 0.222 & $-0.23 \%$ & $1.38 \%$ & -0.642 \\
\hline-5 & $-0.17 \%$ & $1.68 \%$ & -0.642 & $-0.94 \%$ & $5.55 \%$ & -0.657 \\
\hline-4 & $0.26 \%$ & $2.20 \%$ & 0.747 & $0.12 \%$ & $1.60 \%$ & 0.297 \\
\hline-3 & $0.62 \%$ & $1.68 \%$ & $2.286^{*}$ & $-0.50 \%$ & $2.28 \%$ & -0.856 \\
\hline-2 & $0.39 \%$ & $1.55 \%$ & 1.585 & $-0.21 \%$ & $2.09 \%$ & -0.380 \\
\hline-1 & $0.64 \%$ & $2.33 \%$ & 1.717 & $0.45 \%$ & $2.69 \%$ & 0.654 \\
\hline 0 & $3.83 \%$ & $6.29 \%$ & $3.802^{*}$ & $-5.05 \%$ & $8.37 \%$ & $-2.338^{*}$ \\
\hline 1 & $1.80 \%$ & $6.12 \%$ & 1.837 & $1.10 \%$ & $3.77 \%$ & 1.129 \\
\hline 2 & $-0.02 \%$ & $3.93 \%$ & -0.025 & $1.21 \%$ & $2.55 \%$ & 1.834 \\
\hline 3 & $-0.31 \%$ & $1.66 \%$ & -1.156 & $0.54 \%$ & $4.75 \%$ & 0.440 \\
\hline 4 & $-0.16 \%$ & $2.11 \%$ & -0.460 & $-0.62 \%$ & $2.82 \%$ & -0.853 \\
\hline 5 & $-0.07 \%$ & $2.04 \%$ & -0.200 & $-0.75 \%$ & $6.12 \%$ & -0.477 \\
\hline 6 & $-0.26 \%$ & $1.19 \%$ & -1.380 & $-0.95 \%$ & $1.62 \%$ & $-2.274^{*}$ \\
\hline 7 & $-0.31 \%$ & $2.49 \%$ & -0.784 & $-1.27 \%$ & $3.20 \%$ & -1.532 \\
\hline 8 & $0.41 \%$ & $2.38 \%$ & 1.067 & $-0.23 \%$ & $1.66 \%$ & -0.536 \\
\hline 9 & $0.27 \%$ & $2.10 \%$ & 0.792 & $0.77 \%$ & $4.50 \%$ & 0.661 \\
\hline 10 & $0.13 \%$ & $2.86 \%$ & 0.275 & $0.56 \%$ & $2.34 \%$ & 0.919 \\
\hline 11 & $-0.16 \%$ & $2.30 \%$ & -0.438 & $0.33 \%$ & $2.39 \%$ & 0.540 \\
\hline 12 & $0.11 \%$ & $1.70 \%$ & 0.400 & $0.98 \%$ & $2.38 \%$ & 1.587 \\
\hline 13 & $-0.48 \%$ & $1.88 \%$ & -1.597 & $-1.00 \%$ & $1.88 \%$ & $-2.064^{*}$ \\
\hline 14 & $-0.29 \%$ & $2.52 \%$ & -0.726 & $0.20 \%$ & $1.60 \%$ & 0.493 \\
\hline 15 & $-0.14 \%$ & $2.12 \%$ & -0.411 & $0.14 \%$ & $2.25 \%$ & 0.236 \\
\hline 16 & $-0.09 \%$ & $2.24 \%$ & -0.237 & $0.46 \%$ & $2.37 \%$ & 0.748 \\
\hline 17 & $-0.48 \%$ & $2.12 \%$ & -1.414 & $-0.19 \%$ & $1.94 \%$ & -0.382 \\
\hline .18 & $-0.31 \%$ & $1.73 \%$ & -1.111 & $-0.82 \%$ & $1.04 \%$ & $-3.036^{\star}$ \\
\hline 19 & $0.10 \%$ & $1.79 \%$ & 0.341 & $0.05 \%$ & $1.38 \%$ & 0.154 \\
\hline 20 & $-0.15 \%$ & $1.75 \%$ & -0.534 & $0.51 \%$ & $4.68 \%$ & 0.422 \\
\hline
\end{tabular}

Note: * represent parameters that are statistically significant at a $5 \%$ confidence level. 
Table 5 - Average CAR and $t$ ratios ("good" news vs "bad" news)

\begin{tabular}{|c|c|c|c|c|c|c|}
\hline \multirow[b]{2}{*}{ Day } & \multicolumn{3}{|c|}{ "good" news } & \multicolumn{3}{|c|}{ "bad" news } \\
\hline & $\begin{array}{c}\text { Average CAR } \\
(\%)\end{array}$ & $\begin{array}{l}\text { CAR Standard } \\
\text { Deviation }(\%)\end{array}$ & t-test & $\begin{array}{c}\text { Average CAR } \\
(\%)\end{array}$ & $\begin{array}{l}\text { CAR Standard } \\
\text { Deviation }(\%)\end{array}$ & t-test \\
\hline-20 & $0.31 \%$ & $1.69 \%$ & 1.147 & $0.51 \%$ & $1.97 \%$ & 0.998 \\
\hline-19 & $0.42 \%$ & $2.49 \%$ & 1.046 & $0.54 \%$ & $1.90 \%$ & 1.093 \\
\hline-18 & $0.42 \%$ & $2.60 \%$ & 0.999 & $1.61 \%$ & $2.83 \%$ & $2.205^{\star}$ \\
\hline-17 & $0.77 \%$ & $2.91 \%$ & 1.652 & $2.08 \%$ & $4.10 \%$ & 1.964 \\
\hline-16 & $0.72 \%$ & $3.30 \%$ & 1.358 & $2.37 \%$ & $5.77 \%$ & 1.592 \\
\hline-15 & $0.56 \%$ & $3.39 \%$ & 1.027 & $2.29 \%$ & $4.66 \%$ & 1.899 \\
\hline-14 & $0.16 \%$ & $3.70 \%$ & 0.266 & $2.15 \%$ & $5.29 \%$ & 1.574 \\
\hline-13 & $0.32 \%$ & $3.79 \%$ & 0.523 & $1.83 \%$ & $6.56 \%$ & 1.081 \\
\hline-12 & $0.63 \%$ & $4.41 \%$ & 0.889 & $1.32 \%$ & $8.25 \%$ & 0.621 \\
\hline-11 & $1.02 \%$ & $4.87 \%$ & 1.310 & $-0.21 \%$ & $8.31 \%$ & -0.099 \\
\hline-10 & $1.63 \%$ & $4.72 \%$ & $2.153^{\star}$ & $-0.34 \%$ & $8.74 \%$ & -0.151 \\
\hline-9 & $1.62 \%$ & $5.03 \%$ & $2.013^{*}$ & $-0.41 \%$ & $9.01 \%$ & -0.177 \\
\hline-8 & $1.73 \%$ & $5.31 \%$ & $2.038^{*}$ & $-0.41 \%$ & $9.21 \%$ & -0.171 \\
\hline-7 & $1.24 \%$ & $5.47 \%$ & 1.420 & $0.08 \%$ & $8.85 \%$ & 0.036 \\
\hline-6 & $1.31 \%$ & $5.82 \%$ & 1.410 & $-0.15 \%$ & $9.55 \%$ & -0.059 \\
\hline-5 & $1.14 \%$ & $6.63 \%$ & 1.074 & $-1.09 \%$ & $14.26 \%$ & -0.295 \\
\hline-4 & $1.40 \%$ & $7.00 \%$ & 1.253 & $-0.96 \%$ & $14.78 \%$ & -0.253 \\
\hline-3 & $2.02 \%$ & $7.49 \%$ & 1.684 & $-1.47 \%$ & $14.89 \%$ & -0.382 \\
\hline-2 & $2.41 \%$ & $7.77 \%$ & 1.939 & $-1.67 \%$ & $15.77 \%$ & -0.411 \\
\hline-1 & $3.05 \%$ & $8.56 \%$ & $2.229 *$ & $-1.22 \%$ & $17.72 \%$ & -0.266 \\
\hline 0 & $6.88 \%$ & $10.03 \%$ & $4.285^{*}$ & $-6.27 \%$ & $25.24 \%$ & -0.962 \\
\hline 1 & $8.68 \%$ & $12.28 \%$ & $4.416^{*}$ & $-5.17 \%$ & $22.05 \%$ & -0.908 \\
\hline 2 & $8.67 \%$ & $12.91 \%$ & $4.191^{\star}$ & $-3.96 \%$ & $20.01 \%$ & -0.767 \\
\hline 3 & $8.36 \%$ & $12.92 \%$ & $4.040^{\star}$ & $-3.42 \%$ & $16.31 \%$ & -0.813 \\
\hline 4 & $8.20 \%$ & $13.71 \%$ & $3.737^{\star}$ & $-4.05 \%$ & $18.33 \%$ & -0.855 \\
\hline 5 & $8.14 \%$ & $14.48 \%$ & $3.510^{*}$ & $-4.80 \%$ & $23.67 \%$ & -0.785 \\
\hline 6 & $7.88 \%$ & $14.63 \%$ & $3.361^{*}$ & $-5.75 \%$ & $24.48 \%$ & -0.910 \\
\hline 7 & $7.56 \%$ & $14.45 \%$ & $3.269^{*}$ & $-7.02 \%$ & $27.49 \%$ & -0.989 \\
\hline 8 & $7.97 \%$ & $15.39 \%$ & $3.234^{*}$ & $-7.25 \%$ & $28.52 \%$ & -0.984 \\
\hline 9 & $8.24 \%$ & $16.23 \%$ & $3.169^{*}$ & $-6.48 \%$ & $24.39 \%$ & -1.029 \\
\hline 10 & $8.36 \%$ & $17.96 \%$ & $2.907^{\star}$ & $-5.92 \%$ & $22.23 \%$ & -1.032 \\
\hline 11 & $8.20 \%$ & $18.28 \%$ & $2.801^{*}$ & $-5.59 \%$ & $20.30 \%$ & -1.067 \\
\hline 12 & $8.31 \%$ & $19.01 \%$ & $2.729^{\star}$ & $-4.61 \%$ & $18.63 \%$ & -0.959 \\
\hline 13 & $7.83 \%$ & $19.50 \%$ & $2.508^{*}$ & $-5.62 \%$ & $19.85 \%$ & -1.096 \\
\hline 14 & $7.54 \%$ & $19.99 \%$ & $2.354^{*}$ & $-5.42 \%$ & $19.29 \%$ & -1.088 \\
\hline 15 & $7.40 \%$ & $20.09 \%$ & $2.300^{*}$ & $-5.28 \%$ & $19.63 \%$ & -1.042 \\
\hline 16 & $7.31 \%$ & $19.95 \%$ & $2.288^{\star}$ & $-4.82 \%$ & $18.75 \%$ & -0.996 \\
\hline 17 & $6.83 \%$ & $19.94 \%$ & $2.139^{\star}$ & $-5.01 \%$ & $18.81 \%$ & -1.032 \\
\hline 18 & $6.52 \%$ & $19.81 \%$ & $2.056^{*}$ & $-5.83 \%$ & $19.34 \%$ & -1.167 \\
\hline 19 & $6.62 \%$ & $20.11 \%$ & $2.056^{\star}$ & $-5.77 \%$ & $19.91 \%$ & -1.123 \\
\hline 20 & $6.47 \%$ & $20.03 \%$ & $2.018^{*}$ & $-5.26 \%$ & $21.84 \%$ & -0.933 \\
\hline
\end{tabular}

Note: * represent parameters that are statistically significant at a $5 \%$ confidence level. 
Figure 6 - Average Abnormal Returns

("good" news vs "bad" news)
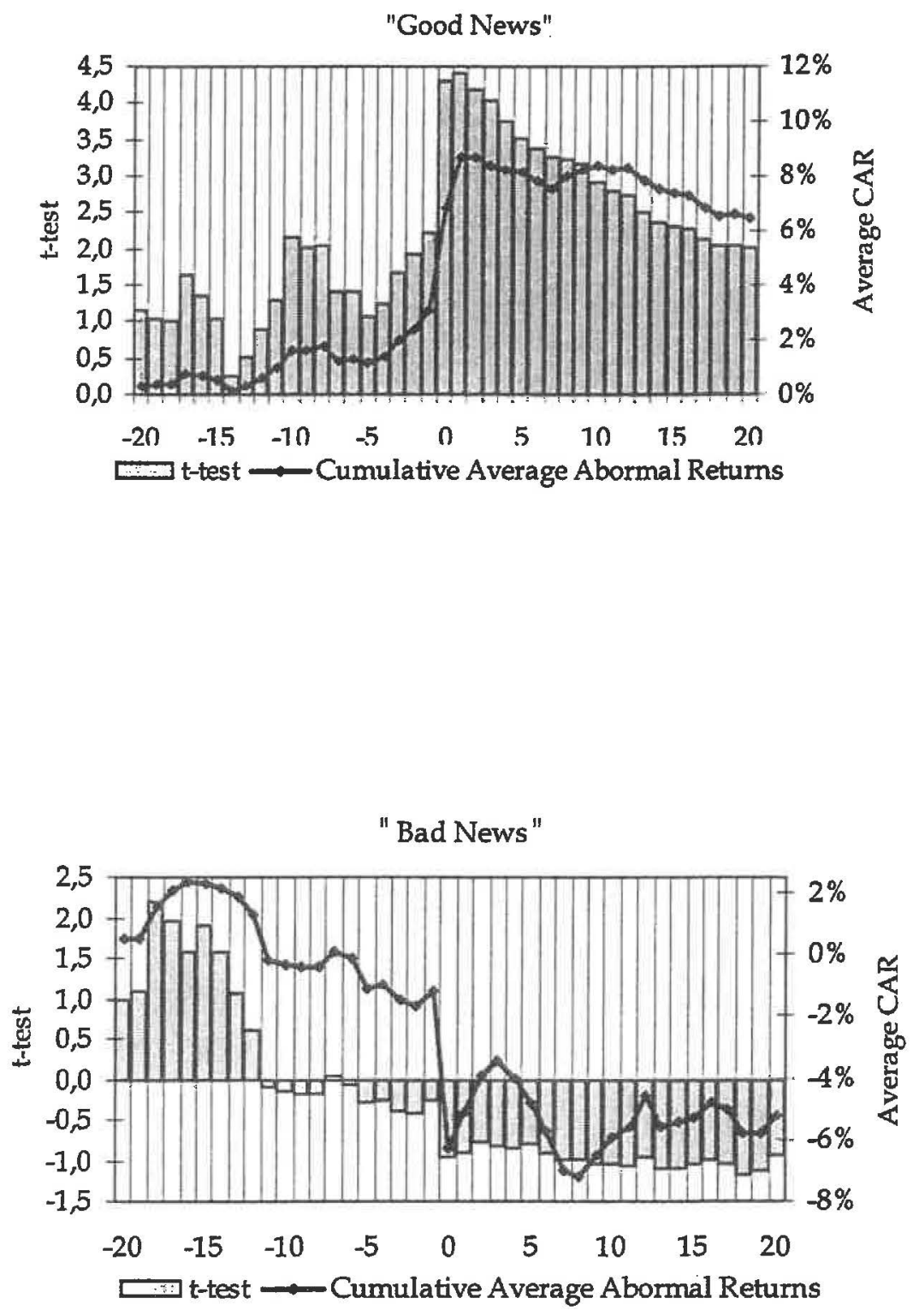
Table 6 - Testing Variances - Number of Sample Cases After Applying "Test 1" According to Different Sampling Time Length Around Trading Halts

Table 6 A - Number of Cases when Testing Timing ("Test 2" and "Test 3") Using Variances for Periods of 5 Days, having Rejected $\mathrm{H}_{0}$ of "Test 1 "

\begin{tabular}{|c|c|c|c|c|}
\hline \multirow{2}{*}{\multicolumn{2}{|c|}{$\begin{array}{c}\text { Testing 5B with 5A } \\
\text { Reject } \mathrm{H}_{0} \text { (Significant Differences) }\end{array}$}} & \multicolumn{2}{|c|}{ Testing 5A with 5AA } & \multirow[b]{2}{*}{ Total } \\
\hline & & No Differences Found & $\leqslant$ (Differences Found) & \\
\hline \multirow[b]{2}{*}{$\begin{array}{l}\text { Testing } \\
\text { 5BB with 5B }\end{array}$} & No Differences Found & $\begin{array}{l}\text { Interruption Justified and } \\
\text { on Timing }\end{array}$ & $\begin{array}{l}\text { Interruption Justified and on } \\
\text { Time but Restarting Early } \\
\qquad 4\end{array}$ & 6 \\
\hline & $\widehat{*}$ (Differences Found) & $\begin{array}{l}\text { Interruption Justified } \\
\text { although Late but } \\
\text { Restarting on Time } \\
2\end{array}$ & $\begin{array}{c}\text { Interruption Justified } \\
\text { although Late but Restarting } \\
\text { Early } \\
2 \\
\end{array}$ & 4 \\
\hline & Total & 4 & 6 & 10 \\
\hline
\end{tabular}

Table 6 B - Number of Cases when Testing Timing ("Test 2" and "Test 3") Using Variances for Periods of 5 Days, Failing to Reject Ho of "Test 1"

\begin{tabular}{|c|c|c|c|c|}
\hline \multirow{2}{*}{\multicolumn{2}{|c|}{$\begin{array}{c}\text { Testing 5B with 5A } \\
\text { Accept } \mathrm{H}_{0} \text { (No Significant Differences) }\end{array}$}} & \multicolumn{2}{|c|}{ Testing 5A with 5AA } & \multirow{2}{*}{ Total } \\
\hline & & No Differences Found & (Differences Found) & \\
\hline \multirow[b]{2}{*}{$\begin{array}{l}\text { Testing } \\
\text { 5BB with 5B }\end{array}$} & No Differences Found & $\begin{array}{l}\text { Why? } \\
26\end{array}$ & $\begin{array}{l}\text { Why to Interrupt if } \\
\text { Restarting so Early? } \\
6\end{array}$ & 32 \\
\hline & $\star$ (Differences Found) & $\begin{array}{l}\text { Why to Interrupt if } \\
\text { Interrupting so Late? } \\
\mathbf{1 1}\end{array}$ & $\begin{array}{l}\text { Why to Interrupt if } \\
\text { Interrupting so Late and } \\
\text { Restarting so Early } \\
1\end{array}$ & 12 \\
\hline & Total & 37 & 7 & 44 \\
\hline
\end{tabular}

Table 6 C - Number of Cases when Testing Timing ("Test 2" and "Test 3") Using Variances for Periods of 10 Days, having Rejected $\mathrm{H}_{0}$ of "Test 1 "

\begin{tabular}{|c|c|c|c|c|}
\hline \multirow{2}{*}{\multicolumn{2}{|c|}{$\begin{array}{c}\text { Testing 10B with 10A } \\
\text { Reject } \mathrm{H}_{0} \text { (Significant Differences) }\end{array}$}} & \multicolumn{2}{|c|}{ Testing $10 \mathrm{~A}$ with $10 \mathrm{AA}$} & \multirow{2}{*}{ Total } \\
\hline & & No Differences Found & * (Differences Found) & \\
\hline \multirow[b]{2}{*}{$\begin{array}{l}\text { Testing } \\
\text { 10BB with 10B }\end{array}$} & No Differences Found & $\begin{array}{c}\text { Interruption Justified and } \\
\text { on Timing } \\
\mathbf{5}\end{array}$ & $\begin{array}{c}\text { Interruption Justified and on } \\
\text { Time but Restarting Early } \\
8\end{array}$ & 13 \\
\hline & $\leqslant$ (Differences Found) & $\begin{array}{c}\text { Interruption Justified } \\
\text { although Late but } \\
\text { Restarting on Time } \\
\mathbf{4}\end{array}$ & $\begin{array}{l}\text { Interruption Justified } \\
\text { although Late but Restarting } \\
\text { Early } \\
1\end{array}$ & 5 \\
\hline \multicolumn{2}{|c|}{ Total } & 9 & 9 & 18 \\
\hline
\end{tabular}


Table 6 D - Number of Cases when Testing Timing ("Test 2" and "Test 3") Using Variances for Periods of 10 Days, Failing to Reject $\mathbf{H}_{0}$ of "Test 1 "

\begin{tabular}{|c|c|c|c|c|}
\hline \multirow{2}{*}{\multicolumn{2}{|c|}{$\begin{array}{c}\text { Testing 10B with 10A } \\
\text { Accept } \mathrm{H}_{0} \text { (No Significant Differences) }\end{array}$}} & \multicolumn{2}{|c|}{ Testing $10 \mathrm{~A}$ with $10 \mathrm{AA}$} & \multirow{2}{*}{ Total } \\
\hline & & No Differences Found & - (Differences Found) & \\
\hline \multirow{2}{*}{$\begin{array}{l}\text { Testing } \\
10 B B \text { with } 10 B\end{array}$} & No Differences Found & $\begin{array}{l}\text { Why? } \\
19\end{array}$ & $\begin{array}{l}\text { Why to Interrupt if } \\
\text { Restarting so Early? } \\
7\end{array}$ & 26 \\
\hline & (Differences Found) & $\begin{array}{l}\text { Why to Interrupt if } \\
\text { Interrupting so Late? } \\
5\end{array}$ & $\begin{array}{l}\text { Why to Interrupt if } \\
\text { Interrupting so Late and } \\
\text { Restarting so Early } \\
5\end{array}$ & 10 \\
\hline \multicolumn{2}{|c|}{ Total } & 24 & 12 & 36 \\
\hline
\end{tabular}

Table $6 \mathrm{E}$ - Number of Cases when Testing Timing ("Test 2" and "Test 3") Using Variances for Periods of 20 Days, having Rejected $\mathrm{H}_{\mathrm{B}}$ of "Test 1"

\begin{tabular}{|c|c|c|c|c|}
\hline \multirow{2}{*}{\multicolumn{2}{|c|}{$\begin{array}{c}\text { Testing 20B with 20A } \\
\text { Reject } \mathrm{H}_{0} \text { (Significant Differences) }\end{array}$}} & \multicolumn{2}{|c|}{ Testing 20A with 20AA } & \multirow{2}{*}{ Total } \\
\hline & & No Differences Found & $\Delta$ (Differences Found) & \\
\hline \multirow[b]{2}{*}{$\begin{array}{l}\text { Testing } \\
\text { 20BB with 20B }\end{array}$} & No Differences Found & $\begin{array}{c}\text { Interruption Justified and } \\
\text { on Timing } \\
8\end{array}$ & $\begin{array}{l}\text { Interruption Justified and on } \\
\text { Time but Restarting Early } \\
3\end{array}$ & 11 \\
\hline & $\star$ (Differences Found) & $\begin{array}{l}\text { Interruption Justified } \\
\text { although Late but } \\
\text { Restarting on Time } \\
4\end{array}$ & $\begin{array}{c}\text { Interruption Justified } \\
\text { although Late but Restarting } \\
\text { Early } \\
12\end{array}$ & 16 \\
\hline \multicolumn{2}{|c|}{ Total } & 12 & 15 & 27 \\
\hline
\end{tabular}

Table 6 F - Number of Cases when Testing Timing ("Test 2" and "Test 3") Using Variances for Periods of 20 Days, Failing to Reject $\mathrm{H}_{0}$ of "Test 1"

\begin{tabular}{|c|c|c|c|c|}
\hline \multirow{2}{*}{\multicolumn{2}{|c|}{$\begin{array}{c}\text { Testing 20B with 20A } \\
\text { Accept } \mathrm{H}_{0} \text { (No Significant Differences) }\end{array}$}} & \multicolumn{2}{|c|}{ Testing 20A with 20AA } & \multirow{2}{*}{ Total } \\
\hline & & No Differences Found & $\approx$ (Differences Found) & \\
\hline \multirow{2}{*}{$\begin{array}{l}\text { Testing } \\
20 B B \text { with } 20 B\end{array}$} & No Differences Found & $\begin{array}{c}\text { Why? } \\
6\end{array}$ & $\begin{array}{l}\text { Why to Interrupt if } \\
\text { Restarting so Early? } \\
5\end{array}$ & 11 \\
\hline & $\hat{*}$ (Differences Found) & $\begin{array}{c}\text { Why to Interrupt if } \\
\text { Interrupting so Late? } \\
\mathbf{8}\end{array}$ & $\begin{array}{l}\text { Why to Interrupt if } \\
\text { Interrupting so Late and } \\
\text { Restarting so Early } \\
8\end{array}$ & 16 \\
\hline \multicolumn{2}{|c|}{ Total } & 14 & 13 & 27 \\
\hline
\end{tabular}


Table 7 - Testing a GARCH $(1,1)$ model

\begin{tabular}{|c|c|c|c|c|c|}
\hline & & & & & \\
\hline & & \multicolumn{2}{|c|}{$\mathrm{H}_{0}: \phi_{A}=\phi_{B}$ vs $H_{1}: H_{1}: \phi_{A} \neq \phi_{B}$} & \multicolumn{2}{|c|}{$H_{0}: \phi_{1}=\phi_{2}$ vs $H_{2}: \phi_{1} \neq \phi_{2}$} \\
\hline & & Test Statistic & $p$-value & Test Statistic & p-value \\
\hline Unicer & 1992 & 0,142 & 0,707 & 0,023 & 0,880 \\
\hline BES & 1992 & $-23,826$ & 1,000 & $+23,2,2$ & 1,000 \\
\hline BPI & 1993 & $31,137^{*}$ & 0,000 & $13,546^{*}$ & 0,000 \\
\hline BPA & 1993 & $-7,201$ & 1,000 & 2,351 & 0,130 \\
\hline Lusotur & 1993 & 1,295 & 0,255 & 1,345 & 0,250 \\
\hline Sonae Ind. & 1993 & 1,256 & 0,262 & 1,113 & 0,290 \\
\hline Sonae SGPS & 1993 & $7,960^{*}$ & 0,005 & $14,539^{*}$ & 0,000 \\
\hline Lisnave & 1994 & 0,497 & 0,481 & 0,281 & 0,600 \\
\hline Modelo & 1994 & 1,396 & 0,237 & 1,257 & 0,260 \\
\hline BTA & 1994 & 1,306 & 0,253 & 0,369 & 0,540 \\
\hline $\mathrm{BCP}$ & 1994 & 2,495 & 0,114 & 2,438 & 0,120 \\
\hline BES & 1994 & $-10,952$ & 1,000 & 1,181 & 0,280 \\
\hline Efacec & 1994 & 0,115 & 0,735 & $17,796^{*}$ & 0,000 \\
\hline Cort. Amorim & 1994 & 0,333 & 0,855 & 0,030 & 0,860 \\
\hline BTA 2 & 1994 & $27,478^{*}$ & 0,000 & $23,844^{*}$ & 0,000 \\
\hline Reditus & 1995 & 1,708 & 0,191 & 2,017 & 0,160 \\
\hline BFE & 1996 & 3,472 & 0,062 & 0,031 & 0,860 \\
\hline CPP & 1996 & $6,650^{*}$ & 0,010 & $-20,598$ & 1,000 \\
\hline BFE 2 & 1996 & 0,040 & 0,950 & $17,564^{*}$ & 0,000 \\
\hline BPI & 1996 & $11,060^{*}$ & 0,001 & $27,603^{*}$ & 0,000 \\
\hline Cerexport & 1997 & 1,112 & 0,292 & 0,306 & 0,580 \\
\hline Reditus & 1997 & 1,161 & 0,281 & 1,556 & 0,210 \\
\hline JM & 1997 & 1,152 & 0,283 & 0,380 & 0,540 \\
\hline Inparsa & 1997 & $3,888^{*}$ & 0,049 & 1,903 & 0,170 \\
\hline CPP & 1997 & $8,789^{*}$ & 0,003 & 8.4.19* & 0,000 \\
\hline $\mathrm{AXA}$ & 1998 & 3,808 & 0,051 & $-87,397$ & 1,000 \\
\hline $\mathrm{BCP}$ & 1998 & 0,421 & 0,517 & 0,291 & 0,590 \\
\hline BPI & 1998 & $13,320^{*}$ & 0,000 & $13,626^{*}$ & 0,000 \\
\hline BANIF & 1998 & $8,670^{*}$ & 0,003 & $8,521^{*}$ & 0,000 \\
\hline CPP & 1998 & $11,397^{*}$ & 0,001 & $3,736^{*}$ & 0,050 \\
\hline BPSM & 1998 & 0,131 & 0,718 & 0,124 & 0,730 \\
\hline BTA & 1998 & $12,972^{\star}$ & 0,000 & $12,804^{*}$ & 0,000 \\
\hline CSMC & 1998 & 0,586 & 0,444 & 0,151 & 0,700 \\
\hline Caima & 1998 & $23,021^{*}$ & 0,000 & $10,468^{*}$ & 0,000 \\
\hline BTA 2 & 1998 & 1,325 & 0,250 & 1,167 & 0,280 \\
\hline CPP 2 & 1998 & $8,891^{*}$ & 0,003 & 4,079 & 1,000 \\
\hline BPSM 2 & 1998 & 1,367 & 0,242 & 1,647 & 0,200 \\
\hline $\operatorname{CSMC} 2$ & 1998 & 0,126 & 0,723 & $9,440^{*}$ & 0,000 \\
\hline Cimpor & 1998 & $12,516^{*}$ & 0,000 & $-5,040$ & 1,000 \\
\hline Mota\&Comp. & 1999 & 2,420 & 0,120 & 1,835 & 0,180 \\
\hline Mota\&Engil & 1999 & $-5,009$ & 1,000 & $9,137^{\star}$ & 0,000 \\
\hline EDP & 1999 & 1,049 & 0,306 & 1,914 & 0,170 \\
\hline Inparsa & 1999 & $20,546^{*}$ & 0,000 & $17,806^{\star}$ & 0,000 \\
\hline Cofina & 1999 & $24,520^{*}$ & 0,000 & $-1,014$ & 1,000 \\
\hline BPA & 1999 & $-5,093$ & 1,000 & 0,010 & 0,750 \\
\hline Sonae Ind. & 1999 & 2,088 & 0,148 & 1,926 & 0,170 \\
\hline Colep & 1999 & 1,410 & 0,235 & $5,689^{\star}$ & 0,020 \\
\hline BPI & 1999 & $-4,870$ & 1,000 & 9,135* & 0,000 \\
\hline $\mathrm{BCP}$ & 1999 & $-23,612$ & 1,000 & $-22,937$ & 1,000 \\
\hline BPSM & 1999 & $3,899^{*}$ & 0,048 & $3,846^{*}$ & 0,050 \\
\hline BTA & 1999 & 1,918 & 0,166 & 2,675 & 0,100 \\
\hline CSMC & 1999 & $26,611^{*}$ & 0,000 & $25,044^{*}$ & 0,000 \\
\hline $\mathrm{CPP}$ & 1999 & 0,112 & 0,737 & 0,068 & 0,790 \\
\hline Pararede & 1999 & $4,670^{*}$ & 0,031 & $5,082^{*}$ & 0,020 \\
\hline
\end{tabular}

Note: The shadowed cells represent the invalid statistics and * represent parameters that are statistically significant at a $5 \%$ confidence level. 
Table 8 - Trading Halt Opportunity Revealed by different Methods

\begin{tabular}{|c|c|c|c|c|c|c|c|c|c|c|c|c|c|c|c|}
\hline & & 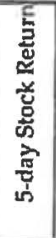 & 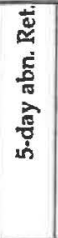 & 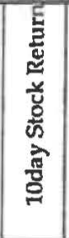 & 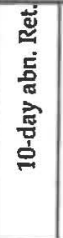 & 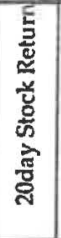 & 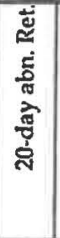 & 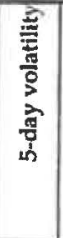 & 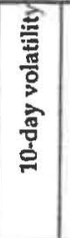 & 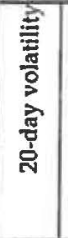 & 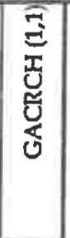 & 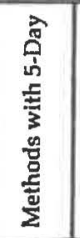 & 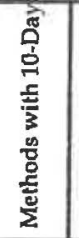 & 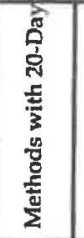 & 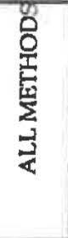 \\
\hline Unicer & 1992 & & & & & & & & & $x$ & & & & x & $\bar{x}$ \\
\hline BES & 1992 & & & & & & & & & & & & & 7 & \\
\hline BPI & 1993 & & & & & & & & & $x$ & $x$ & & & $x$ & $x$ \\
\hline BPA & 1993 & & & & & & & & $x$ & $x$ & & & x & x & $\bar{x}$ \\
\hline Lusotur & 1993 & & & & & & & & & & & & & 1 & \\
\hline Sonae Ind. & 1993 & & & & & & & & & $x$ & & & & $x$ & $x$ \\
\hline Sonae SGPS & 1993 & & & & & & & & & त्र & $x$ & & & x & $x$ \\
\hline Lisnave & 1994 & & & & & & & & & & & & & & \\
\hline Modelo & 1994 & & & & & & & & & $x$ & & & & $x$ & $x$ \\
\hline BTA & 1994 & & & & & & & & & & & & & & \\
\hline$B C P$ & 1994 & & & & & & & & & & & & & & \\
\hline BES & 1994 & & & & & & & $x$ & & $x$ & & x & & $x$ & $x$ \\
\hline Efacec & 1994 & & & & & & & & & $?$ & X & & & 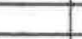 & $\bar{x}$ \\
\hline Cort. Amorim & 1994 & & & & & & & & & X & & & & $x$ & $x$ \\
\hline BTA2 & 1994 & & & $x$ & $x$ & $x$ & $x$ & & & 7 & $x$ & & $x$ & $x$ & $x$ \\
\hline Reditus & 1995 & & & & & & & & $x$ & $x$ & & & $x$ & $x$ & $x$ \\
\hline BFE & 1996 & & & & & & & & & & & & & & \\
\hline CPP & 1996 & & & & & & & & & & & & & & \\
\hline BFE 2 & 1996 & & & & & & & & & & $x$ & & & & $x$ \\
\hline BPI & 1996 & & & & & & & & $x$ & $x$ & $x$ & & $x$ & $x$ & $x$ \\
\hline Cerexport & 1997 & $x$ & & X & & & & & $x$ & & & $x$ & $x$ & & $x$ \\
\hline Reditus & 1997 & & & & & & & & & & & & 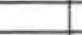 & & \\
\hline $\mathrm{IM}$ & 1997 & & & $x$ & & $x$ & $x$ & & & $x$ & & & $x$ & $x$ & $\bar{x}$ \\
\hline Inparsa & 1997 & $x$ & & & & & & & $x$ & $x$ & & $x$ & $x$ & $x$ & $x$ \\
\hline CPP & 1997 & & & & & & & $x$ & 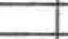 & 7 & $x$ & $x$ & + & 7 & $x$ \\
\hline $\mathrm{AXA}$ & 1998 & & & & & & & & $x$ & $x$ & - & - & $x$ & $x$ & $x$ \\
\hline$B C P$ & 1998 & & & & & & & & & 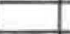 & & & & & \\
\hline BPI & 1998 & & & & & & & $x$ & & $x$ & $x$ & $x$ & & $x$ & $x$ \\
\hline BANIF & 1998 & & & & & & & $x$ & $x$ & $x$ & $x$ & $x$ & $x$ & $x$ & $x$ \\
\hline CPP & 1998 & & & & & & & $x$ & $x$ & $x$ & $x$ & $x$ & $x$ & $x$ & $x$ \\
\hline BPSM & 1998 & & & & & & & & 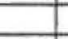 & 7 & 7 & + & 3 & 7 & - \\
\hline BTA & 1998 & & & & & & & $x$ & $x$ & $x$ & $x$ & $x$ & $x$ & $x$ & $x$ \\
\hline CSMC & 1998 & $x$ & $x$ & $x$ & $x$ & & & $x$ & & & 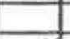 & $x$ & $x$ & $\rightarrow$ & $x$ \\
\hline Caima & 1998 & & & $x$ & $x$ & $x$ & $x$ & & & & $x$ & & $x$ & $x$ & $x$ \\
\hline BTA 2 & 1998 & & & & & & & & & & & & & & \\
\hline CPP 2 & 1998 & & & & & & & & & & & & & & \\
\hline BPSM 2 & 1998 & & & & & & & & & & & & & & \\
\hline SSMC 2 & 1998 & & & $x$ & & $x$ & $x$ & & & & $x$ & & $x$ & $x$ & $x$ \\
\hline Cimpor & 1998 & & & & & & & & x & & & & $x$ & & $x$ \\
\hline Mota\&Comp. & 1999 & & & & & & & & $x$ & $x$ & & & $x$ & $x$ & $x$ \\
\hline Mota\&Eingil & 1999 & & & & & & & & + & $\rightarrow$ & $x$ & & + & 7 & $x$ \\
\hline EDP & 1999 & & & & & & & & $x$ & $x$ & & & $x$ & $x$ & $x$ \\
\hline inparsa & 1999 & & & & & & & X & xत & $x$ & $x$ & $x$ & $x$ & $x$ & $x$ \\
\hline Cofina & 1999 & & & & & & & & $x$ & $x$ & & & $x$ & $x$ & $\bar{x}$ \\
\hline EPA & 1999 & & & & & & & & & & & & 7 & 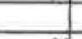 & \\
\hline Sorae Ind. & 1999 & & & & & & & & $x$ & $x$ & & & $x$ & $x$ & $x$ \\
\hline Colep & 1999 & & & & & & & $x$ & T & & $x$ & $x$ & 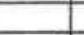 & 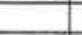 & $x$ \\
\hline BPI & 1999 & & & & & & & & $x$ & $x$ & $x$ & & $x$ & $x$ & $x$ \\
\hline$B C P$ & 1999 & & & & & & & & 7 & $x$ & T & 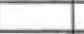 & + & $x$ & $x$ \\
\hline BPSM & 1999 & $x$ & $x$ & & $x$ & & & & $x$ & $x$ & $x$ & $x$ & $x$ & $x$ & $x$ \\
\hline BTA & 1999 & & & & & & & & & & & & 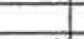 & 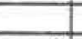 & \\
\hline CSMC & 1999 & & & & & & & & $x$ & $x$ & त्व & & $x$ & $x$ & $x$ \\
\hline$C P P$ & 1999 & & $\cdot$ & & & & & & & & & & & T & \\
\hline Pararede & 1999 & & & & $x$ & & & $x$ & & $x$ & $x$ & $x$ & $x$ & $x$ & $x$ \\
\hline Total Sample & & 54 & 54 & 54 & 54 & 54 & 54 & 54 & 54 & 54 & 54 & 54 & 54 & 54 & 54 \\
\hline \# Observations & & 4 & 2 & 6 & 5 & 4 & 4 & 10 & 18 & 27 & 20 & 13 & 24 & 30 & 38 \\
\hline \#/Tot Sample & & $7 \%$ & $4 \%$ & $11 \%$ & $9 \%$ & $7 \%$ & $7 \%$ & $19 \%$ & $33 \%$ & $50 \%$ & $37 \%$ & $24 \%$ & $44 \%$ & $56 \%$ & $70 \%$ \\
\hline
\end{tabular}




\section{APPENDIX 1}

Sample used in the study

\begin{tabular}{|c|c|c|c|c|c|c|c|}
\hline $\mathbf{N}$. & Firm & Year & Halt Starting Date & Time & Halt Ending Date & Time & N. of Days \\
\hline 1 & Unicer-Uniāo Cerv,-Nom & 1992 & $09-04-92$ & - & $09-14-92$ & - & 6 \\
\hline 2 & B.Espirito Santo-Nom. & 1992 & $09-08-92$ & - & $09-15-92$ & - & 5 \\
\hline 3 & B.Português Atlântico-Nom & 1993 & $02-01-93$ & - & $02-09-93$ & - & 6 \\
\hline 4 & BPI-Nom. & 1993 & $04-13-93$ & - & 04-19-93 & - & 4 \\
\hline 5 & Lusotur-Soc.Fin.Turismo & 1993 & $10-18-93$ & - & $10-21-93$ & - & 4 \\
\hline 6 & Sonae Indústria-SGPS & 1993 & $11-19-93$ & - & $11-25-93$ & - & 4 \\
\hline 7 & Sonae-SGPS & 1993 & $12-17-93$ & - & $05-22-93$ & - & 3 \\
\hline 7 & Sonae-SGPS & 1993 & $12-27-93$ & - & $12-30-93$ & - & 3 \\
\hline 8 & Lisnave-Estal.Nav.Lisboa & 1994 & $01-03-94$ & - & 01-04-94 & - & 1 \\
\hline 9 & Modelo-SGPS & 1994 & $02-10-94$ & - & $02-17-94$ & - & 4 \\
\hline 10 & B.Totta \& Açores-Nom & 1994 & $03-30-94$ & - & $04-05-94$ & - & 2 \\
\hline 11 & B.Comercial Português-Nom & 1994 & $04-08-94$ & - & $04-15-94$ & - & 5 \\
\hline 12 & BES Nom & 1994 & $04-18-94$ & - & $04-22-94$ & - & 5 \\
\hline 13 & Efacec-E.F.Máq.Eléctricas & 1994 & $08-16-94$ & - & $08-22-94$ & - & 4 \\
\hline 14 & Corticeira Amorim-SGPS & 1994 & $10-17-94$ & - & $10-21-94$ & - & 4 \\
\hline 15 & B.Totta \& Açores-Nom & 1994 & $12-29-94$ & - & $12-30-94$ & - & 1 \\
\hline 16 & Reditus-SGPS & 1995 & $05-09-95$ & - & $05-10-95$ & - & 1 \\
\hline 17 & B.Fomento Exterior-Nom & 1996 & $01-19-96$ & - & $01-22-96$ & - & 1 \\
\hline 18 & Crédito Predial Port.-Nom & 1996 & $07-04-96$ & 9:10 & 07-05-96 & - & 1 \\
\hline 19 & B.Fomento Exterior-Nom & 1996 & $08-22-96$ & $10: 38$ & $08-28-96$ & 9:00 & 3 \\
\hline 20 & BPI-SGPS-Nom & 1996 & $08-23-96$ & - & 08-28-96 & - & 3 \\
\hline 21 & Cexexport-Cer.Exportação & 1997 & $01-15-97$ & - & $01-20-97$ & - & 3 \\
\hline 22 & Jerórimo Martins-SGPS & 1997 & $02-03-97$ & - & $02-07-97$ & - & 4 \\
\hline 23 & Reditus-SGPS & 1997 & $02-27-97$ & - & $02-28-97$ & - & 1 \\
\hline 24 & Inparsa-Ind.Part.SGPS & 1997 & $07-10-97$ & 9:15 & 07-11-97 & 9:00 & 1 \\
\hline 25 & Crédito Predial Port.-Nom & 1997 & $07-29-97$ & - & $07-30-97$ & - & 1 \\
\hline 26 & BPI & 1998 & $01-23-98$ & $9: 20$ & $01-23-98$ & 11:05 & 1 \\
\hline 27 & Crédito Predial Port.-Nom & 1998 & $02-11-98$ & $18: 00$ & $02-12-98$ & 14:00 & 1 \\
\hline 28 & B.Pinto Sotto Mayor-Nom & 1998 & $02-11-98$ & $18: 00$ & $02-12-98$ & 14:00 & 1 \\
\hline 29 & B.Totta \& Açores-Nom & 1998 & $02-11-98$ & 18:00 & $02-12-98$ & 14:00 & 1 \\
\hline 30 & C.S.Mundial Confiança-Nom & 1998 & $02-11-98$ & $18: 00$ & $02-12-98$ & $14: 00$ & 1 \\
\hline 31 & Caima - Comp. de celulose & 1998 & $03-25-98$ & 9:30 & 03-25-98 & $12: 00$ & 1 \\
\hline 32 & AXA Portugal-Comp.S.-Nom. & 1998 & $04-01-98$ & 17:12 & $04-02-98$ & $11: 30$ & 1 \\
\hline 33 & Banif-Nom & 1998 & $07-23-98$ & - & $07-29-98$ & - & 4 \\
\hline 34 & Crédito Predial Port.-Nom & 1998 & $11-13-98$ & $8: 35$ & $11-13-98$ & $12: 00$ & 1 \\
\hline 35 & $\mathrm{BCP}$ & 1998 & $11-13-98$ & 8:35 & $11-13-98$ & $12: 00$ & 1 \\
\hline 36 & B.Pinto Sotto Mayor-Nom & 1998 & $11-13-98$ & 8:35 & $11-13-98$ & $12: 00$ & 1 \\
\hline 37 & B.Totta \& Açores-Nom & 1998 & $11-13-98$ & 8:35 & $11-13-98$ & $12: 00$ & 1 \\
\hline 38 & C.S.Mundial Confiança-Nom & 1998 & 11-13-98 & $8: 35$ & $11-13-98$ & $12: 00$ & 1 \\
\hline 39 & Cimpor & 1998 & $11-13-98$ & $8: 35$ & $11-13-98$ & $12: 00$ & 1 \\
\hline 40 & Inparsa-Ind.Part.SGPS & 1999 & $02-26-99$ & 9:12 & $02-26-99$ & 13:15 & 1 \\
\hline 41 & Sonae Indústria & 1999 & $02-26-99$ & $9: 12$ & $02-26-99$ & 13:15 & 1 \\
\hline 42 & Mota-Engil, SGPS & 1999 & $07-23-99$ & $15: 45$ & $07-26-99$ & 8:55 & 3 \\
\hline 43 & Mota \& Companhia & 1999 & $07-23-99$ & 15:55 & $07-26-99$ & $8: 55$ & 1 \\
\hline 43 & Mota \& Companhia & 1999 & $07-29-99$ & 14:56 & $07-30-99$ & $8: 43$ & 1 \\
\hline 44 & BPI & 1999 & 08-17-99 & 11:27 & $08-17-99$ & $14: 15$ & 1 \\
\hline 45 & Cofina & 1999 & $08-17-99$ & $11: 27$ & 08-17-99 & $14: 15$ & 1 \\
\hline 46 & B.Comercial Português-Nom & 1999 & $11-11-99$ & $11: 20$ & $11-15-99$ & $9: 00$ & 2 \\
\hline 47 & B.Pinto Sotto Mayor-Nom & 1999 & $11-11-99$ & 9:00 & $11-15-99$ & 9:00 & 2 \\
\hline 47 & B.Pinto Sotto Mayor-Nom & 1999 & $11-18-99$ & 9:16 & $11-19-99$ & 8:32 & 1 \\
\hline 48 & B.Português Atlântico-Nom & 1999 & $11-11-99$ & $11: 20$ & $11-15-99$ & 9:00 & 2 \\
\hline 49 & B.Totta \& Açores-Nom & 1999 & $11-11-99$ & 9:00 & $11-15-99$ & 9:00 & 2 \\
\hline 50 & C.S.Mundial Confiança-Nom & 1999 & $11-11-99$ & 9:00 & $11-15-99$ & 9:00 & 2 \\
\hline 51 & Crédito Predial Port.-Nom & 1999 & $11-11-99$ & 9:00 & $11-15-99$ & 9:00 & 2 \\
\hline 52 & Pararede - SGPS & 1999 & $11-12-99$ & $11: 12$ & $11-15-99$ & $10: 10$ & 1 \\
\hline 53 & Colep Port-Emb.Prod.E.Eq. & 1999 & $12-03-99$ & 9:15 & $12-06-99$ & $8: 46$ & 1 \\
\hline 53 & Colep Port-Emb.Prod.E.Eq. & 1999 & $12-15-99$ & $15: 24$ & $12-17-99$ & 8:54 & 2 \\
\hline 54 & EDP & 1999 & $12-22-99$ & $9: 15$ & $12-22-99$ & 13:00 & 1 \\
\hline
\end{tabular}




\section{APPENDIX 2}

Charts for Prices. Returns and Volatility for each Trading halt in the Sample Unicer (1992)
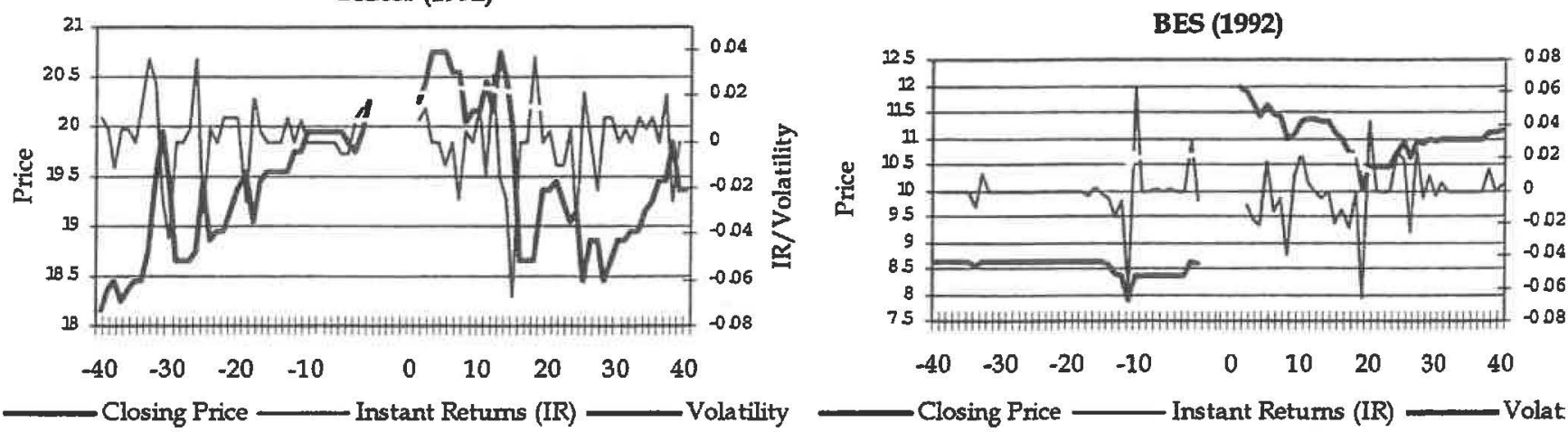

BPA (1993)

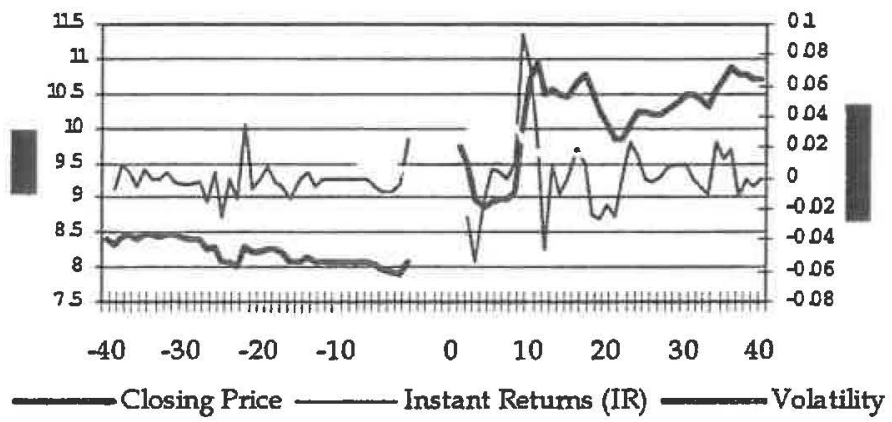

$\begin{array}{lllllllll}-40 & -30 & -20 & -10 & 0 & 10 & 20 & 30 & 40\end{array}$

Closing Price — Instant Retums (IR) __ Volat

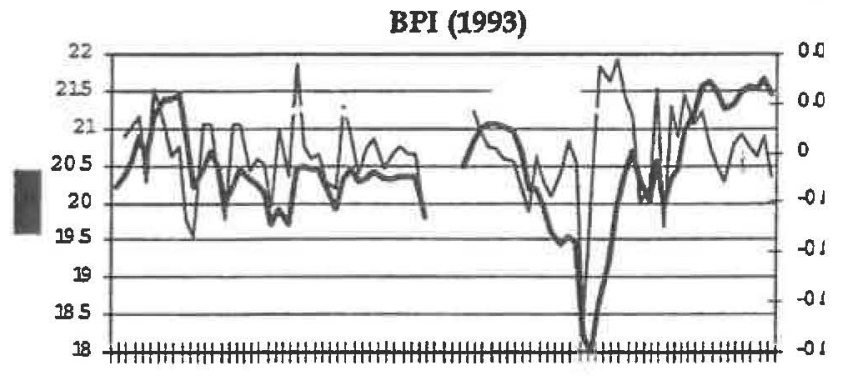

$\begin{array}{lllllllll}-40 & -30 & -20 & -10 & 0 & 10 & 20 & 30 & 40\end{array}$

Closing Price _- Instant Retums (IR) —_ Vola

Lusotur (1993)

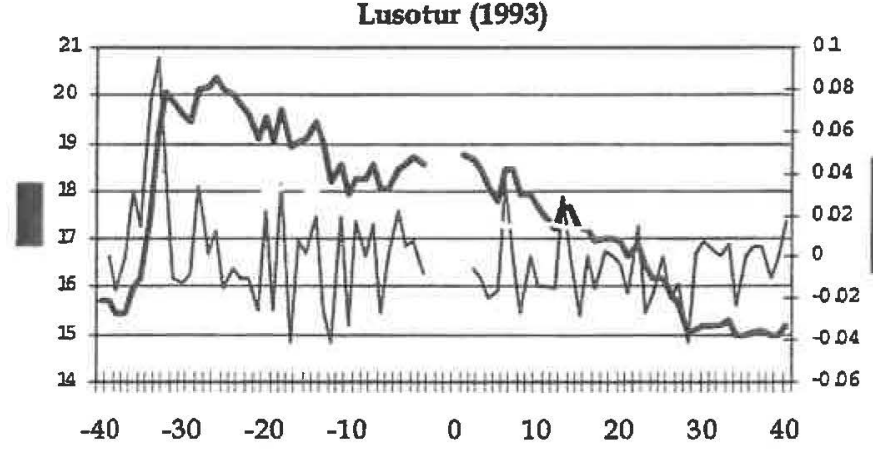

Closing Price — Instant Returns (IR) _ Volatility

Sonae SGPS (1993)

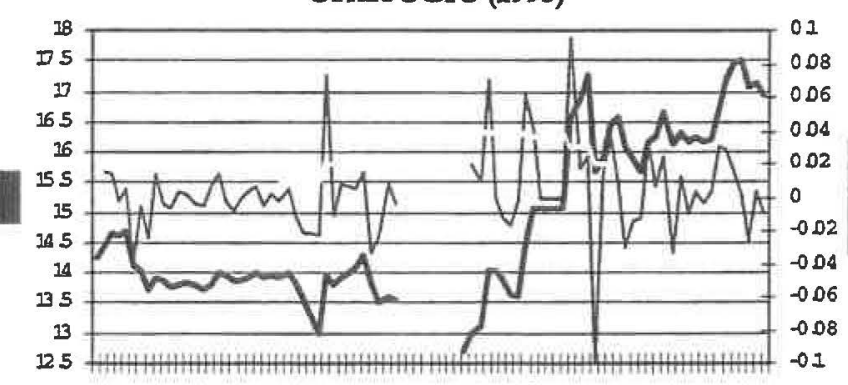

$\begin{array}{lllllllll}-40 & -30 & -20 & -10 & 0 & 10 & 20 & 30 & 40\end{array}$

Closing Price — Instant Returns (IR) - Volatility

Sonae Indústria (1993)

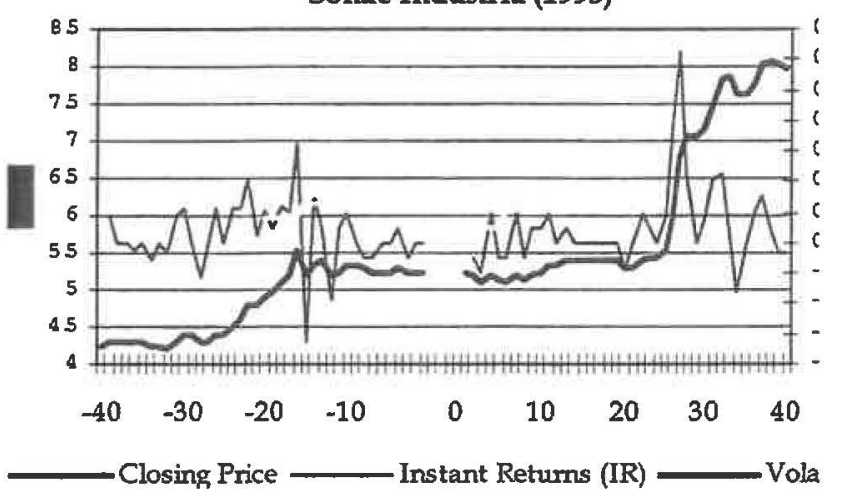

Lisnave (1994)

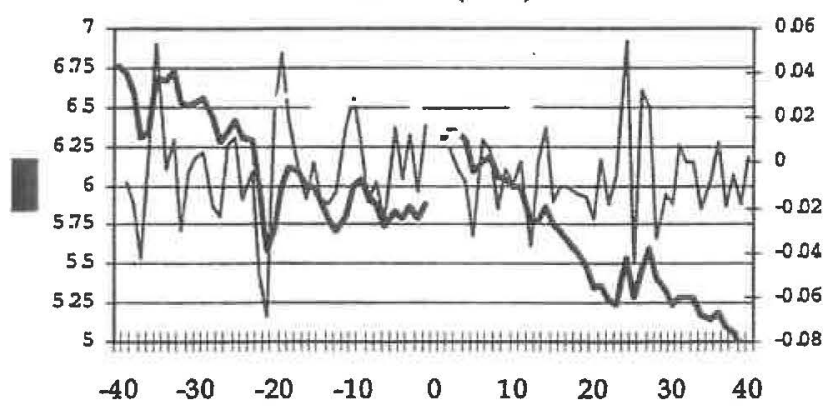

Closing Price —_ Instant Returns (IR) —_ Volatil 
Modelo (1994)

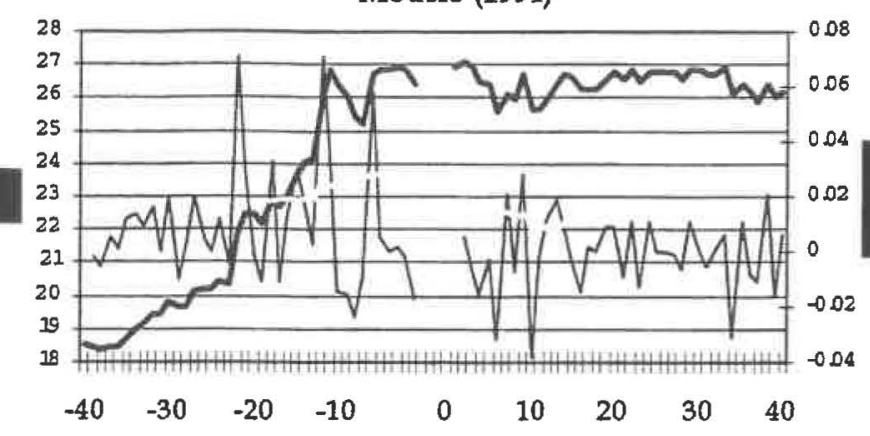

Closing Price — Instant Retums (IR) _- Volatility

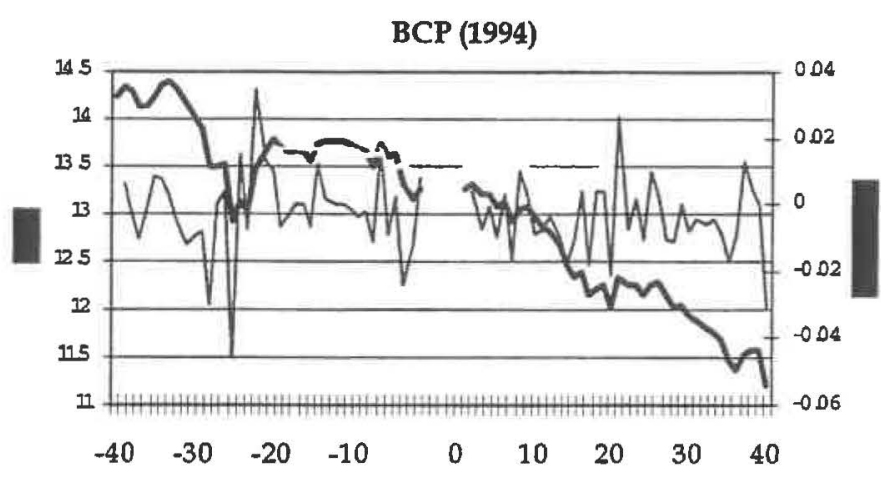

Closing Price - Volatility

Efacec (1994)

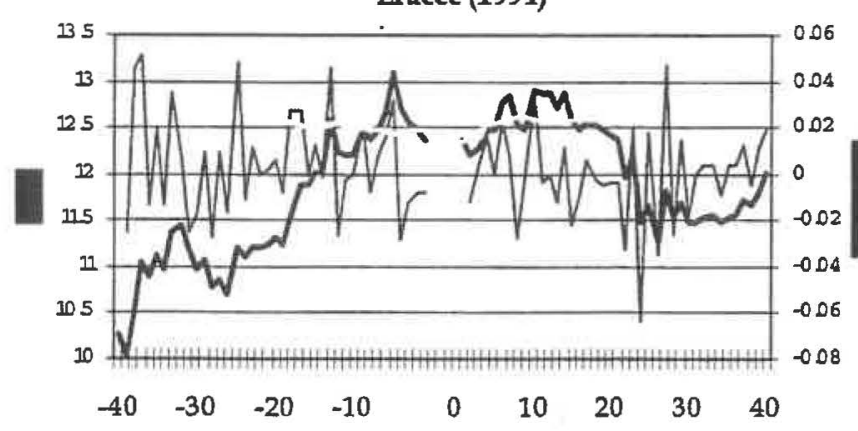

—Closing Price — Instant Returns (IR) — Volatility

BTA2 (1994)

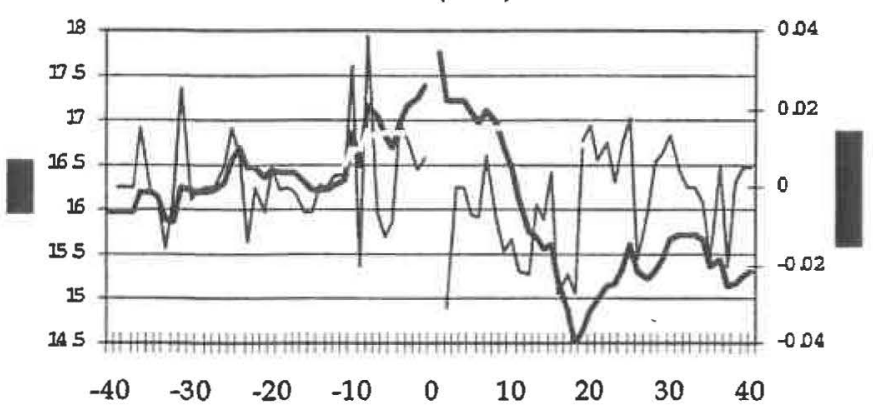

Closing Price

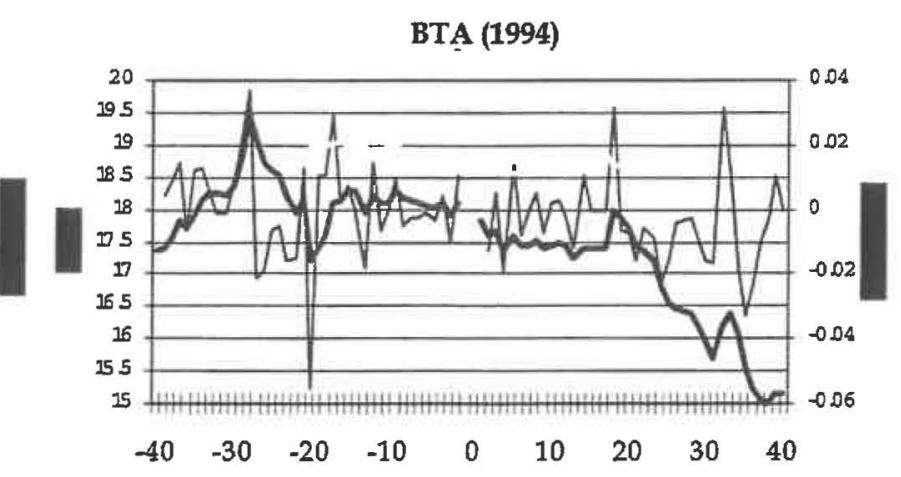

Closing Price —Instant Returns (IR) — Volatility

BES (1994)

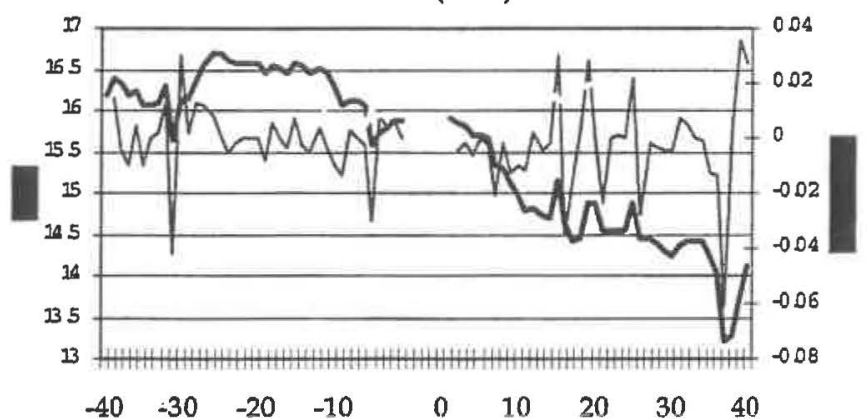
Volatility

\section{Corticeira Amorim (1994)}

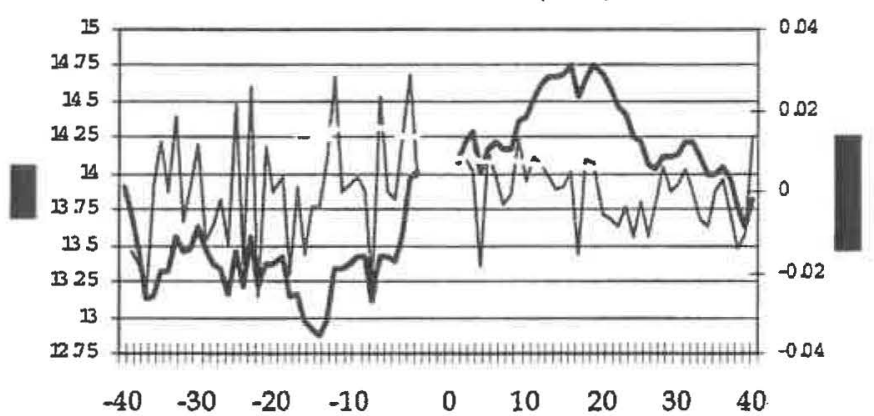

$\begin{array}{lllllllll}-40 & -30 & -20 & -10 & 0 & 10 & 20 & 30 & 40\end{array}$

Closing Price — Instant Returns (IR) — Volatility

Reditus (1995)

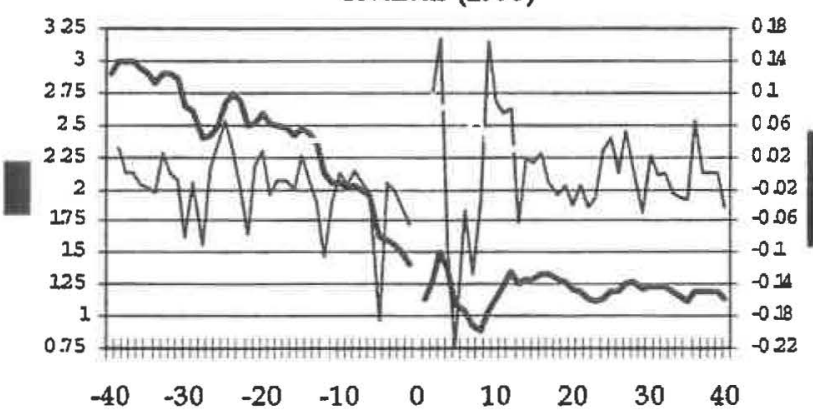

Closing Price _ Instant Retums (IR) _ Volatility 
BFE (1996)

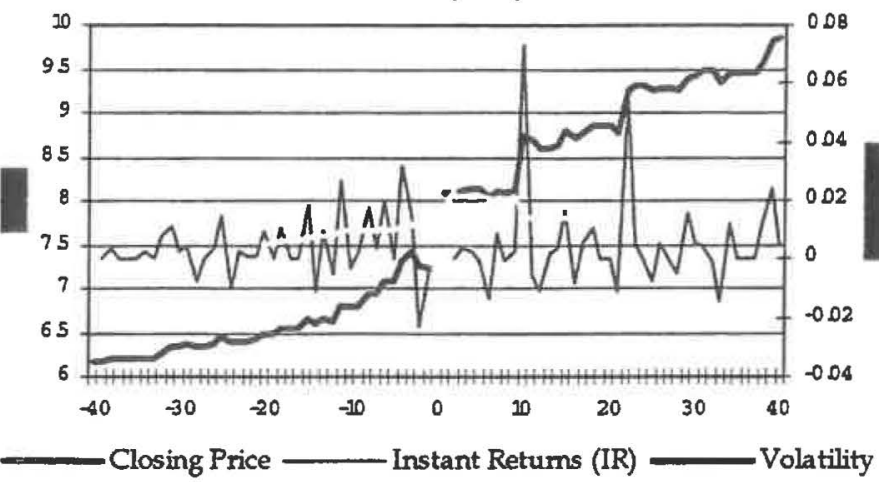

BFE2 (1996)

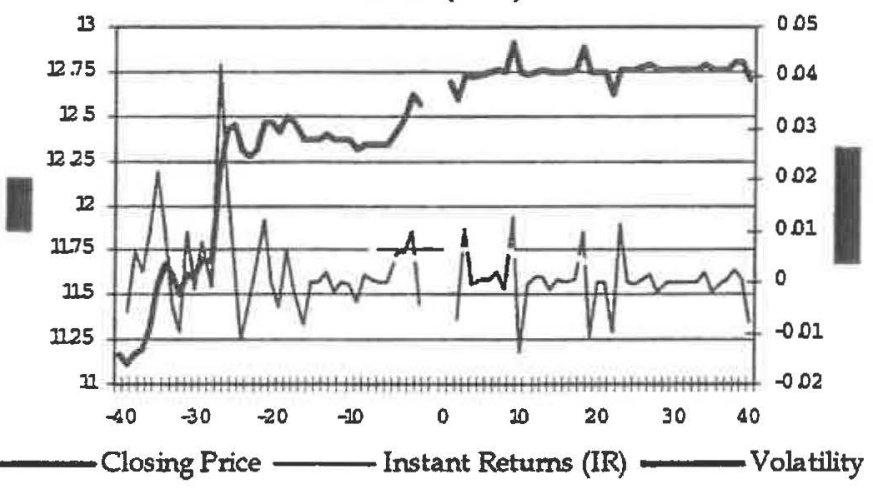

Cerexport (1997)

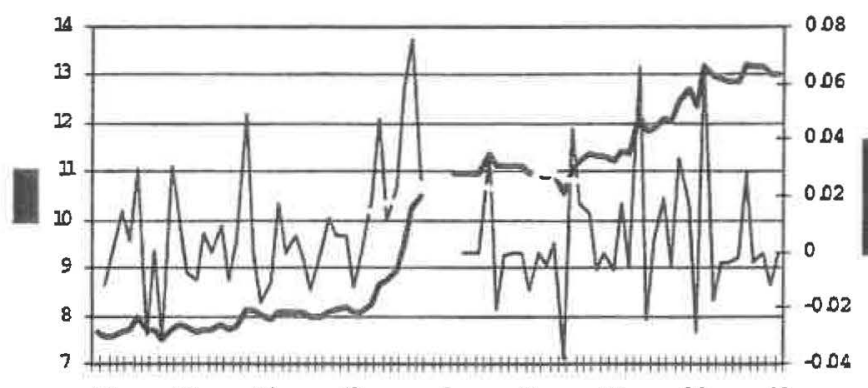

$\begin{array}{lllllllll}-40 & -30 & -20 & -10 & 0 & 10 & 20 & 30 & 40\end{array}$

Closing Price — Instant Returns (IR) _- Volatility

Reditus (1997)

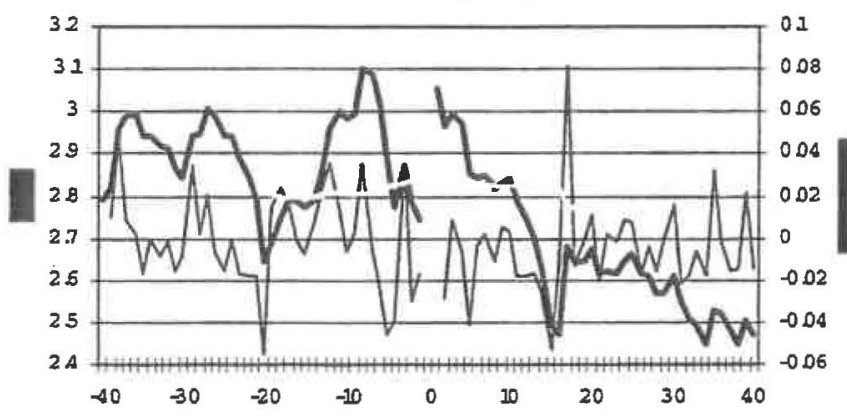

Closing Price

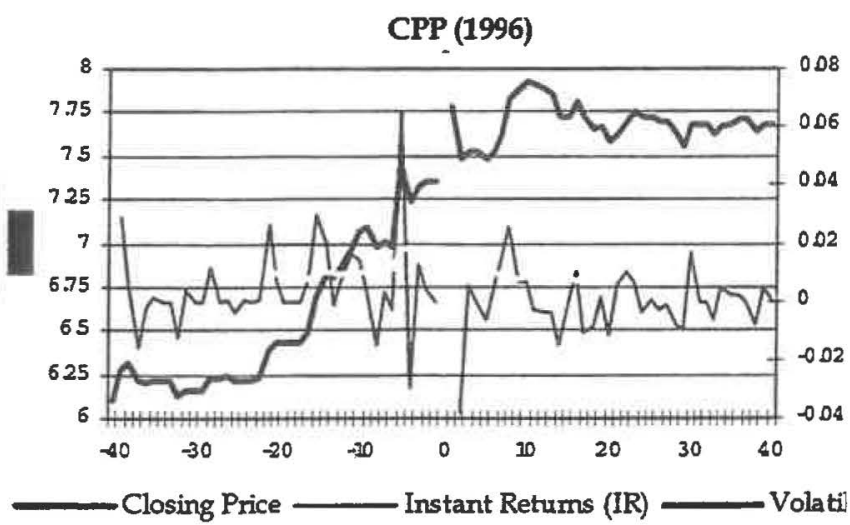

BPI (1996)

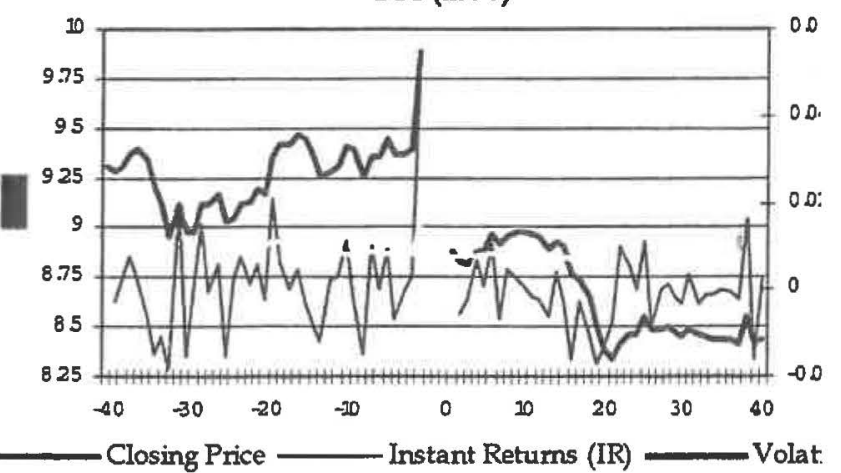

Jerónimo Martins (1997)

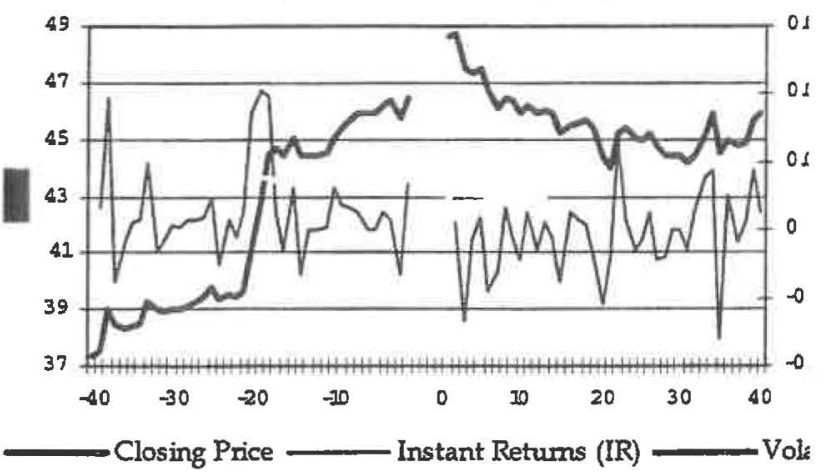

Inparsa (1997)

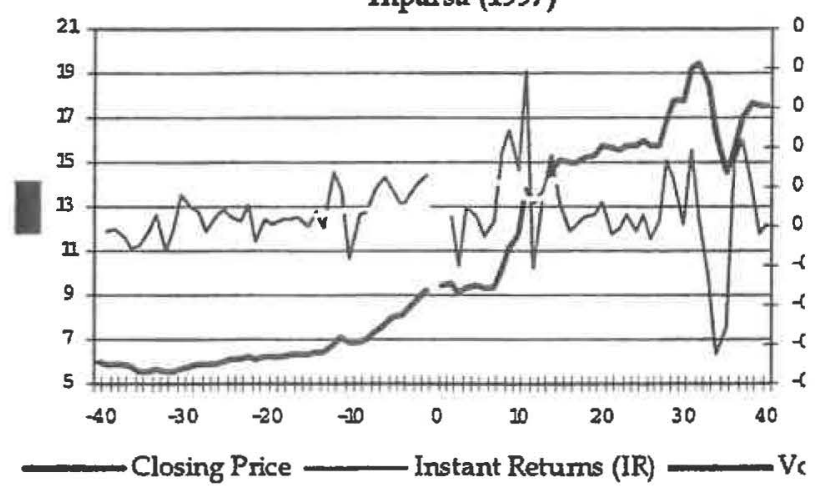



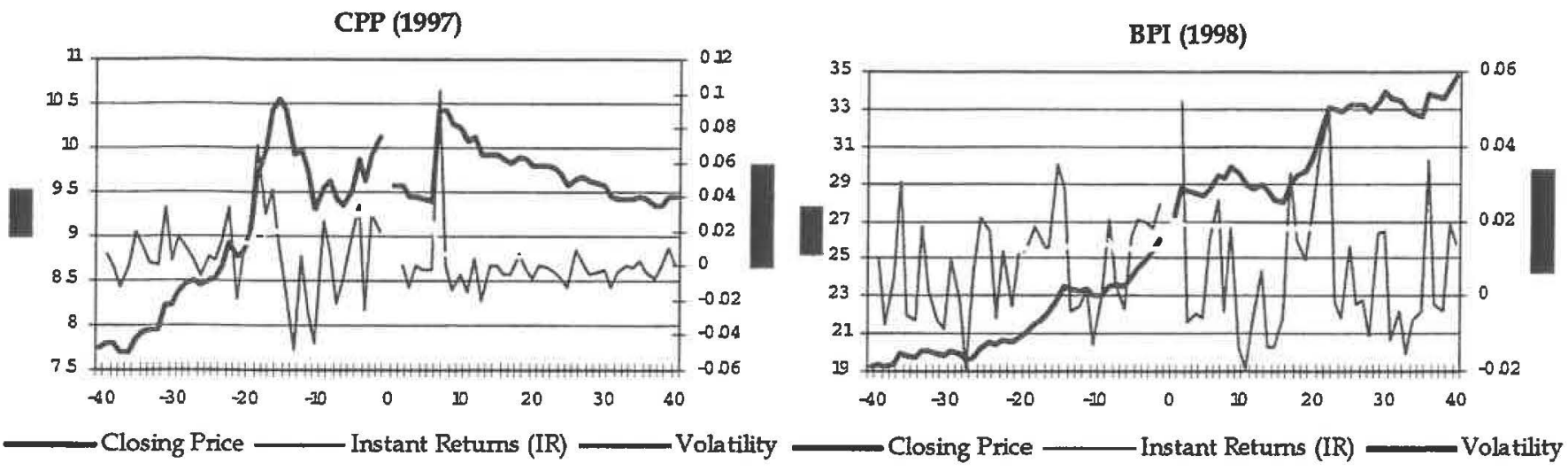

\section{CPP (1998)}

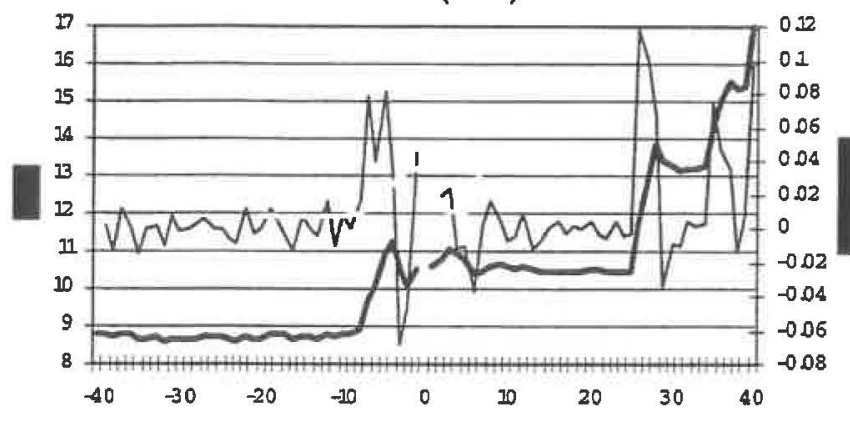

- Closing Price _- Instant Retums (IR)

Volatility

BTA (1998)
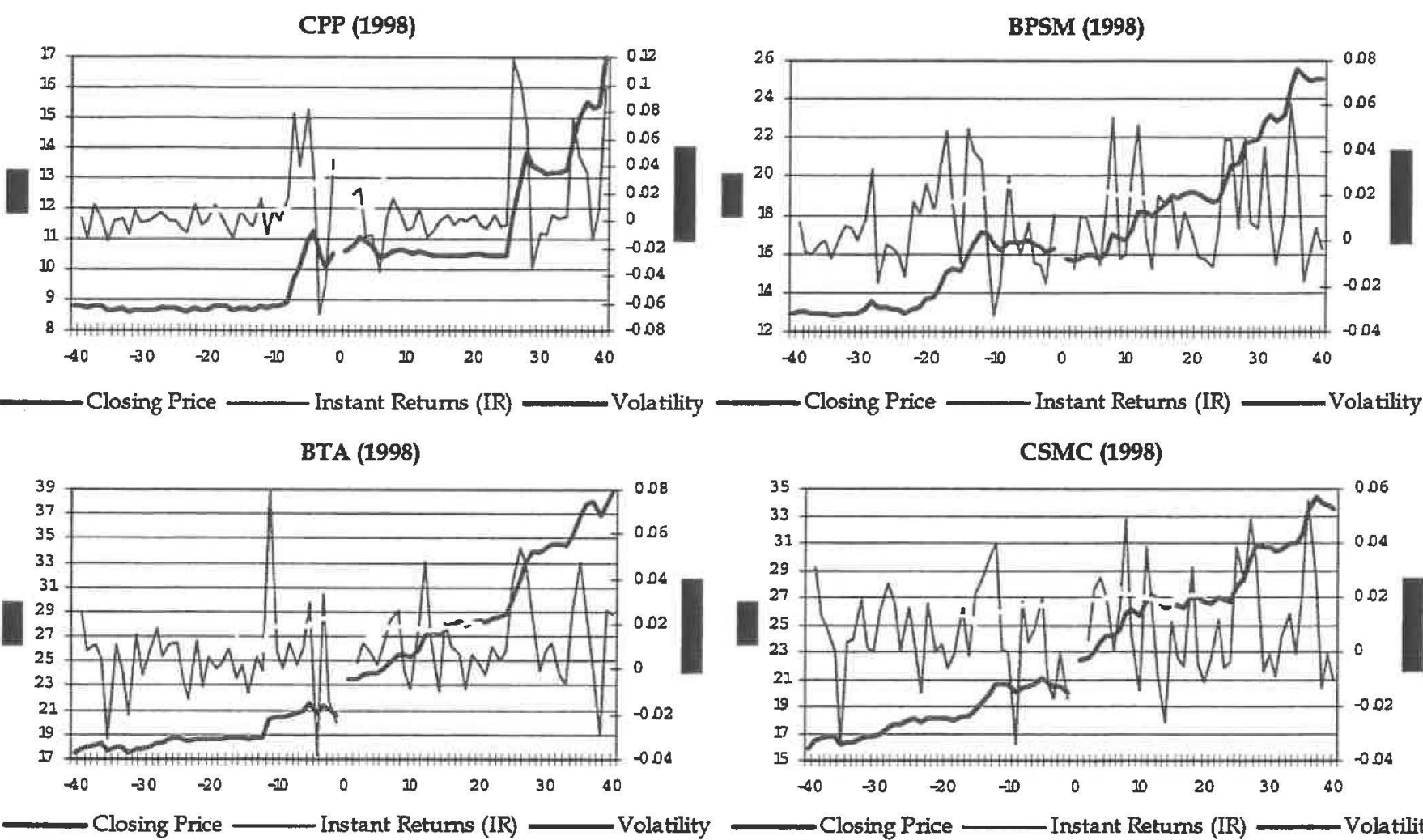

Closing Price

-Instant Returns (IR)

Volatility

CSMC (1998)

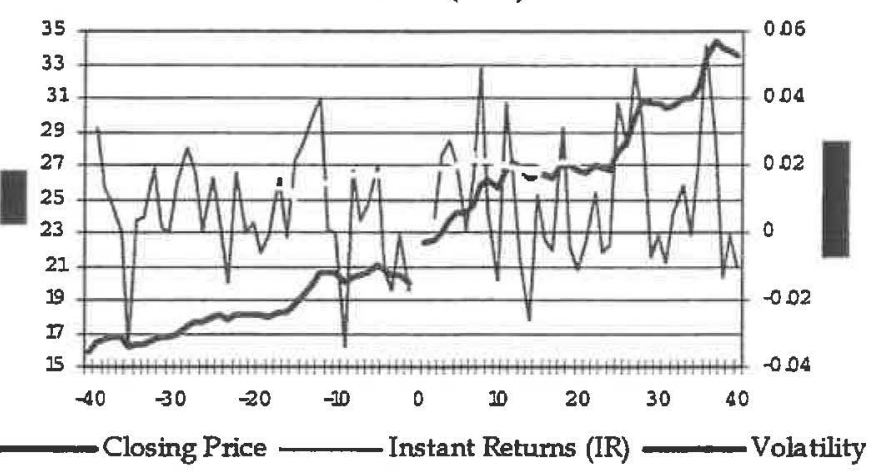

Caima (1998)
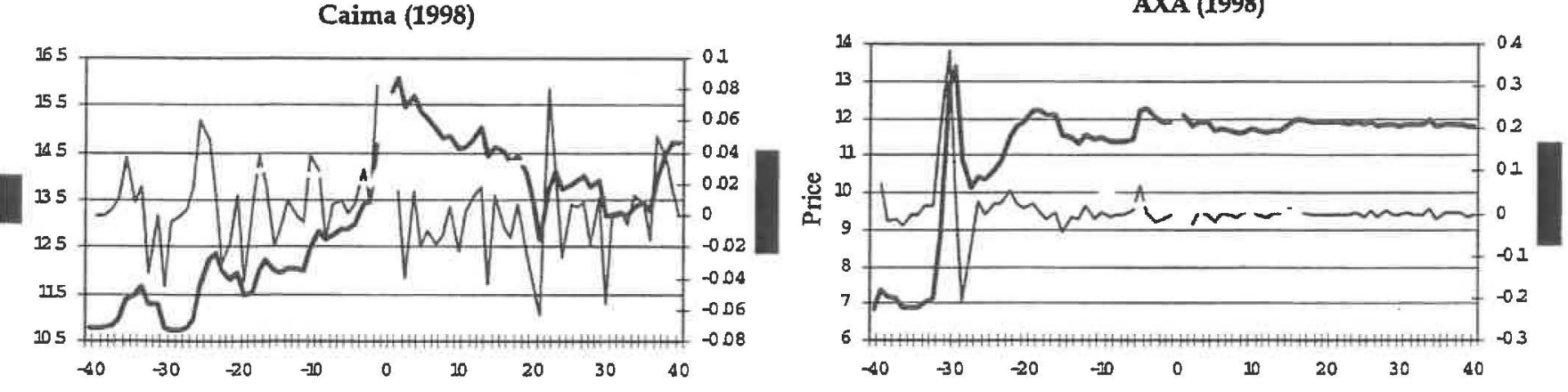

Closing Price — Instant Retums (IR) — Volatility - Vola tility 
Banif (1998)

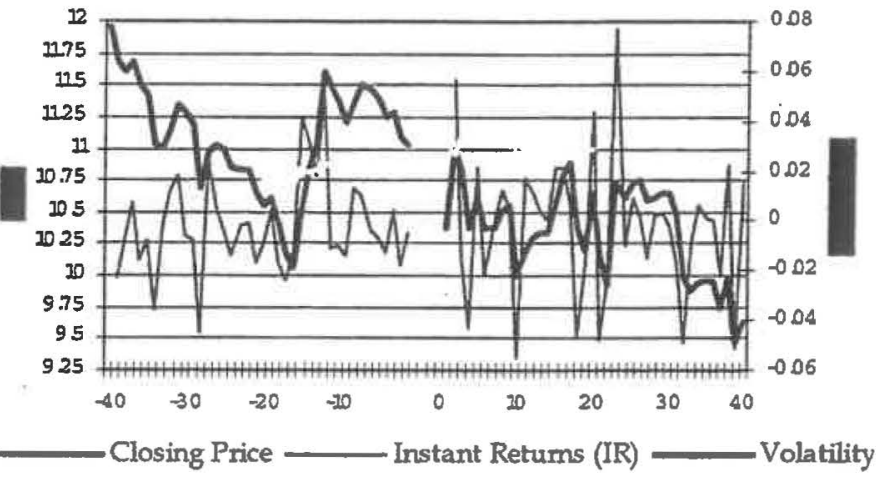

BCP (1998)

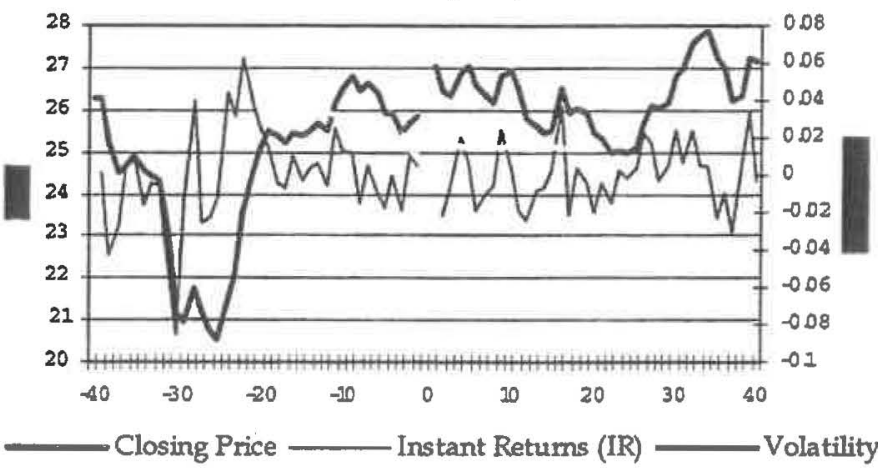

BTA2 (1998)

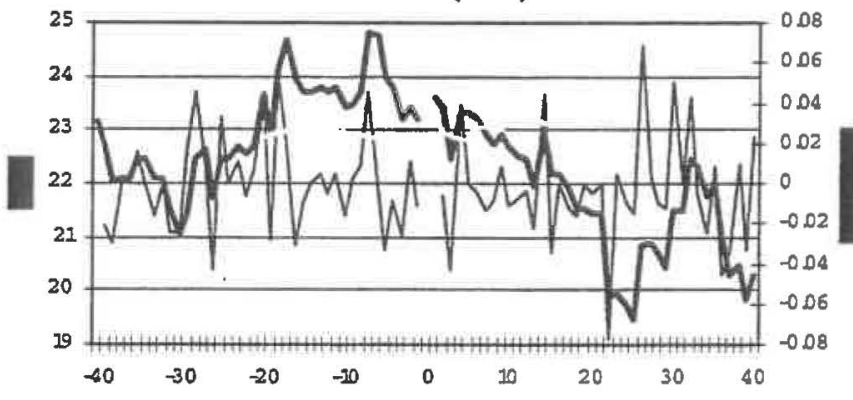

Closing Price _ـ Instant Retums (IR)

Cimpor (1998)

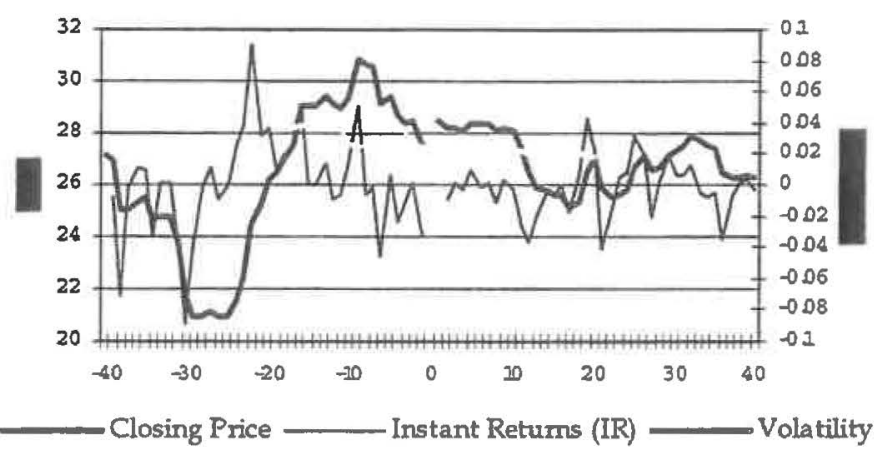

CPP2 (1998)

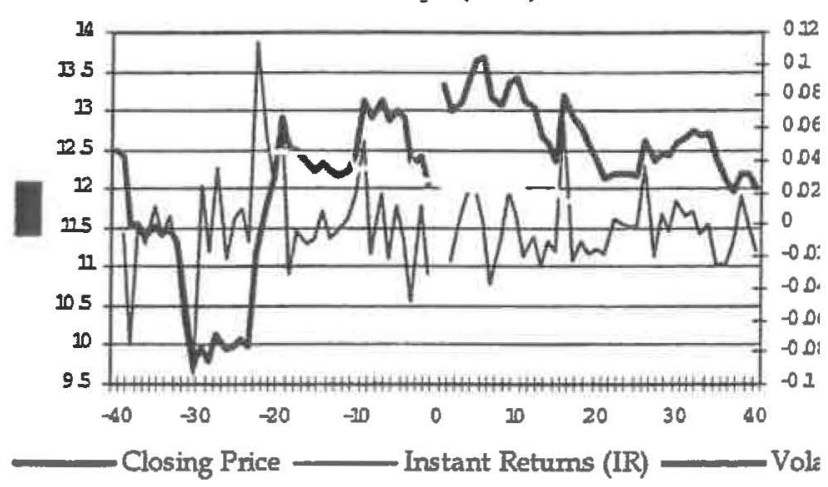

BPSM2 (1998)

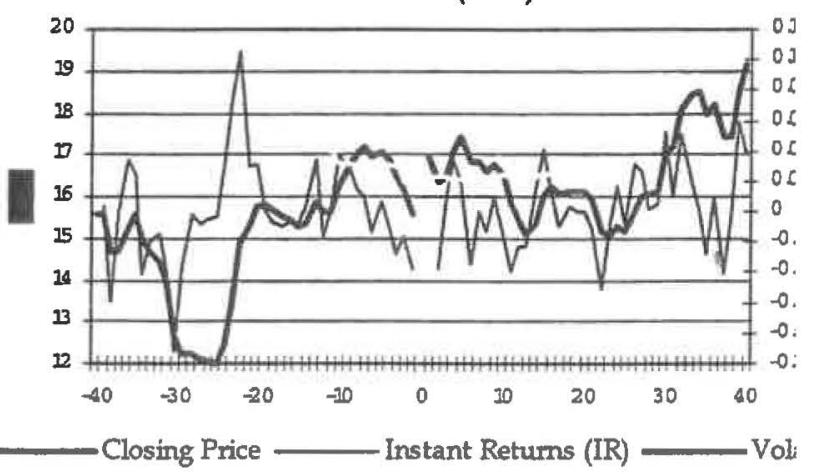

CSMC2 (1998)

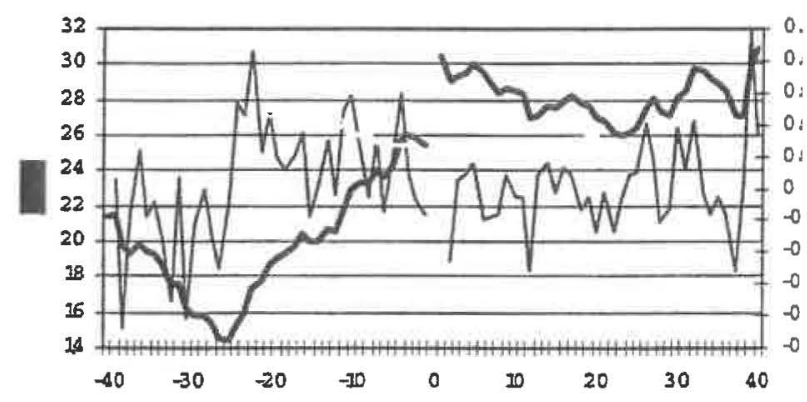

- Vol

Inparsa (1999)

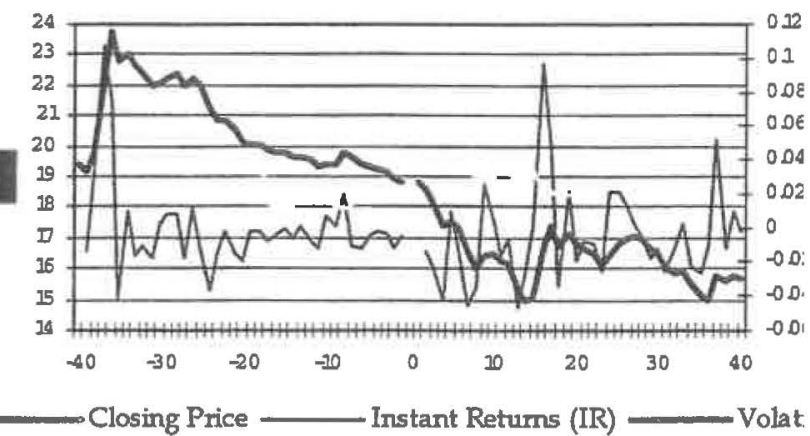


Sonae Indústria (1999)

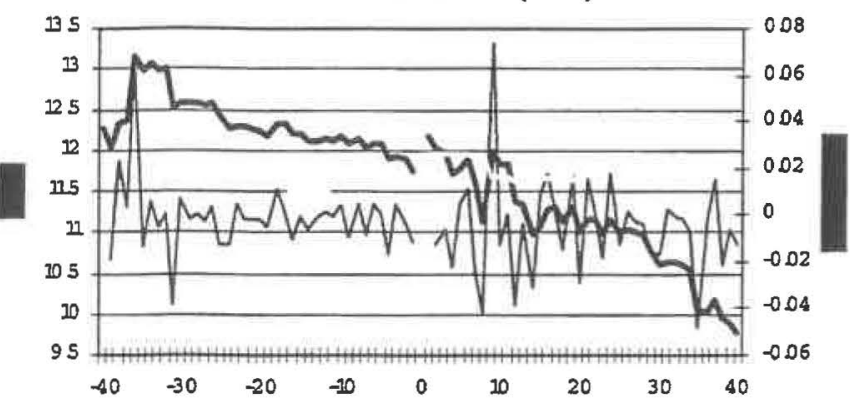

-Closing Price —_ Instant Returns (IR) _ Volatility

Mota\&Companhia (1999)

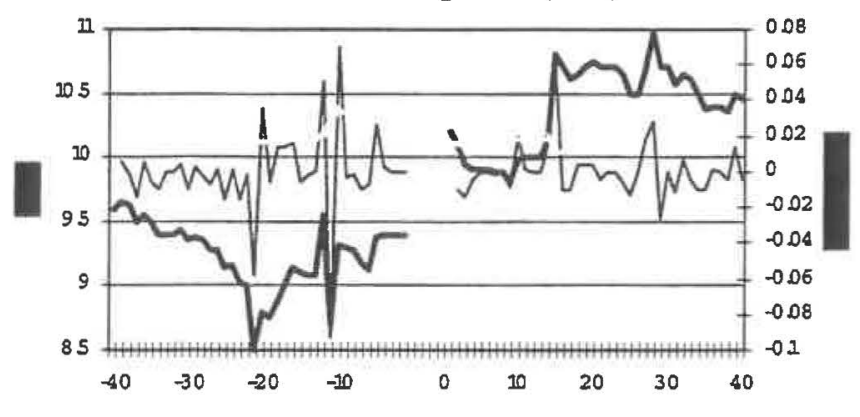

Closing Price — Instant Returns (IR) _ Volatility

Cofina (1999)

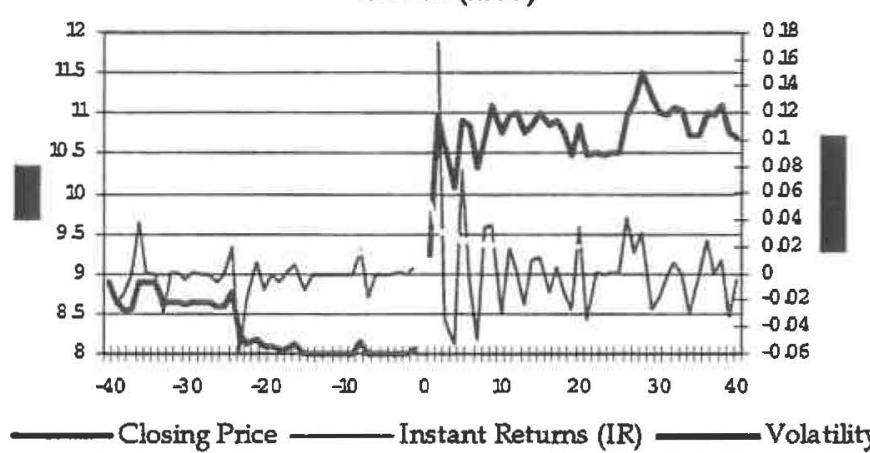

BPSM (1999)

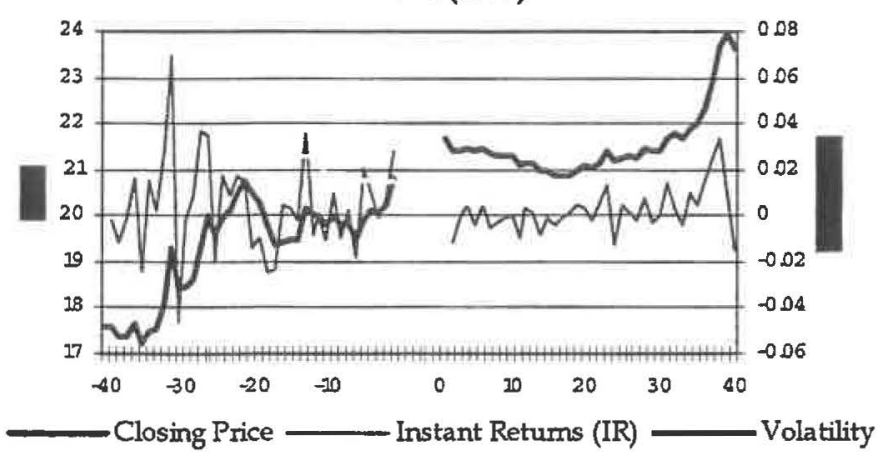

Mota\&Engil (1999)

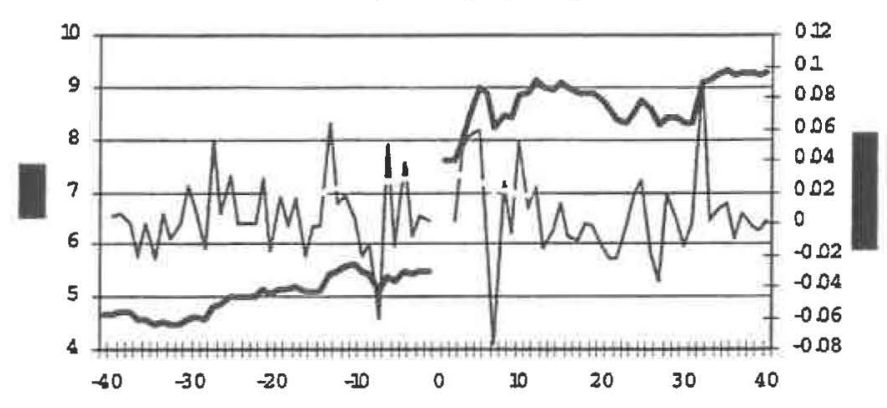

C Closing Price — Instant Returns (IR) _ Vola tility

BPI (1999)
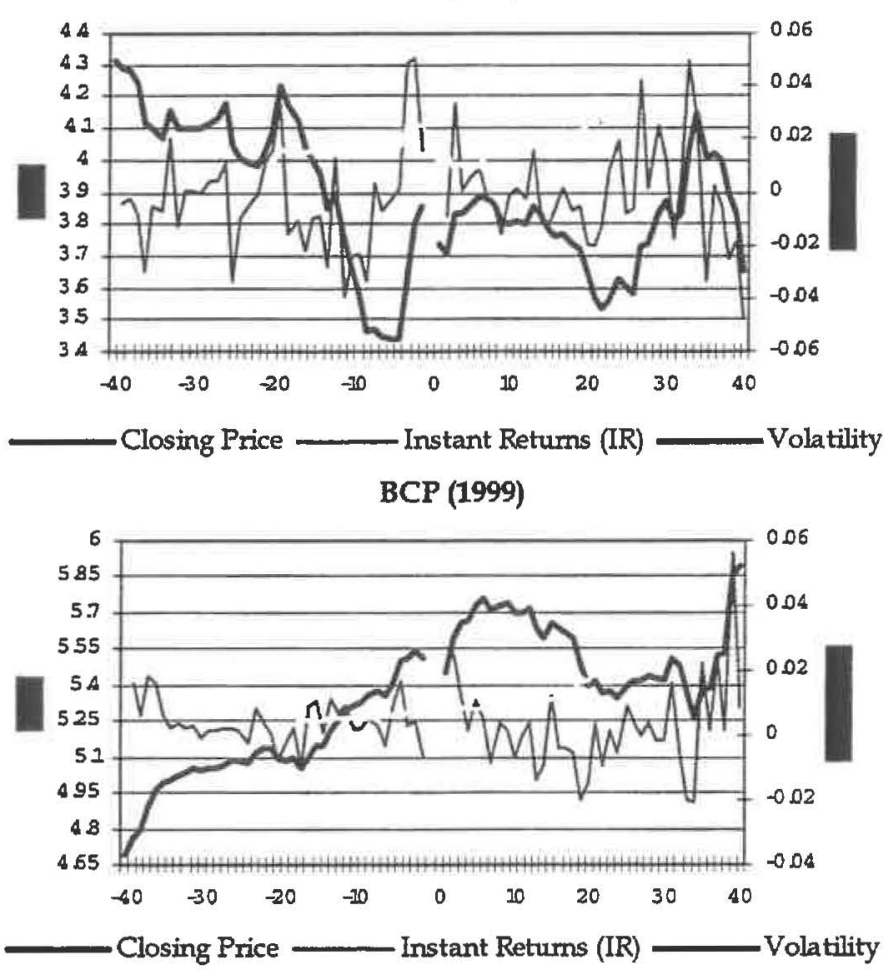

BPA (1999)

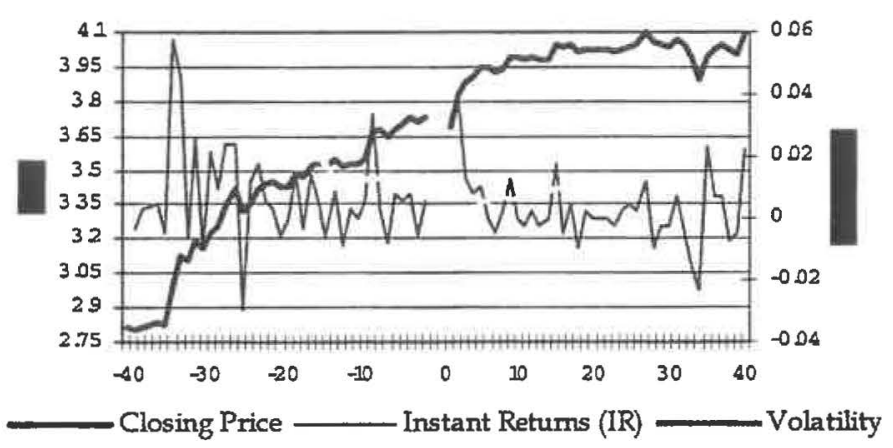


BTA (1999)

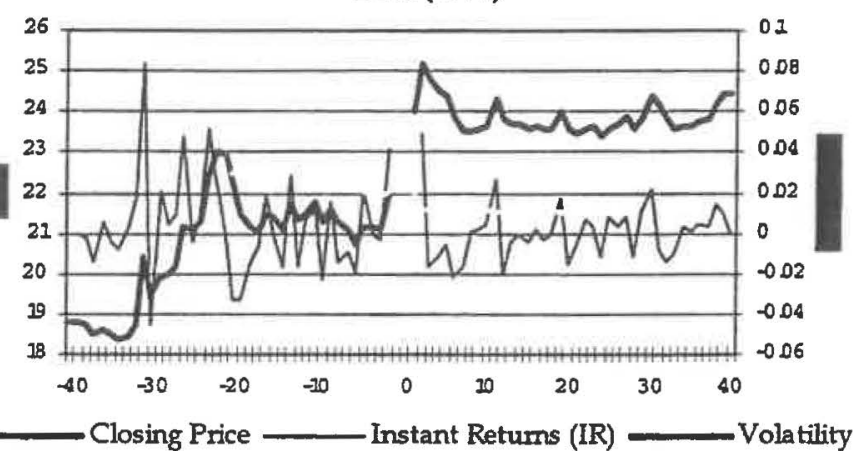

CPP (1999)

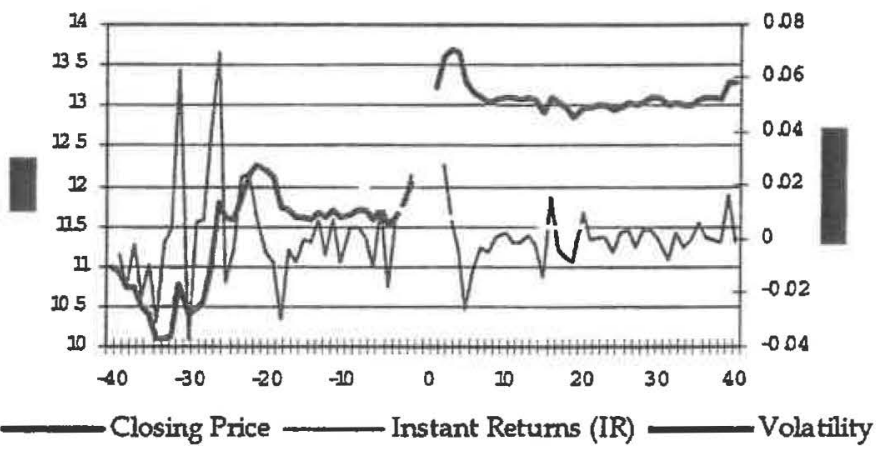

Colep (1999)

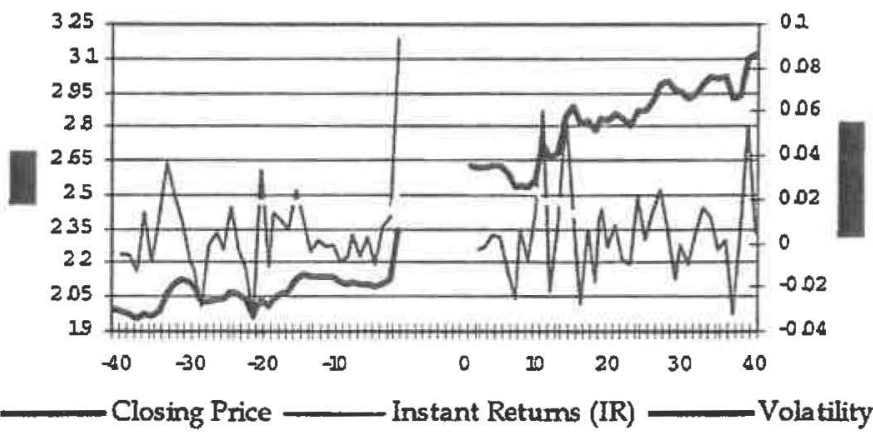

CSMC (1999)

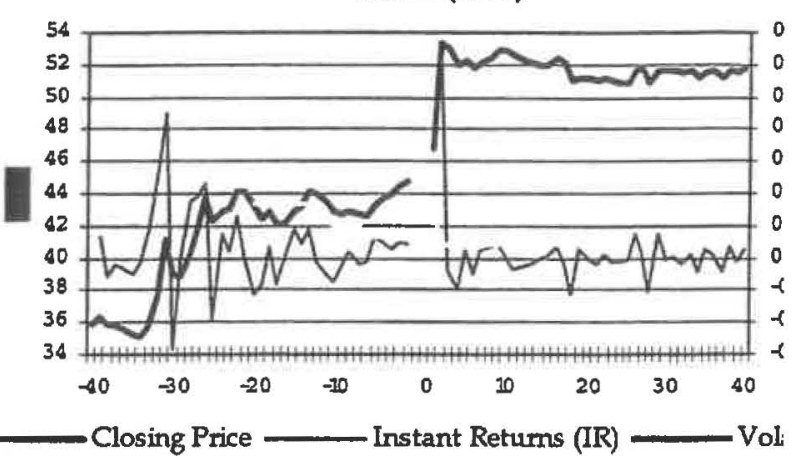

Pararede (1999)

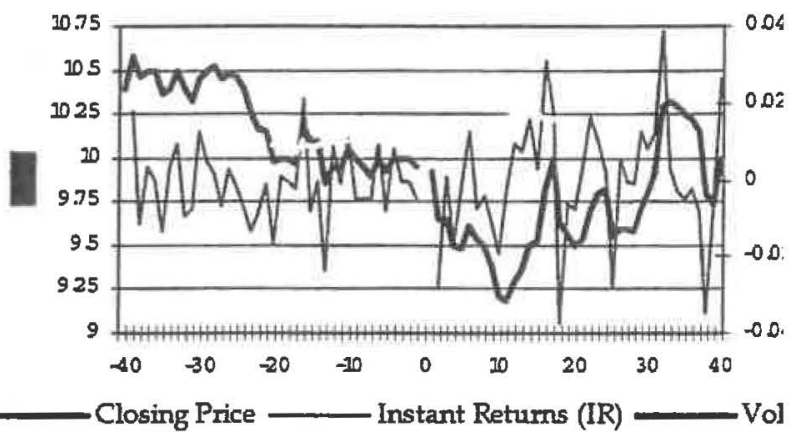

EDP (1999)

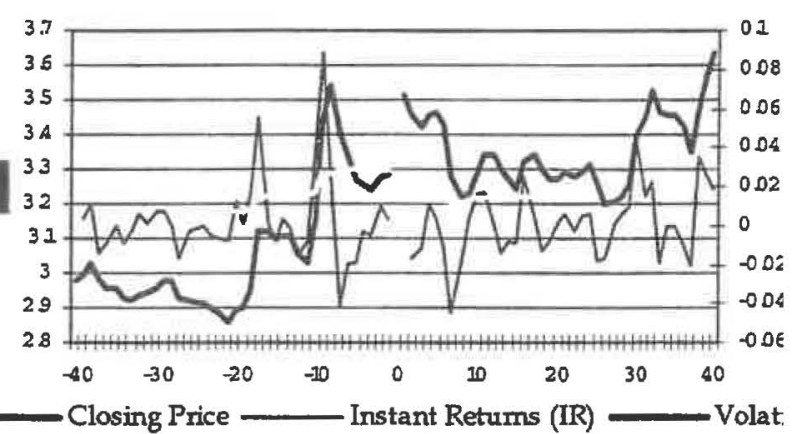




\section{APPENDIX 3}

\section{Stock Price Returns around Trading halts}

\begin{tabular}{|c|c|c|c|c|c|c|c|c|c|c|c|c|c|c|c|c|c|}
\hline Firm & & Year & \multicolumn{5}{|c|}{3 Days } & \multicolumn{5}{|c|}{20 Day= } & \multicolumn{5}{|c|}{ 20 Duyfir } \\
\hline Unicer & & & & $B A$ & flemences. & Altisolate 1 & $\mathrm{AN}$ & $8 B$ & BA & esesents & Abuabute is & M & $\mathrm{BB}$ & IM & ence & Abwelade \& & $\mathrm{AA}$ \\
\hline Bes Nom & 2 & 1992 & $0=29$ & $0,0,070$ & $0,00 \%$ & 0,008 & 0,5048 & 0,1321 & 0,3536 & $-0,15 \%$ & $0,15 \%$ & 0,6057 & 0,0778 & $0,0 \times 133$ & $-0,4 B \%$ & $0,48 \%$ & $-0,3867$ \\
\hline Average 1992 & & & & thens & $-1,34 \%$ & $1,34 \%$ & $-0,5453$ & $-1,9614$ & 1,5318 & $-1,38 \%$ & $1,38 \%$ & 0,2962 & 0,0596 & 0,9035 & $-0,64 \%$ & $0,64 \%$ & $-1,7066$ \\
\hline BPA Nom & 3 & 2993 & $-0,0159$ & 1,2353 & $\begin{array}{l}-0,67 \% \\
-1,61 \%\end{array}$ & $0,67 \%$ & & & & $-0,76 \%$ & $0,76 \%$ & & & & $-0,56 \%$ & $0,56 \%$ & \\
\hline BPI Nom & 4 & 1993 & 0,7708 & $-1,5815$ & & 1,618 & 20000 & $-0,4318$ & $-0,853]$ & $1,21 \%$ & $1,21 \mathrm{x}$ & 1,5165 & 0,0215 & $-0,1593$ & $0,13 \%$ & $0,13 \%$ & $-0,161$ \\
\hline Lusotur & 5 & 1993 & $-0,9450$ & 0,0363 & $-0,02 \%$ & 1,018 & $325055^{\circ}$ & 0,4989 & 0,0411 & (1) & $0,002 x$ & $-0,4549$ & $-0,3920$ & $-0,10 \%$ & $0,07 \%$ & $0,07 \%$ & $-0,9003$ \\
\hline Sonae Indústria, SCPS & & & & & & & 0,5491 & $-0,279$ & 0,9042 & & 0 & (2), & 1,5506 & 0,721 & $-0,45 \%$ & $0,4 \%$ & 02588 \\
\hline Sonae SGPS & & & 0,0000 & 0,80017 & $-0,58 \%$ & $0.58 \%$ & $-1,8240$ & 0,7188 & $-0,3428$ & $0.19 \%$ & $0,19 \%$ & 0,5425 & 0,4936 & 0,5915 & $-0,37 \%$ & $0,37 \%$ & -25599 \\
\hline$\frac{\text { Sonal Sols }}{\text { Average } 1993}$ & 7 & 1993 & 1,3968 & $-1 / 4706$ & $2,49 \%$ & $2 A 9 \%$ & 0,0350 & $-1,1316$ & $-0,9404$ & $1,24 \%$ & $1,24 \%$ & 0.8099 & $-0,1129$ & $-1,4345$ & $1,44 \%$ & $1,44 \%$ & 1,1217 \\
\hline Lisnave & & & & & $0,26 \%$ & $1,24 \%$ & & & & $0,38 \%$ & $0,68 \%$ & & & & $0.26 \%$ & $0,49 \%$ & \\
\hline Modelo SGPS & 9 & 1994 & 0,0997 & 1,0411 & $-1,03 \%$ & $1,03 \%$ & 0,0344 & 0,2959 & 0,954 & $-0,66 \%$ & $0,66 \%$ & 0,9202 & $-1,2914$ & 2,0009 & $-1,078$ & $1,07 \%$ & 0,7681 \\
\hline BTA Nom & 10 & 1994 & 0,0000 & 0,6112 & $-0,42 \%$ & $0,42 \%$ & $-0,7494$ & $-0,0682$ & 0,4947 & $\begin{array}{l}-0,35 \% \\
-0,18 \%\end{array}$ & $0,18 \%$ & $\begin{array}{l}-1,1434 \\
-0,3144\end{array}$ & $-0,6383$ & 0,1682 & $-0,08 x$ & $0,08 \%$ & 1.9149 \\
\hline BCP Nom & 11 & 1994 & 0,8951 & $-0,7656$ & $0,48 x$ & $0,48 \%$ & 0,3765 & 1,0556 & $-0,1262$ & $0,06 \%$ & $0,06 \%$ & 0,2195 & 0,0051 & 0,6666 & $-0,22 x$ & $0,22 \%$ & $-1,0153$ \\
\hline BES Nom & 12 & 1994 & $-0,2980$ & 0,1099 & $0,08 \%$ & $0,08 \%$ & $23562^{2}$ & 0,6689 & 0,9125 & -0,38\% & $0,38 \%$ & $-0,8397$ & $0,75 \%$ & 0,5963 & $-0,23 \%$ & $0,23 \%$ & 0,1225 \\
\hline Efacec & 13 & 2994 & 1,0703 & $-0,9488$ & $1,11 \%$ & $1,11 \%$ & 0,4141 & 0,8112 & $-0,3465$ & $0,28 \%$ & $0,27 \%$ & 1,2668 & 0,2352 & 0,8873 & $-0,48 \%$ & $0,48 \%$ & 0,459 \\
\hline Corticeira Amorim & 14 & 2994 & $-0,8108$ & 0,8985 & $-0,69 \%$ & $0,69 \%$ & $-0,3989$ & $.0,8233$ & 0.257 & $-0,19 \%$ & $0,19 \%$ & 0,6579 & $-0,7972$ & 0,1773 & $-0,06 \%$ & $0,06 \%$ & $2,400 *$ \\
\hline BTA (2) Nom & 15 & 1994 & $-0,0267$ & 2,1469 & $-1,55 \%$ & $1,55 \mathrm{x}$ & 0,1521 & $-1,0259$ & $22546^{\circ}$ & $-159 \%$ & $1,59 \%$ & $-0,3665$ & $-0,3550$ & $264+5^{\circ}$ & $-1,16 \%$ & $1,16 \%$ & 20300 \\
\hline Average 1994 & & & & & $-0,37 \%$ & $0,77 \%$ & & & & $.0,38 \%$ & $0,46 \%$ & & & & $.0,52 \%$ & $0,52 \%$ & \\
\hline Reditus, SGPS & 16 & 1995 & 1,7512 & $-0,6299$ & $4,74 \%$ & $4,74 \pi$ & $-0,6003$ & 0,8034 & $-1,0098$ & $4,53 \%$ & $4.53 \%$ & 0,2504 & 1,7765 & $-1,3375$ & $3,14 \%$ & $3,14 \%$ & 0,1708 \\
\hline Average 1995 & & & & & $4,74 \%$ & $474 \%$ & & & & $4,53 \%$ & $4,53 \%$ & & & & $3,14 \%$ & $3,14 \%$ & \\
\hline BFE Nom & 17 & 1996 & 0,4176 & 0,3810 & $-0,37 \%$ & $0,37 \%$ & $-0,7257$ & $-0,0208$ & 0,0525 & $-0,04 \%$ & $0,04 \%$ & $-0,1447$ & $-0,9747$ & $-0,1288$ & $0,07 x$ & $0,07 x$ & $-0,3691$ \\
\hline CPP Nom & 18 & 1996 & $-0,6112$ & 0,9752 & $-1,7,7 \%$ & $1,72 \%$ & $-1,7690$ & 0,3904 & 0,394 & $-0,37 \%$ & $0,37 \%$ & 0,9033 & $-1,2011$ & 1,5833 & $.0,80 \%$ & $0,80 x$ & $-0,5898$ \\
\hline BFE (2) Nom & 19 & 1996 & $-1,4669$ & 0,7227 & $-0,27 \%$ & $0,20 \%$ & 0,1702 & $-1,2631$ & 0,4333 & $-0,12 x$ & $0,12 \%$ & 0,0967 & 1,8941 & 0,097 & $-0,02 \%$ & $0,02 \%$ & $-0,0114$ \\
\hline BPINom & 20 & 1996 & $-0,9083$ & 0,8586 & $-0,92 \%$ & $0,92 x$ & 0,5886 & $-0,7545$ & 0,8701 & $-0,51 \%$ & $0,51 \%$ & 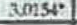 & $-1,1466$ & 1,9638 & $-0,69 \%$ & $0,69 x$ & $-1,3240$ \\
\hline Average 1996 & & & & & $-0,82 \%$ & $0,82 \%$ & & & & $-0,26 \%$ & $0,26 \%$ & & & & $-0,36 \%$ & $0,39 \%$ & \\
\hline Cerexport & 21 & 1997 & $-1,7037$ & 23607 & $-3,60 \%$ & $3,60 \%$ & 0.6275 & $2,79^{\circ}$ & $2031^{\circ}$ & $-2,54 \%$ & $254 \%$ & $-0,4994$ & $-1,5907$ & 15594 & $-1,06 \%$ & 1,068 & $-0,9116$ \\
\hline Jer. Martins, SGPS & 22 & 1997 & 0.8562 & 123915 & $-1.04 \%$ & $1,04 \%$ & $-0,8722$ & 1,1049 & $2226 \pi$ & $-0,95 \%$ & $0,55 x$ & $-0,0877$ & $-0,4292$ & $22 * 31^{*}$ & $-1,30 \%$ & $1,30 \%$ & $-1,7163$ \\
\hline Reditus, SGPS & 23 & 1997 & 1,1500 & $-0,2846$ & $0,48 \%$ & $0,48 x$ & $-1,0675$ & 1,3663 & $-0,0155$ & $0,02 \%$ & 0,028 & $-0,1986$ & $-0,7136$ & 0,7952 & $-0,68 \%$ & $0,68 \%$ & $-0,4934$ \\
\hline Inparss & 24 & 1997 & $-1,4179$ & $3.2366^{\circ}$ & $-3,95 \%$ & $3.95 \%$ & 29018 & $-1,2958$ & $-0,5695$ & 1,15\% & 1,15\% & 1,2401 & -29056 & $-0,4173$ & $0,49 \%$ & $0,49 \%$ & 1,2535 \\
\hline CPP Nom & 25 & 1997 & -14636 & 1,7787 & $-1,95 \%$ & $1,95 \mathrm{x}$ & $-0,7775$ & 0,4663 & $-0,072$ & $0,10 \%$ & $0,10 x$ & 0,6863 & $-0,0735$ & 0,6947 & $-0,61 \%$ & $0,61 \%$ & 0,5287 \\
\hline Avernge 1997 & & & & & -2012 & $220 \%$ & & & & $-0,44 \%$ & $0,95 \%$ & & & & $-0,63 \%$ & $0,82 \%$ & \\
\hline BPI & 26 & 1998 & 2.3197 & 0,8298 & $-0,95 \%$ & $0,95 \%$ & 0,6054 & 0,359 & 0,6098 & $-0,49 \%$ & $0,49 x$ & $-0,2971$ & $-1,9338$ & 0,8689 & $-0,45 \%$ & $0,45 \%$ & $.0,1449$ \\
\hline CPP Nom & 27 & 1998 & 0,6083 & 0,3825 & $-1,17 \%$ & $1,17 \%$ & 0,4575 & $-1,159$ & 1,1666 & $-1,91 \%$ & $1,91 \times$ & $-0,0388$ & $-1,2938$ & 1,1793 & $-0,99 \%$ & $0,99 \%$ & $-2,0200$ \\
\hline BPSM Nom & 28 & 1998 & $-0,1357$ & $-0,4897$ & $0,38 \%$ & $0,38 \%$ & $-1,3538$ & $3,357^{\circ}$ & $\cdot 1,5147$ & $1,32 \%$ & $1,32 \%$ & $-0,1495$ & $-1,1020$ & 0,097 & $-0,07 \%$ & $0,07 \%$ & $-0,5596$ \\
\hline BTA Nom & 29 & 1998 & 0,5922 & $-0,6568$ & $0,97 \%$ & $0,97 \%$ & $-0,5920$ & OAB & 09382 & $0,74 \%$ & $0,74 \%$ & 0,0720 & $-0,4955$ & $-0,6047$ & $0,37 \%$ & $0,37 \%$ & $-0,9874$ \\
\hline CSMC Nom & 30 & 1998 & 0,3900 & .23004 & $2003 \%$ & $203 \%$ & $-0,3394$ & 2,18070 & 2020 & $202 \%$ & $2,02 \%$ & $2,2675^{*}$ & $-0,0069$ & 0.55332 & $0,33 \%$ & $0,33 \%$ & $-0,5284$ \\
\hline $\begin{array}{l}\text { Caima - Comp. de } \\
\text { Celulose }\end{array}$ & 31 & 1998 & $-0,6842$ & 1,8029 & $-3,318$ & $3,31 \%$ & 0,1078 & $-1,6426$ & $27765^{*}$ & $-277 \%$ & $277 \%$ & 0,6099 & $.0,6024$ & $20260^{\circ}$ & $-218 \%$ & $2,18 \%$ & $-1,4526$ \\
\hline AXA Portugal Nom & 32 & 1998 & $-0,5162$ & 0,8874 & $-1,42 \%$ & 1 A2\% & $-0,8150$ & $-0,746$ & 0,9015 & $-0,75 \%$ & $0,75 x$ & $-1,3208$ & 0,9647 & 0,2717 & $-0,14 \pi$ & $0,14 \%$ & $-0,0227$ \\
\hline BANIF Nom & 33 & 1998 & 1,0889 & $-0,2230$ & $0,76 \times$ & $0,76 \%$ & 0,1798 & 1.2845 & 0,1864 & 0,208 & $0,20 \%$ & $-0,1256$ & $-1,2615$ & 0,3480 & $-0,28 \%$ & $0,28 \%$ & 0,8008 \\
\hline CPP (2) Nom & 341 & 1998 & 1,3136 & $-1,3206$ & $1,88 \%$ & $1 / 28 \%$ & 1,0492 & 0,4047 & $-0,014$ & $0,02 \%$ & $0,02 \%$ & 0,6197 & $-0,0769$ & 0,7048 & $-0,56 \%$ & $0,56 \%$ & $-0,4569$ \\
\hline$B C P$ & 351 & 1998 & 0.6089 & $-0,0410$ & $0,04 \%$ & $0,04 \%$ & $-0,2586$ & 1,4519 & 0,1625 & $-0,10 \%$ & $0,10 \%$ & 0,2490 & $-0,4420$ & 1,2839 & $-0,60 \%$ & $0,60 \%$ & $-1,2799$ \\
\hline BPSM (2) Nom & 361 & 1998 & $2 \times 8454^{4}$ & 0,9127 & $1,50 \%$ & $1,50 \%$ & 0,6368 & 0,2941 & 0,5912 & $-0,66 \%$ & $0,66 \%$ & $-0,7695$ & 0,1047 & 0,5970 & $-0,41 \%$ & $0,41 \%$ & $-1,1372$ \\
\hline BTA (2) Nom & 371 & 1998 & 1,6737 & $-0,6946$ & $1,05 x$ & $1,05 \%$ & 0,2738 & 0,6902 & 0,2094 & $0,20 \%$ & $0,20 \%$ & 0,0246 & 0,4207 & 0,8311 & $-0,59 \%$ & $0,59 \%$ & $-0,1006$ \\
\hline $\operatorname{CSMC~(2)~Nom~}$ & 38 & 1998 & 0,2088 & 1,2049 & $-2,12 \%$ & $2,12 \%$ & 0,0204 & 0,2937 & $2,1900^{\circ}$ & $-233 \%$ & $2,33 \%$ & $-0,1821$ & $-1,9674$ & s. Asio & $-241 \%$ & $2,41 \%$ & $-1,3608$ \\
\hline Cimpor & 39 & 1998 & 0,7542 & $-1,3785$ & $1,10 \%$ & $1,10 \%$ & 2,0434 & 1,7626 & $-0,1426$ & $0,13 \%$ & $0,13 \%$ & 0,2390 & $-0,3793$ & 1,2929 & $-0,90 x$ & $0,90 \%$ & -0.2402 \\
\hline Average 1998 & & & & & $0,05 \%$ & $1,33 \%$ & & & & $-0,34 \%$ & $0,97 \%$ & & & & $-0,64 \%$ & $0,73 \%$ & \\
\hline Inparsa & 401 & 1999 & 1,0735 & 1,2089 & $-1,05 \%$ & $1,05 \%$ & $-0,1856$ & $-1,0162$ & 1,5492 & $-1,23 \%$ & $1,23 \%$ & $-1,1213$ & 0,7135 & 0,2260 & $-0,18 \%$ & $0,18 \%$ & 0,2765 \\
\hline Sonae Indústria & 41 & 1999 & 0,9794 & $-0,1029$ & $0,07 \%$ & $0,07 \%$ & 0,1836 & 0,6347 & $-0,0183$ & 0,028 & $0,02 \%$ & 0,2449 & 0,6534 & 0,3750 & $-0,23 \%$ & $0,23 \%$ & 0,0121 \\
\hline Mota \& Engil, SCPS & 42 & 1999 & $-0,1864$ & 2,0190 & $-1,66 \%$ & $1,66 \%$ & -26094 & 0,8195 & $-1,0753$ & $1,77 \%$ & $1,77 \%$ & $-0,2357$ & 0,6039 & 0,0141 & $0,00 \%$ & $0,00 \%$ & .22111 \\
\hline Mota \& Companhia & 43 & 1999 & 0.2383 & 1,9399 & $-1,16 \%$ & $1,16 \%$ & $-1,4390$ & $-0,3796$ & 1,187 & $-0,96 \%$ & $0,96 \%$ & $-1,2076$ & $-2,0249$ & 0,3298 & $-0,26 \%$ & $0,26 \%$ & 0,8608 \\
\hline BPI & 44 & 1999 & -3.8574 & 1,1305 & $-1,50 \%$ & $1,50 \%$ & 1,5797 & $-0,8878$ & 0,115 & $-0,11 \%$ & $0,11 \%$ & 1,5268 & 0,1033 & 0,0141 & $-0,01 \%$ & $0,01 \%$ & $-0,6569$ \\
\hline Cofina & 45 & 1999 & $-0,2210$ & $-0,7363$ & 3,078 & $3,07 \%$ & 0,6529 & 0,9452 & $-0,7496$ & $1,65 \%$ & $1,65 \%$ & 0,9518 & $-0,7114$ & $-0,6208$ & $0,72 \%$ & $0,72 \%$ & 0,6948 \\
\hline BCP Nomn & 46 & 1999 & $-0,8108$ & $-2,0096$ & $0,55 \%$ & $0,55 \%$ & 27800 & $-0,2737$ & $-0,1617$ & $0,06 \%$ & $0,06 \%$ & $2,16060^{\circ}$ & $-0,2423$ & 1,3086 & $-0,37 \pi$ & $0,37 \%$ & $-1,0038$ \\
\hline BPSM Nom & 47 & 1999 & -25086 & $2 \sin \hat{0}^{\circ}$ & $-1,49 \%$ & $1,49 \%$ & 0,0169 & $-1,1209$ & $1, A 173$ & $-0,68 \%$ & $0,68 \%$ & $-1,18000$ & 1,0508 & 0,4441 & $-0,16 \%$ & $0,16 \%$ & $-\sin 69$ \\
\hline BPA Nom & 48 & 1999 & 0,3149 & $-1,3715$ & $0,93 \%$ & $0,93 \%$ & 1,7321 & $-0,7305$ & $-0,3922$ & $0,21 \%$ & $0,21 \%$ & 1,4667 & 1,2170 & $-0,1202$ & $0,04 \%$ & $0,04 \%$ & 1,4247 \\
\hline BTA Nom & 49 & 1999 & -0.9434 & 0,5653 & $-0,94 \%$ & $0,94 \%$ & $-0,3149$ & $-0,9706$ & 0,1081 & $-0,10 \%$ & $0,10 \%$ & 0,6357 & 2,1367 & $-0,1657$ & $0,10 \%$ & $0,10 \%$ & $-0,5851$ \\
\hline CSMC Nom & 50 & 1999 & $+4,437$ & $-0,3567$ & $1,00 \%$ & $1,00 \%$ & 0,6063 & $-0,794$ & $-0,6213$ & $0,86 \%$ & $0,86 \%$ & 1,0449 & 0,8813 & $-0,4784$ & $0,36 \%$ & $0,36 \%$ & 0,5991 \\
\hline CPP Nom & 51 & 1999 & $-1,2801$ & 0,7887 & $-0,90 \%$ & $0,90 \%$ & $-0,0327$ & $-1 / A 641$ & 0,6865 & $-0,40 \%$ & $0,40 \%$ & $-0,0586$ & 0,8924 & 0,0141 & $-0,01 \%$ & $0,01 \%$ & $-0,7753$ \\
\hline Pararede, SGPS & 52 & 1999 & $0 A 707$ & 0,7058 & $-0,53 \%$ & $0,53 \%$ & 0,3361 & $-0,4824$ & 1,8065 & $-0,77 \%$ & $0,77 \%$ & $-1,6535$ & $-1,0094$ & 0,2266 & $-0,10 \%$ & $0,10 \%$ & $-0,6890$ \\
\hline Colep Port & 53 & 1999 & $-1,3316$ & 1,2666 & $-2,34 \%$ & $234 \%$ & $-0,7878$ & $-0,0694$ & 0,3452 & $-0,53 \%$ & $0,53 \%$ & $-0,1024$ & $-0,8927$ & 0,6105 & $-0,44 \%$ & $0,44 \%$ & $-0,1258$ \\
\hline EDP & 54 & 1999 & 0.9349 & 0.3030 & $-0.22 x$ & $0,22 \%$ & 0.0190 & $-0,1719$ & 1,0086 & $-1,32 \%$ & $1.32 \%$ & $-0,8990$ & $-1,2002$ & 1.4070 & $-1,03 \%$ & $1,03 \%$ & $-1,4979$ \\
\hline Average 1999 & & & & & $-0,41 \%$ & $1,16 \%$ & & & & $-0,10 \%$ & $0,71 \%$ & & & & $-0,11 \%$ & $0,27 \%$ & \\
\hline Orobal Antriage & & & & & $0,0 \%$ & $8,60 \%$ & & & & $0.33 \%$ & $1.77 \%$ & & & & $0.06 \%$ & $0.87 \%$ & \\
\hline
\end{tabular}

Legend: BB represents Test 2; BA the Test 1 and AA the Test 3 . The values below are the statistical tests.

Note: The shadowed cells represent parameters that are statistically significant at a $5 \%$ confidence level. 


\section{APPENDIX 4}

\section{Abnormal returns around trading halts}

\begin{tabular}{|c|c|c|c|c|c|c|c|c|c|c|c|c|c|c|c|}
\hline find & Nas & $y=r$ & $\therefore$ & & 7. 504 & & & $F^{\circ}$ & & $1000 \%$ & & & & 2000 & \\
\hline & & & $\therefore$ as & B. & Diffement & Abmotatex & is & $\sin$ & $\therefore \tan ^{2}$ & Diflorenein. & Abanitis & s: & $\mathbf{B a}$ & Drafkest & tholutin $x$ \\
\hline Unvoer & 1 & $1 \% 2$ & $-0,1314$ & $-0,1599$ & $0,10 \pi$ & $0,10 \%$ & 0,3423 & 0,7019 & 0,0098 & $0,00 \%$ & $0,00 \%$ & 0,0656 & 0,2827 & $-0,14 x$ & $0,14 \%$ \\
\hline Bes Nozn & 2 & 1992 & 0,4300 & 1,1396 & $-1,04 x$ & $1,04 \%$ & $-0,2383$ & $-1,6064$ & 1,0550 & $-0,90 x$ & $0,90 \%$ & 0,0548 & 0,1414 & $-0,10 \%$ & $0,10 \%$ \\
\hline Average 1992 & & & & & $-0,47 \%$ & $0,57 \%$ & & & & $-0,45 \%$ & $0.45 \%$ & & & & $0,12 \%$ \\
\hline BPA Nom & 3 & 1993 & $-0,6889$ & 1,2690 & $-1,74 \%$ & $1,74 \%$ & Axus: & 1,147 & $-0,8190$ & $1,13 \%$ & 2,13\% & 0,9847 & $-0,4738$ & $0,37 \%$ & $0,37 \%$ \\
\hline BPI Nom & 4 & 1993 & 0,2894 & $-0,8292$ & $0,52 x$ & $0,52 x$ & 18488 & 0,4438 & 0,0956 & $-0,04 \%$ & $0,04 \%$ & $-0,1347$ & 0,5797 & $-0,29 \%$ & $0,29 \%$ \\
\hline Lusotur & 5 & 1993 & $-0,9240$ & 0,3623 & $-0,36 \%$ & $0,36 \%$ & 0,6307 & 0,2494 & 0,3296 & $-0,24 \%$ & $0,24 \%$ & $-0,1485$ & 0,1284 & $-0,07 x$ & $0,07 x$ \\
\hline Sonae Indústria, SGPS & 6 & 1993 & 0,2531 & 0,3124 & $0,28 \%$ & $0,28 \%$ & $-0,3380$ & 0,7339 & $-0,6193$ & $0,35 \%$ & $0,35 \%$ & 0,6019 & 0,1313 & $-0,08 \pi$ & $0,08 \%$ \\
\hline Sorae SGPS & 7 & 2993 & 1,3834 & $-1,4505$ & $209 \%$ & $209 \%$ & 0,1099 & $-0,9770$ & $-0,6918$ & $0,81 \%$ & $0,81 \%$ & 0,4917 & $-0,8877$ & $0,87 \pi$ & $0,87 \%$ \\
\hline ADerage 1993 & & & & & $0,16 \%$ & $7,00 \%$ & & & & $0,40 \%$ & $0,57 \%$ & & & & $0,34 \%$ \\
\hline Lisnave & 8 & 1994 & $-0,1100$ & 0,6545 & $-0,57 \%$ & $0,57 \%$ & 0,5147 & $-0,0576$ & 0,8937 & $-0,67 \%$ & $0,67 \%$ & 0,6233 & 1,3704 & $-0,82 \%$ & $0,82 \%$ \\
\hline Modelo SGPS & 9 & 1994 & 0,3466 & 0,0982 & $-0,07 \%$ & $0,07 \%$ & $-1,3062$ & 15633 & $-0,3558$ & $0,29 \%$ & $0,29 \%$ & $-0,0049$ & 0,8521 & $-0,52 x$ & $0,52 x$ \\
\hline BTA Nom & 10 & 1994 & $-0,4344$ & 0,4584 & $0,26 \%$ & $0,26 \%$ & $-0,5787$ & 0.0632 & 0,0868 & $-0,03 \%$ & $0,03 x$ & $-0,7301$ & -0.2178 & $0,07 x$ & $0,07 \%$ \\
\hline BCP Nom & 11 & 2994 & 0,2104 & 0,2518 & $-0,13 x$ & $0,13 \%$ & $-0,3442$ & 0,3726 & 0,2779 & $-0,09 \%$ & $0,09 \%$ & $-1,4851$ & $-0,8993$ & $0,23 x$ & $0,23 \%$ \\
\hline BES Nom & 12 & 1994 & 0,3807 & 0,0635 & $0,03 \%$ & $0,04 \%$ & $-0,3099$ & 0.2869 & $-0,1113$ & $0,05 \%$ & $0,05 \%$ & $\infty, 057$ & $-0,0078$ & $0,00 x$ & $0,00 \%$ \\
\hline Efacec & 13 & 1994 & 0,2078 & $-1,2985$ & $0,99 x$ & $0,99 \%$ & 0,6625 & 0,9754 & 0,8232 & 0,558 & $0,55 \%$ & $.0,5380$ & $-0,5909$ & $0,61 \%$ & $0,61 \%$ \\
\hline Corticeira Amorim & 14 & 1994 & $-0,6806$ & 0,7106 & $-0,49 \%$ & $0,49 \times$ & 6,0487 & $-0,5723$ & 0,3173 & $-0,16 \%$ & $0,16 \%$ & 0,9960 & Q.5854 & $-0,21 \%$ & $0,23 \%$ \\
\hline BTA (2) Nom & 15 & 2994 & 0,1782 & 1,9998 & $-1,38 x$ & $1,38 \%$ & 0,3724 & $-1,2219$ & $2520 \%$ & $-1,61 x$ & $1,61 \%$ & 0,86921 & $23359:$ & $-0,97 x$ & $0,97 \%$ \\
\hline Average 1994 & & & & & $-0,23 \%$ & $0,49 \%$ & & & & $-0,21 \%$ & $0,43 \%$ & & & & $0,43 \%$ \\
\hline Reditus, SCPS & 16 & 1995 & 1,7244 & $-1,0664$ & $8, A 3 \%$ & $8,43 \%$ & $0.06 \%$ & 0,857 & $-1,1649$ & $5,30 \%$ & $5,30 \%$ & 0,1367 & .15152 & $3,76 \%$ & $3,76 \%$ \\
\hline Average 1995 & & & & & $8,43 \%$ & $8,43 \%$ & & & & $5,30 \%$ & $5,30 \%$ & & & $3,76 \%$ & $3,76 \%$ \\
\hline BFE Niom & 17 & 1996 & 0,8781 & 0,1950 & $-0,15 x$ & $0,15 \%$ & $-1,0420$ & 0,3004 & $-0,1924$ & $0,25 \%$ & $0,15 \%$ & 0,4768 & $-0,6944$ & $0,35 \%$ & $0,35 \%$ \\
\hline CPP Nom & 18 & 1996 & $-0,5367$ & 0,7099 & $-1,26 \%$ & $1,26 \%$ & $-1,6754$ & 0,5754 & 0,0017 & $0,00 \%$ & $0,00 \%$ & 0,8458 & 0,5766 & $-0,28 \%$ & $0.28 \%$ \\
\hline BFE (2) Norn & 19 & 1996 & $-2,3004$ & 1,3492 & $-0,57 \%$ & $0,57 \%$ & 0,3999 & $-0,4773$ & 1,2887 & $-0,36 \%$ & $0,36 \%$ & $-2,0235$ & 0,4496 & $-0,09 \%$ & $0,08 \%$ \\
\hline BPI Nom & 20 & 1996 & $-1,0427$ & 1,1222 & $-1,15 \%$ & $1,15 \%$ & 0,3501 & $-0,7032$ & 1,0728 & $-0,64 x$ & $0,64 \%$ & $22 \times 18$ & 20456 & $0.75 \%$ & $0,75 x$ \\
\hline Aterioge 1995 & & & & & $0,78 \%$ & $0,76 \%$ & & & & $-0,27 \%$ & $0,29 \%$ & & & $-0,19 \%$ & $0,37 \%$ \\
\hline Cerexport & 21 & 1997 & $-2,0200$ & 2.1266 & $-276 \%$ & $2,76 \%$ & 0,5683 & $22522:$ & 2043 & $-1,73 x$ & $1,73 \%$ & 0,0645 & $1,52 \%$ & $-0,99 x$ & $0,99 \%$ \\
\hline Jer. Martins, SGPS & 22 & 1997 & 0,6755 & 1,5376 & $-1,13 x$ & $1,13 \%$ & $-1,4101$ & $-0,033$ & 1,6575 & $-0,77 \%$ & $0,77 \%$ & 0,3182 & 22391 & $-0,83 x$ & $0,83 \times$ \\
\hline Reditus, SGPS & 23 & 1997 & 0,7155 & 0,1137 & $0,20 \%$ & $0,20 \%$ & $-1,4334$ & 0,9096 & 0,0987 & $-0,10 \%$ & $0,10 \%$ & 0,5191 & 0,6162 & $-0,51 \%$ & $0,5 \%$ \\
\hline Inparsa & 24 & 1997 & $-0,7420$ & 2,2684 & $-2,20 \%$ & $220 \%$ & $5,0.0$ & $-0,8288$ & $-1,1133$ & $2,01 \%$ & $201 \%$ & 1,5664 & $-0,7992$ & $0,92 x$ & $0,92 \%$ \\
\hline CPP Nom & 25 & 1997 & $.1,1795$ & 0,0177 & $-0,04 \pi$ & $0,04 \%$ & 0,7306 & 0,0380 & 0,0118 & $-0,01 \%$ & $0,01 \%$ & $-0,3400$ & $-0,3142$ & $0,23 \%$ & $0,23 \%$ \\
\hline Average 1997 & & & & & $-1,27 \%$ & $1,27 \%$ & & & & $-0,22 \%$ & $0,92 \%$ & & & $-0,24 \%$ & $0,70 \%$ \\
\hline BPI & 26 & 1998 & $-2,2069$ & 0,4866 & $-0,49 x$ & $0,49 x$ & 0,9037 & $-0,3292$ & 0,6008 & $-0,36 \%$ & $0,36 \%$ & 0,0017 & 1,0010 & $-0,37 x$ & $0,37 \%$ \\
\hline CPP Nom & 27 & 2998 & 0,4256 & 0,3361 & $-0,87 \%$ & $0,87 \%$ & 1,4468 & .1 .8575 & 1,5721 & $-2,24 \%$ & $224 \%$ & 0,1904 & 1,5304 & $.1,24 \%$ & $1,24 x$ \\
\hline BPSM Nom & 28 & 1998 & $-1,2491$ & 0,2176 & $0,12 \%$ & $0,12 \%$ & $-0,3546$ & $716 \%$ & $-0,9736$ & $0,51 \%$ & $0,51 \%$ & $-1,4789$ & 0,1895 & $-0,0 \%$ & $0,10 \%$ \\
\hline BTA Nom & 29 & 1998 & 0,0066 & 0,3279 & $-0,42 \%$ & $0,42 \%$ & $-0,9267$ & 0,034 & 0,2635 & $0,17 \%$ & $0,17 \%$ & $-1,0748$ & $-0,3656$ & $0,22 \%$ & $0,23 x$ \\
\hline CSMC Nom & 30 & 1998 & $-0,5828:$ & $2 \times 15$ & $1,57 \%$ & $2,57 \%$ & 1,6617 & 1,6799 & -2563 & $1,26 \%$ & $1,26 \%$ & 2,8159 & $0,0,916$ & $0,17 \%$ & $0,17 x$ \\
\hline Caima - Comp. de Celulose & 31 & 1998 & $-0,7454$ & 1,2785 & $-2,69 \%$ & $2,69 \%$ & 1,0477 & $-2,7997$ & 2 2007 & $-2,86 \%$ & $2,86 \%$ & 0,4784 & 3016 & $-2,46 x$ & $246 \%$ \\
\hline AXA Portugal Non & 32 & 1998 & $-1,2541$ & 0,9791 & $-1,72 x$ & $1,72 \%$ & $-0,2735$ & $-0,0400$ & 0,6002 & $-0,60 \%$ & $0,60 \%$ & $-1,2370$ & 0,4241 & $0,36 \%$ & $0,36 \%$ \\
\hline BANIF Nom & 33 & 1998 & $-0,3527$ & $-0,6852$ & $1,04 \%$ & $1,04 \mathrm{x}$ & 0,6385 & 0,5177 & $-0,8176$ & $0,67 \%$ & $0,67 \%$ & $-0,0800$ & $-0,2917$ & $0,16 x$ & $0,16 \%$ \\
\hline CPP (2) Nom & 34 & 1998 & 0,3988 & $-1,1453$ & $2,10 x$ & $1,10 \%$ & 1,1678 & $-0,0237$ & -0.5759 & $0,38 \%$ & $0,38 \%$ & 0,7009 & $-0,0481$ & $0,03 \%$ & $0,03 \%$ \\
\hline BCP & 35 & 2998 & $-1,9251$ & 1,2595 & $-1,01 x$ & $1,01 x$ & $-0,7519$ & 0,5437 & 0,1828 & $-0,09 \%$ & $0,09 \%$ & 0,2078 & 0,2632 & $-0,09 \%$ & $0,09 \%$ \\
\hline BPSM (2) Nam & 36 & 1998 & 1,7924 & $-1,4211$ & $1,69 \%$ & $1,69 \%$ & 1,5319 & 0,4104 & $-0,0292$ & $0,02 \%$ & $0,02 \%$ & 0,2863 & $-0,3529$ & $0,19 \%$ & $0,19 \%$ \\
\hline BTA (2) Nom & 37 & 1998 & $0,23 \pi$ & $-0,6292$ & $1,17 \%$ & $1,17 \%$ & 0,3954 & 0,0794 & $-0,2613$ & $0,26 \%$ & $0,26 \%$ & $-0,0650$ & $-0,4515$ & $0,32 \%$ & $0,32 \%$ \\
\hline $\operatorname{CSMC}(2) \mathrm{Nom}$ & 38 & 1998 & $-0,4559$ & 0,2752 & $-0,76 x$ & $0,76 \%$ & 1,0246 & $-0,1980$ & 0,8479 & $-1,25 \%$ & $1,25 \%$ & 0,3725 & 3141 & $-1,90 \%$ & $1,90 \%$ \\
\hline Cimpor & 39 & 1998 & $-0,5263$ & 0,6970 & $-0,53 x$ & $0,53 \%$ & $0,7 \pi 17$ & 1,6429 & $-0,1260$ & $0,09 \%$ & $0,09 \%$ & $-0,5763$ & $0,25 \% 1$ & $-0,15 \%$ & $0,15 \%$ \\
\hline Average 1998 & & & & & $-0,25 \%$ & $2,08 \%$ & & & & $-0,31 \%$ & $0,77 \%$ & & & $-0,35 \%$ & $0,55 \%$ \\
\hline Inparso & 40 & 1999 & 1,0017 & 0,4882 & $-0,40 \%$ & $0,40 \%$ & 0,2183 & $-0,8688$ & 1,0253 & $0,56 \%$ & $0,56 \%$ & $-0,6814$ & 0,3028 & $-0,19 \%$ & $0,19 \%$ \\
\hline Sonae Indústria & 41 & 1999 & 0,7504 & 0,1955 & $-0,09 x$ & $0,09 \%$ & $-1,0230$ & 0,6626 & $-0,5159$ & $0,34 \%$ & $0,34 \%$ & 1,2437 & 0,5867 & $-0,2 \%$ & $0,27 \%$ \\
\hline Mata \& Engil, SGPS & 42 & 1999 & $-0,2425$ & $-1,7109$ & $10,02 \%$ & $20,02 \%$ & 1,5733 & 0,8827 & $.1,5680$ & $5,40 \%$ & $5,40 \%$ & 1,6274 & $-0,4952$ & $0,49 \%$ & $0,49 \%$ \\
\hline Mota \& Comparhia & 43 & 1999 & 0.8097 & $-0,3095$ & $0,22 x$ & $0,22 \pi$ & 0,4192 & $-0,3576$ & 0,6495 & $-0,52 \pi$ & $0,52 \%$ & 0,3712 & $-0,0417$ & $0,03 \%$ & $0,03 \%$ \\
\hline BPI & 44 & 1999 & 1.3605 & 1,5030 & $-1,64 \%$ & $1,64 \%$ & 1,0215 & $-0,8638$ & 0,5281 & $-0,43 \%$ & $0,43 \%$ & $-0,1532$ & $-0,2118$ & $0,71 \%$ & $0,11 \%$ \\
\hline Cofina & 45 & 1999 & 0,6289 & $-1,3223$ & $5,90 \%$ & $5,90 \%$ & 1,3076 & $-0,0745$ & $-1,0010$ & $251 \%$ & $2,51 x$ & 0,8415 & $-0,6440$ & $0,80 \%$ & $0,80 \%$ \\
\hline BCP Nom & 46 & 1999 & $-0,0509$ & 0.2116 & $-0,23 \%$ & $0.13 \%$ & 1,9573 & $-0,7557$ & 3,6079 & $-0,62 \%$ & $0,62 \%$ & 2,9193 & 39009 & $-2,05 \%$ & $1,05 \%$ \\
\hline BPSM Nom & 47 & 1999 & $-1,627 \%$ & 2003 & $-1,36 \%$ & $1,36 \%$ & 0,5490 & 0,7996 & 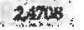 & $-1,07 \%$ & $1,07 \%$ & $-1,2521$ & 1,3468 & $-0,45 x$ & $0,45 \%$ \\
\hline BPA Nom & 48 & 1999 & 0,9945 & 0,1314 & $0,11 \%$ & $0,11 \%$ & 1,0650 & $-1,0949$ & 1,20548 & $0,57 x$ & $0,57 \%$ & 1,2237 & J,7857 & $-0,59 \%$ & $0,59 \%$ \\
\hline BTA Nom & 49 & 1999 & $-0,7098$ & 0,9348 & $-1,44 \mathrm{x}$ & $1,44 x$ & $-0,4533$ & $-1,2271$ & 0,7608 & $-0,68 \%$ & $0,68 \%$ & 0,5905 & 1,4586 & $-0,78 \%$ & $0,78 \%$ \\
\hline CSMC Nom & 50 & 1999 & -26013 & $-0,5158$ & $2,31 \%$ & $1,31 \%$ & 1,0032 & $\mid-1,1716$ & $-0,4531$ & $0,59 \%$ & $0,59 \%$ & 1,439 & 0,4249 & $-0,32 \%$ & $0,32 \%$ \\
\hline CPP Nom & 51 & 1999 & $-0,8309$ & 1,1843 & $-1,40 x$ & $1,40 \%$ & $-0,1914$ & $\mid-1,8428$ & 1,6497 & $-0,83 \%$ & $0,98 *$ & $-0,0374$ & 1,4909 & $-0,62 \%$ & $0,62 \%$ \\
\hline Pararede, SGPS & 52 & 1999 & 0,2571 & 2,0089 & $-1,80 \%$ & $180 \%$ & $-0,7238$ & $-0,6375$ & 2005 & $-1,53 \%$ & $1,53 x$ & $-3,7733$ & 1,7716 & $-0,77 x$ & $0,77 \%$ \\
\hline Colep Port & 53 & 1999 & $-1,4340$ & 0,1678 & $-0,46 \%$ & $0,46 \%$ & 0,7497 & $-0,0368$ & $0,052 \mathrm{~s}$ & $0,08 \%$ & 0,008 & $-0,0878$ & 0,4294 & $-0,37 \%$ & $0,33 \%$ \\
\hline EDP & 54 & 1999 & 0,8182 & $-0,1460$ & $0.08 \%$ & $0,08 x$ & 0,5041 & $-0,4970$ & 0,8739 & $-0,85 \%$ & $0,85 \%$ & 0,6823 & 1,2856 & $-0,81 \%$ & $0,81 \%$ \\
\hline Average 1999 & & & & & $0,59 \%$ & $1,76 \%$ & & & & $0,06 \%$ & $2,11 \%$ & & & $-0,32 \%$ & $0,51 \%$ \\
\hline Globw Ad angs & & & & & $0,7 \%$ & 19286 & & & & 0,564 & $x, 22 \%$ & & & 0,534 & $0.85 \%$ \\
\hline
\end{tabular}

Legend: BB represents "Test 2"; BA the "Test 2" and AA "Test 3 ". The values below are the statistical test.

Note: The shadowed cells represent parameters that are statistically significant at a $5 \%$ confidence level. 


\section{APPENDIX 5}

\section{Volatility around trading halts}

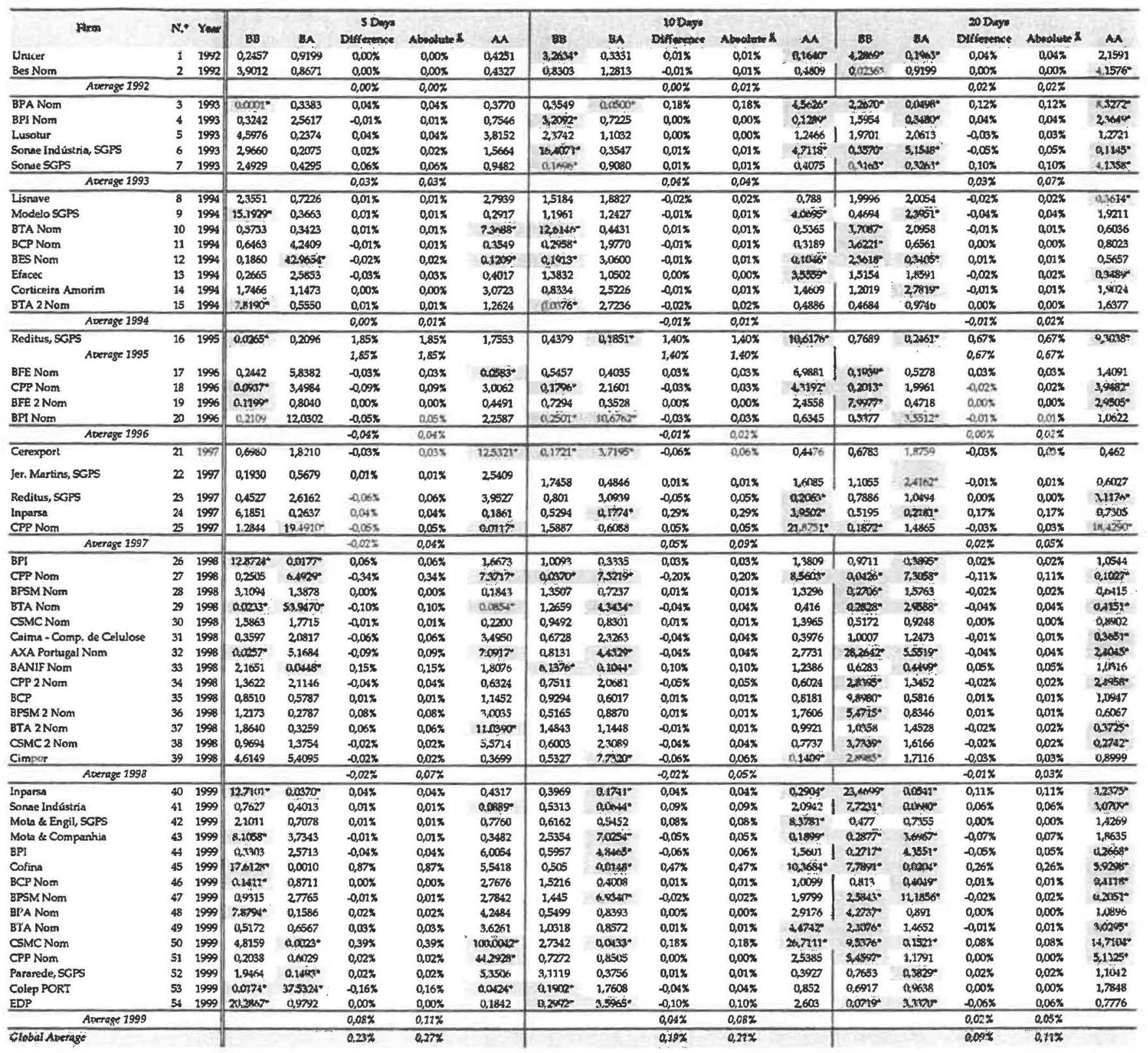

Legend: BB represents Test 2; BA the Test 1 and AA the Test 3 . The values below are the statistical tests.

Note: The shadowed cells represent parameters that are statistically significant at a $5 \%$ confidence level. 